\title{
How does the pronunciation of native languages affect beginning singers? A research focusing on native Mandarin Chinese and American English speaking singers
}

\author{
Ruobing Zhao \\ ruzhao@mail.wvu.edu
}

Follow this and additional works at: https://researchrepository.wvu.edu/etd

Part of the Music Performance Commons

\footnotetext{
Recommended Citation

Zhao, Ruobing, "How does the pronunciation of native languages affect beginning singers? A research focusing on native Mandarin Chinese and American English speaking singers" (2019). Graduate Theses, Dissertations, and Problem Reports. 3857.

https://researchrepository.wvu.edu/etd/3857

This Problem/Project Report is protected by copyright and/or related rights. It has been brought to you by the The Research Repository @WVU with permission from the rights-holder(s). You are free to use this Problem/Project Report in any way that is permitted by the copyright and related rights legislation that applies to your use. For other uses you must obtain permission from the rights-holder(s) directly, unless additional rights are indicated by a Creative Commons license in the record and/ or on the work itself. This Problem/Project Report has been accepted for inclusion in WVU Graduate Theses, Dissertations, and Problem Reports collection by an authorized administrator of The Research Repository @ WVU. For more information, please contact researchrepository@mail.wvu.edu.
} 
2019

How does the pronunciation of native languages affect beginning singers? A research focusing on native Mandarin Chinese and American English speaking singers

Ruobing Zhao

Follow this and additional works at: https://researchrepository.wvu.edu/etd Part of the Music Performance Commons 
How Does the Pronunciation of Native Languages Affect Beginning Singers?

A Research Focusing on Native Mandarin Chinese and American English Speaking Singers

Ruobing Zhao

A Research Project

Submitted to the College of Creative Arts at

West Virginia University

In partial fulfillment of the requirement for the degree of

Doctor of Musical Arts

in

Voice Performance

Hope Koehler, D.M.A, Committee Chair and Research Adviser

William Koehler, D.M.A

Evan MacCarthy, Ph.D.

Lynn Hileman, D.M.A

Jack Hammersmith, Ph. D.

School of Music

Morgantown, West Virginia

2019

Keywords: Diction, Mandarin Chinese Pronunciation, American English Pronunciation, Classical Singers, Beginning Singers, Native Languages.

Copyright 2019 Ruobing Zhao 


\begin{abstract}
How Does the Pronunciation of Native Languages Affect Beginning Singers?

A Research Focusing on Native Mandarin Chinese and American English Speaking Singers
\end{abstract}

Ruobing Zhao

The classical style of singing is taught at music institutions around the world as a mainstream artform. The main languages of classical vocal repertoires are Italian, German, French and English, which means most classical singers need to sing in non-native languages. When people learn a new sound from a foreign language, they often search for reference points within their native language(s), which usually is the reason behind singers performing with incorrect accents or diction.

This research focuses on beginning singers whose native language is either Mandarin Chinese or American English. This research introduces the romanization system and basic pronunciation rule of Mandarin Chinese, and explains the reasons for common diction issues exemplified by Mandarin Chinese singers, singing in any of the four Western languages. On the other hand, American English, as one of the four Western singing languages, is widely used in twentieth- and twenty-first-century vocal repertoires. North American English accents contain sounds that make non-native singing difficult. Meanwhile, certain allophones confuse beginning singers, whose primary language is American English, when they sing in the other three Western languages. A brief recapitulation of American English pronunciation is presented in this research, through which discussions are focused on problematic vowels and consonants, and all nonexistent vowels and consonants, that beginning American singers have to deal with when they sing in the other three Western languages.

This research explores how Mandarin Chinese and American English beginning singers sing in their own languages in order to investigate the impact of native language pronunciation on foreign-language singing, and to identify the common vocal faults and issues of incorrect diction that frequently coincide with cross linguistic singing. 


\section{Table of Contents}

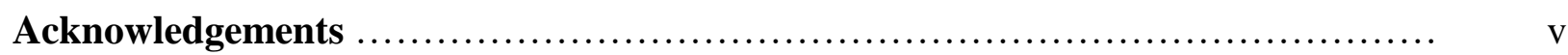

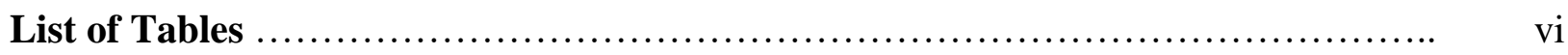

List of Music Examples ............................................... vii

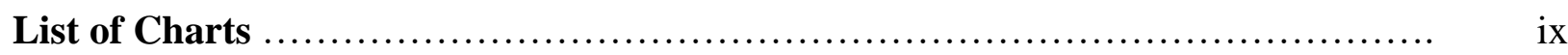

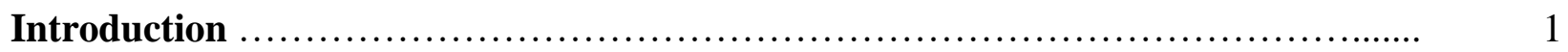

Chapter I: The Pronunciation of Mandarin Chinese and Its Singers .............. 4

1.1 Mandarin Chinese Romanization System and Pronunciations ................... 4

1.2 Single Syllable Rule and Four-tone System .............................. 6

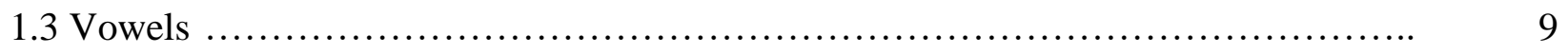

Single Vowels ...................................................... 9

Vowel Combinations .................................................... 17

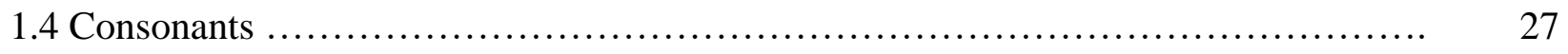

Basic Consonants .................................................. 27

Flat-tongue and Curled-tongue Consonants $\ldots \ldots \ldots \ldots \ldots \ldots \ldots \ldots \ldots \ldots \ldots \ldots \ldots \ldots \ldots \ldots \ldots \ldots \ldots$

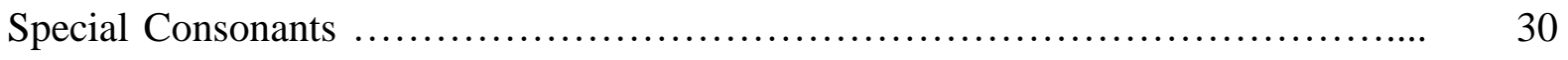

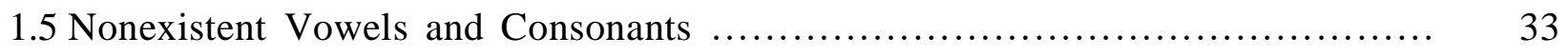

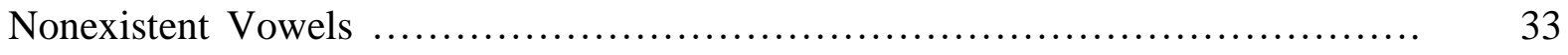

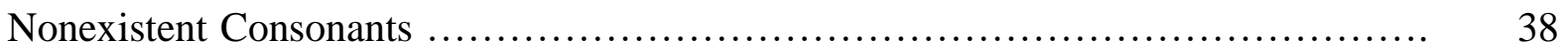

Chapter II. The Pronunciation of North American English and Its Beginning Singers 44

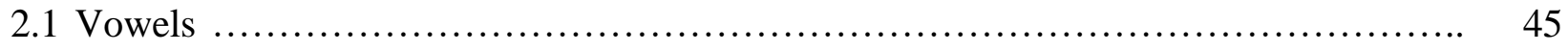

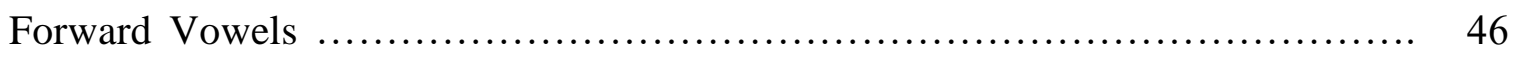

Central/ Mixed Vowels .............................................. 50

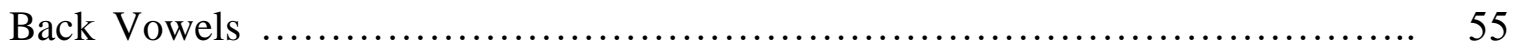

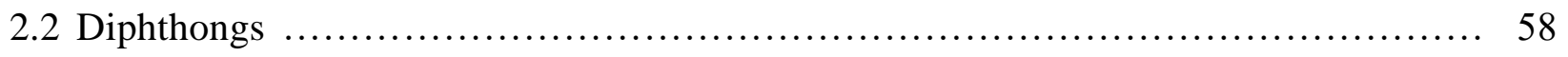

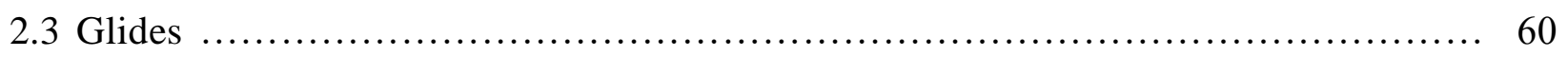

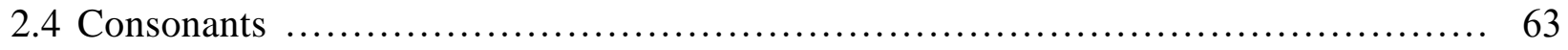

2.5 Nonexistent Vowels and Consonants ..................................... 67 


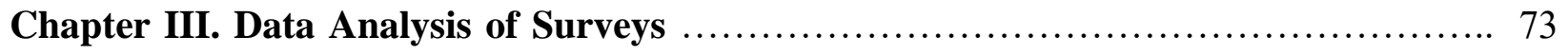

3.1 Mandarin Chinese Surveys Reports ............................................ 74

Similar Feedbacks ....................................................... 75

Different Feedbacks ................................................................ 83

Different Questions .......................................................... 87

Open-ended Question Feedbacks ............................................ 90

3.2 American English Survey Reports ................................................. 92

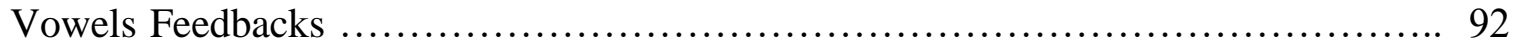

Consonants Feedbacks ....................................................... 100

Open-ended Question Feedbacks ...............................................104

Chapter IV. The Effect of Native Languages Pronunciation ........................ 107

4.1 The Overall Mandarin Chinese Effects and Possible Solutions ......................... 108

4.2 The Overall American English Effects and Possible Solutions ...................... 112

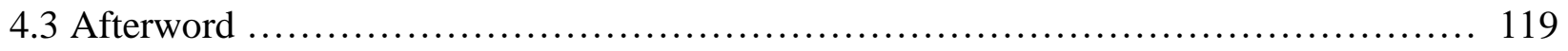

Appendix 1: Notes for Selected Music Examples ..................................... 122

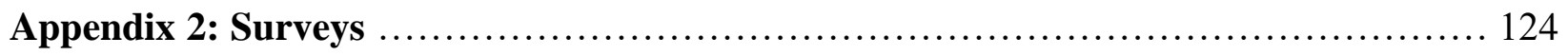

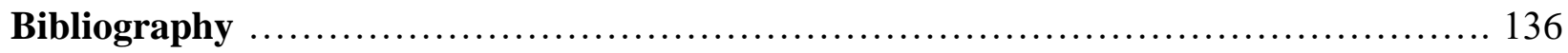




\section{Acknowledgments}

I would like to express my gratitude to all my committee members: Dr, Hope Koehler, Dr. William Koehler, Dr. Evan MacCarthy, Dr. Lynn Hileman, and Dr. Jack Hammersmith. I am tremendously grateful for their unfailing encouragement and support of me through these years of study at West Virginia University.

I am deeply grateful to Dr. Hope Koehler, my voice teacher and committee chair, for her excellent teaching and wisdom. She did not only teach and guide me through music, she caredand helped me through many difficult times during these years. I would like to thank Dr. William Koehler, who gave substantial help in my final project research. I also would like to thank Dr. Evan MacCarthy for helping me with my bibliography.

I am especially thankful to my vocal coach, Prof. James Kenon Mitchell, who selflessly helped me with my final project research and all my doctoral recitals, despite not sitting on my committee. I am also grateful to my former vocal coach, Prof. Linda Jones, who helped my research by suggesting sources and addressing all my research related questions through emails.

Secondly, I would like to thank my family for their love and support through these years. Last, I would like to thank all of the voice teachers, vocal coaches, and professional singers who participated the surveys for my research. 


\section{List of tables}

Table 1.1: Mandarin Chinese Vowels and Consonants $\ldots \ldots \ldots \ldots \ldots \ldots \ldots \ldots \ldots \ldots \ldots \ldots . \ldots$

Table 1.2: Mandarin Chinese Four-tone System $\ldots \ldots \ldots \ldots \ldots \ldots \ldots \ldots \ldots \ldots \ldots \ldots \ldots \ldots . \ldots \ldots$

Table 1.3: Six Mandarin Chinese Single Vowels .................................. 9

Table 1.4: Mandarin Chinese Vowel Combinations ................................. 18

Table 1.5: Vowel Combinations with Two Vowels $\ldots \ldots \ldots \ldots \ldots \ldots \ldots \ldots \ldots \ldots \ldots \ldots \ldots \ldots . \ldots$

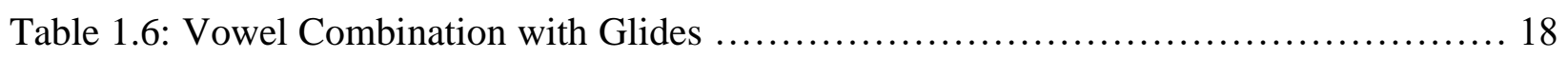

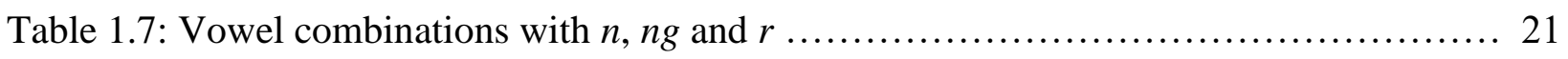

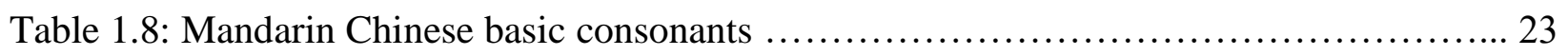

Table 1.9: Mandarin Chinese Flat-Tongue and Curled-Tongue Consonants ............... 27

Table 1.10: Mandarin Chinese special consonants .................................. 30

Table 1.11: Comparing the curled-tongue and flat-tongue consonants with the special

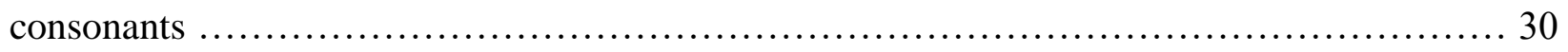

Table 1.12: Nonexistent vowels from Western Languages ............................... 33

Table 1.13: Nonexistent Consonants from Western Languages .............................38

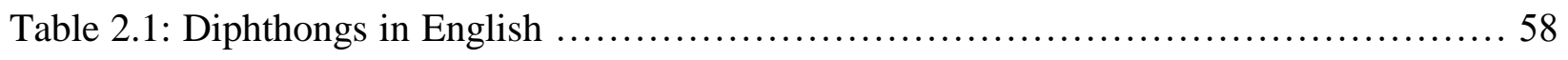

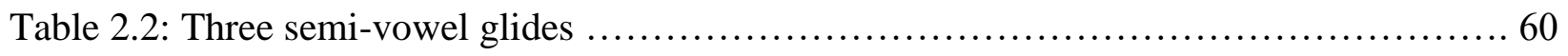

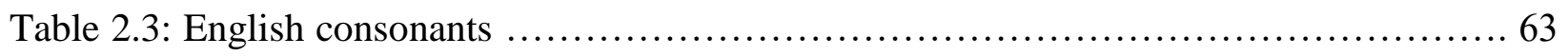

Table 2.4: Nonexistent Vowels and Consonants in English ............................ 67 


\section{List of Charts}

Chart 2.1: The English Vowel Chart ............................................. 45

Chart 3.1: The Dark [a] for Mandarin Chinese Singers ................................ 76

Chart 3.2: Special English Vowel [æ] for Mandarin Chinese Singers ...................... 76

Chart 3.3: Close [o] vs. Open [0] for Mandarin Chinese Singers .......................... 77

Chart 3.4: Close $[\mathrm{u}]$ vs. Open $[\mathrm{v}]$ for Mandarin Chinese Singers ............................ 78

Chart 3.5: Diphthongs for Mandarin Chinese Singers .................................... 79

Chart 3.6: The Final and Medial [n] and [y] for Mandarin Chinese Singers ................... 80

Chart 3.7: Final and Medial [m] for Mandarin Chinese Singers ............................. 81

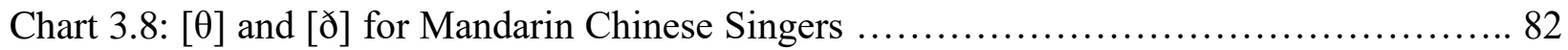

Chart 3.9: The Schwa [ə] for Mandarin Chinese Singers ................................. 84

Chart 3.10: The Common Issue of Schwa [ə] for Mandarin Chinese Singers ….............. 85

Chart 3.11: Close [e] vs. open [e] for Mandarin Chinese Singers ....................... 86

Chart 3.12: Close [i] and open [I] for Mandarin Chinese Singers ........................... 87

Chart 3.13: $[\widehat{\mathrm{d}}]]$ and $[\widehat{\mathrm{t}}]]$ for Mandarin Chinese Singers ................................... 88

Chart 3.14: Bright [a] for Mandarin Chinese Singers ...................................... 89

Chart 3.15: Open Vowels vs. Close Vowels for Mandarin Chinese Singers ....................90

Chart 3.16: Dark [a] vs. Bright [a] for American English Beginning Singers .................. 92

Chart 3.17: Close [i] vs. Open [r] for American English Beginning Singers ................ 93

Chart 3.18: Close [e] vs. Open [e] for American English Beginning Singers .................. 94

Chart 3.19: The Difficulty of Producing a Single [e] without an [I] to Follow ................. 94

Chart 3.20: Close [o] vs. Open [0] for American English Beginning Singers .................. 95

Chart 3.21: The Difficulty of Producing a Single [o] without a [u] or [ซ] to Follow ............. 95 
Chart 3.22: Close [u] vs. Open [च] for American English Beginning Singers .................96

Chart 3.23: Diphthongs for American English Beginning Singers ..........................97

Chart 3.24: $[\Lambda]$ and $[ə][\Lambda]$ for American English Beginning Singers ....................... 97

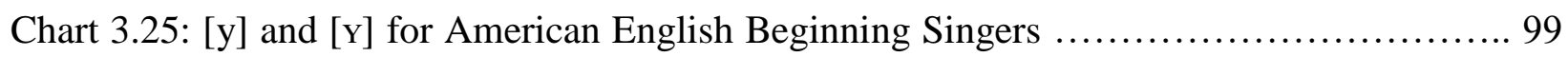

Chart 3.26: $[\varnothing]$ and $[œ]$ for American English Beginning Singers ........................ 100

Chart 3.27: Final and Medial [1] for American English Beginning Singers ....................101

Chart 3.28: Final and Medial [n] for American English Beginning Singers ................... 101

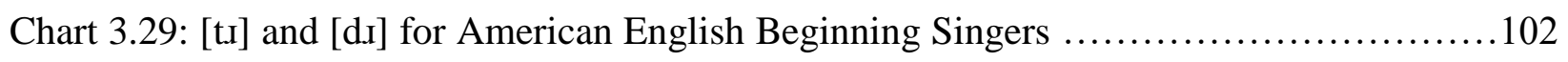

Chart 3.30: Rolled [r] and Flipped [r] for American English Beginning Singers ...............103

Chart 3.31: American $[\mathrm{x}]$ Changes the Following Vowel ............................... 104 


\section{List of Music Examples}

Music Example 1.1 ........................................................ 8

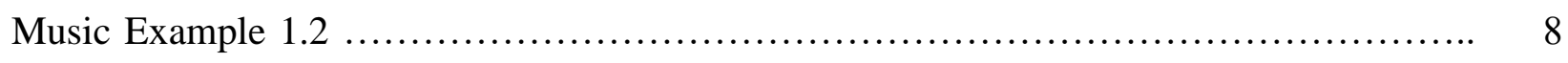

Music Example 1.3 ..................................................... 10

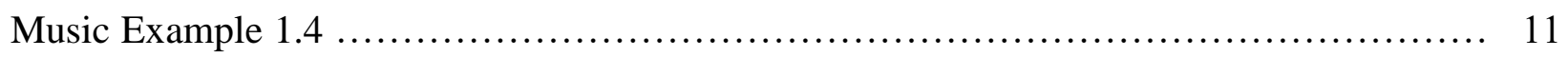

Music Example 1.5 ...................................................... 12

Music Example 1.6 ...................................................... 14

Music Example 1.7 ........................................................ 14

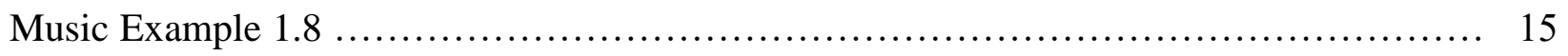

Music Example 1.9 ....................................................... 17

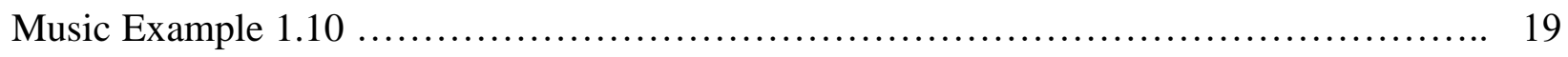

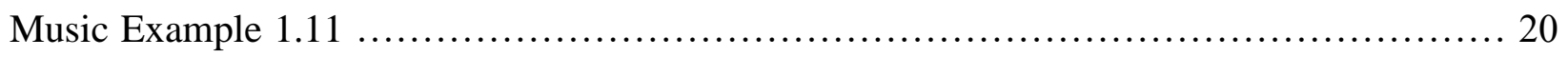

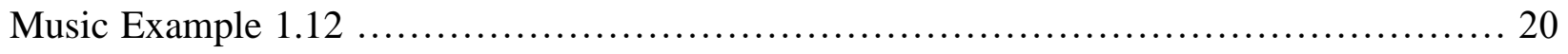

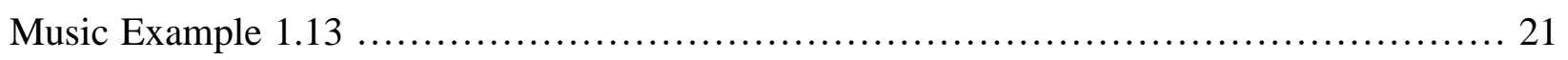

Music Example 1.14 ...........................................................22

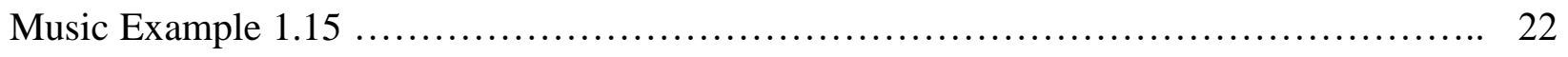

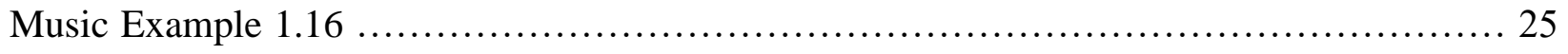

Music Example 1.17 ........................................................... 25

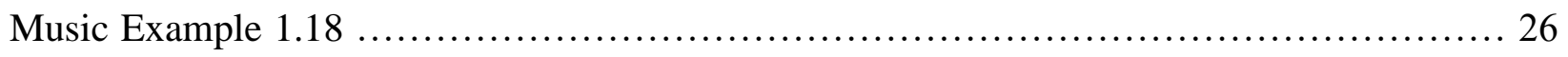

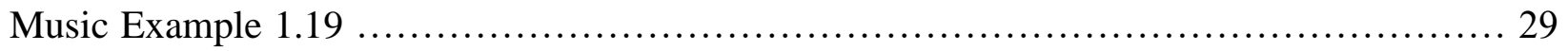

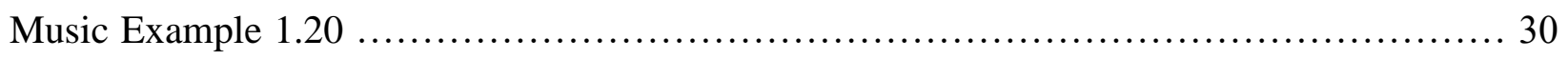

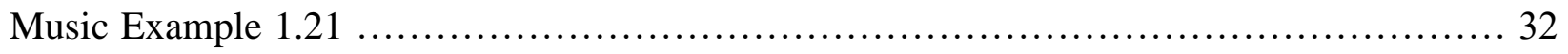

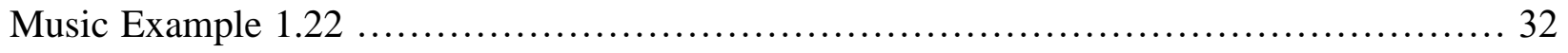




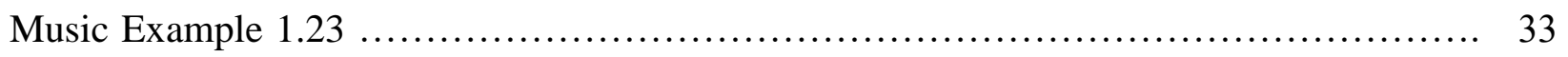

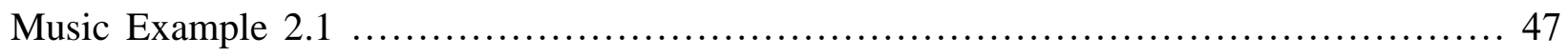

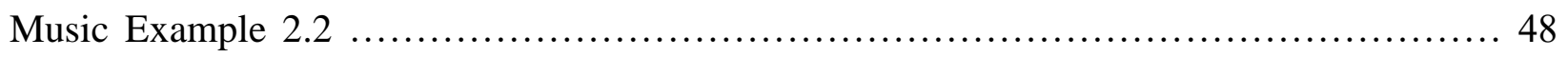

Music Example 2.3 ................................................................. 50

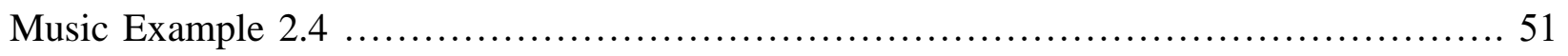

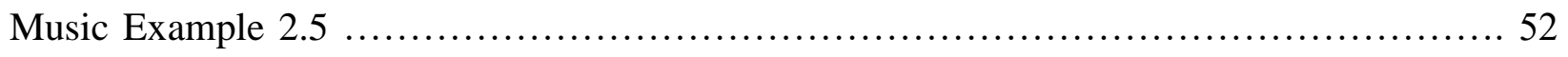

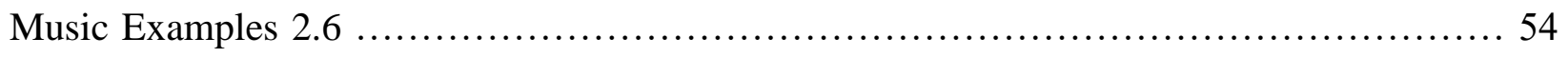

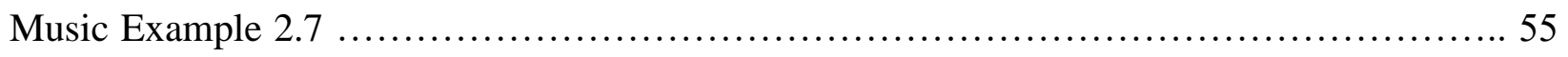

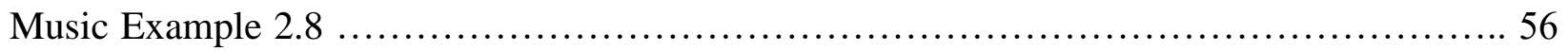

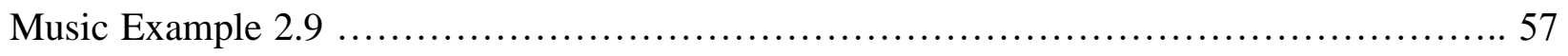

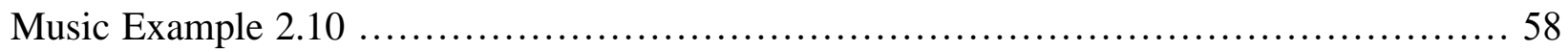

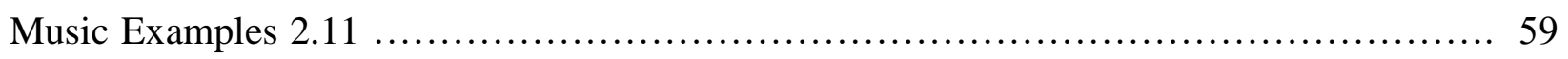

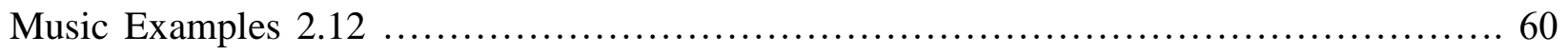

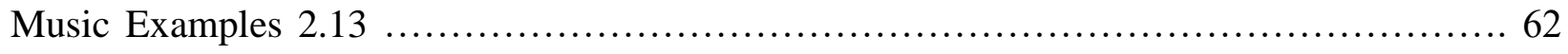

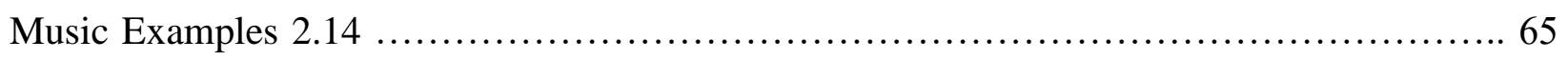

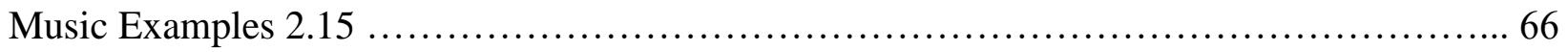




\section{Introduction}

The classical style of singing is considered the most conventional in the voice departments at most universities, conservatories and institutions around the world. The primary languages of its literatures are Italian, German, French, and English (we will call them the four Western singing languages in this research), which means many classical singers need to sing in non-native languages. This creates difficulties for all beginning classical singers, especially for those whose native languages are not in the Romanization system, such as some Asian languages. Even for classical singers whose native languages are based in the Romance system, there are still different rules for pronunciation and special sounds among the four Western singing languages that cause difficulties.

We often notice that people have accents when they speak foreign languages. What causes the accent? When someone starts learning a new sound from a new language, their first reaction would be searching a reference from the pronunciation of their native language. Therefore, when people have accents, it either means certain foreign sounds do not exist in their native languages or they pronounce them differently. The same applies for singers who have accents or "strange" diction when they sing in foreign languages. Again, we also notice that certain sounds cause specific vocal faults. This poses the question: how does the pronunciation of native languages affect classical singers, especially beginners?

This research will be focusing on pedagogical observations among beginning singers whose native language is either Mandarin Chinese or American English. With more and more Mandarin Chinese singers coming to the U.S. to pursue their music education and careers, American voice teachers and vocal coaches are teaching more singers whose native languages are Mandarin Chinese. Teaching Mandarin Chinese singers has many challenges, and diction 
certainly is a very significant one because inappropriate diction causes vocal faults. The first chapter of this research will introduce the basic pronunciation rules of Mandarin Chinese, explain the pronunciation of every vowel and consonant with IPA labels, explain how Mandarin Chinese singers produce their vowels and consonants in singing, and how they deal with all the nonexistent vowels and consonants based on the pronunciation of Mandarin Chinese.

The second chapter of this research will focus on the pronunciation of American English and their beginning singers. A brief recapitulation of North American standard English will be presented in the order of vowels, diphthongs, semi-vowel glides, and consonants. All common and possible issues that American English beginning singers might have with the North American standard English will be discussed in detail with musical examples. This chapter will also discuss all nonexistent vowels and consonants and how American English beginning singers usually deal with them and their related issues.

Three surveys have been conducted for this research to seek evidence and support for these common and possible diction issues and the vocal faults that the pronunciation of Mandarin Chinese and American English bring to beginning singers. The three surveys asked specific questions about how much difficulty Mandarin Chinese or American English beginning singers have producing certain vowels. The participants of these three surveys include Chinese voice teachers, vocal coaches, professional singers who have taught Mandarin Chinese beginning singers, North American voice teachers, vocal coaches, and professional singers who have taught Mandarin Chinese singers (not necessarily beginners) as well as American English beginning singers. A data analysis of these three surveys is presented in the third chapter of this research, which also includes the comparison between the answers from Chinese participants and North American participants about teaching Mandarin Chinese singers, and analysis of the answers 
about American English beginning singers from North American participants that include a few participants from the U.K, Canada, and China who have taught North American English beginning singers at an undergraduate level.

How do Mandarin Chinese singers and North American English beginning singers sing in their native languages and other foreign languages? How do they deal with the diction and vocal difficulties that relate to the pronunciation in their native languages? What can be done to help them to correct those issues? We will find out in this research. 


\section{Chapter I}

\section{The Pronunciation of Mandarin Chinese and Their Singers}

Mandarin Chinese is the most widely spoken language in the world; however, the pronunciation system is not entirely familiar to the speakers of Western languages. This chapter will briefly introduce the pronunciation system of Mandarin Chinese, including the Chinese Romanization system (Pinyin); the four-tone system and its impact on singers; the pronunciation of Mandarin Chinese vowels, vowel combinations and consonants; and the nonexistent vowels and consonants from the four Western singing languages and how Mandarin Chinese singers deal with their more intricate parts and how can they be conquered. Musical examples of Chinese folk and art songs will be presented to demonstrate the way that Mandarin Chinese singers produce vowels and consonants in their native language, and also to explain the vocal faults caused by pronunciations of Mandarin Chinese.

\subsection{Mandarin Chinese Romanization System and Pronunciations}

Mandarin Chinese is not one of the alphabetic languages, which use their own characters. For making the pronunciation of Mandarin Chinese into a general sense, and also helping children and the non-Chinese speakers to learn Mandarin Chinese, the Chinese scholars developed the Chinese Romanization system (Pinyin) in the 1970s. Table 1.1 presents the Romanization system and their pronunciations, which does not follow an alphabetic order, but are instead classified based on their functions. In Mandarin Chinese, almost every letter represents one consistent pronunciation, but exceptions exist and they will be discussed later. 
Unlike the consonants in the alphabets of the four Western singing languages that each consonant has a name and the name does not necessarily represent the actual pronunciation of that consonant, the consonants in the Mandarin Chinese alphabet are pronounced as the actual pronunciations of the consonants with a [ə] to follow, except for the three special vowels and two glides. In curled-tongue and flat-consonants, the [ə] is pronounced without opening the mouth, therefore, it is labeled as ${ }^{\left.{ }^{\circ}\right]}$ in this paper. In table 1, all the [ə:] are labeled as long vowels, and unlike the [ə] in the four Western languages, the Mandarin Chinese [ə:] is always stressed (please see [ə:] in Vowels later in this chapter).

Table 1.1: Mandarin Chinese vowels and consonants.

\begin{tabular}{|c|c|c|c|c|c|}
\hline Vowels & $\begin{array}{l}\text { Basic } \\
\text { Consonants }\end{array}$ & $\begin{array}{l}\text { Special } \\
\text { Consonants }\end{array}$ & $\begin{array}{l}\text { Curled-tongue } \\
\text { Consonants }\end{array}$ & $\begin{array}{l}\text { Flat-tongue } \\
\text { Consonants }\end{array}$ & Glides \\
\hline a [a:] & b [bə:] & j [-dzi:] & zh [d] $\left.{ }^{2}:\right]$ & $\mathrm{z}\left[\mathrm{z}^{\circ}:\right]$ & y [ji:] \\
\hline o [o:] & p [рә:] & q [-t fi: $]$ & $\operatorname{ch}\left[\mathrm{t} \int^{\circ}:\right]$ & $\mathrm{c}\left[\mathrm{ts}^{\curvearrowright}:\right]$ & w [wu:] \\
\hline e [ə:] & m [mə:] & x [- $\left.\int \mathrm{i}:\right]$ & $\operatorname{sh}\left[\int^{\circ}:\right]$ & $\mathrm{s}\left[\mathrm{s}^{\mathrm{P}:}\right]$ & \\
\hline i [i:] & $f$ [fə:] & & $\mathrm{r}\left[3^{2}:\right]$ & & \\
\hline $\mathrm{u}$ [u:] & d [də:] & & & & \\
\hline \multirow[t]{6}{*}{$\ddot{\text { ü [y:] }}$} & $\mathrm{t}$ [tə:] & & & & \\
\hline & n [nə:] & & & & \\
\hline & 1 [ lə:] & & & & \\
\hline & g [gə:] & & & & \\
\hline & k [kə:] & & & & \\
\hline & h [hə:] & & & & \\
\hline
\end{tabular}




\section{2 Single Syllable Rule and Four-tone System}

Mandarin Chinese is a language with a single syllable in every word, which also means that every syllable is stressed. The only exception is when the syllable is at the end of an interrogative sentence or a few specific phrases. However, these exceptions do not usually apply for singing. In China, whether for the Chinese traditional folk style of singing or the Western Classical style of singing, when it comes to singing in Mandarin Chinese, singers stress every single syllable. This makes the Chinese diction more clear, but also creates some unnecessary jaw and tongue tensions. The single syllable system also creates trouble for Mandarin Chinese singers when they sing some unstressed vowels in the four Western languages.

In table 1.2, there are four Chinese characters, and each one means a different word. The letters under the characters are the Mandarin Chinese Pinyin, which is the Romanization and pronunciations of those characters in the Mandarin Chinese pronunciation system. We can see that the letters are the same, but with four different marks above the letter $a$, which marks present the four-tone system of Mandarin Chinese. From these pronunciations, we can see they are almost the same, but the Chinese characters are different. Therefore, the four-tone system is essential in speaking Mandarin Chinese, which differentiates the meanings among many words with similar pronunciations. However, even with the utterly similar pronunciation and same tone, the Chinese characters could be very different; one pronunciation might fit more than five different Chinese characters. In Mandarin Chinese, the four tones are called tone 1 (T1), tone 2 (T2), tone 3 (T3) and tone 4 (T4). 
Table 1.2: Four-tone System. ${ }^{1}$

\begin{tabular}{|l|l|l|l|}
\hline 汤 & 糖 & 躺 & 烫 \\
\hline tāng & táng & tăng & tàng \\
\hline
\end{tabular}

As the images above the $a$ in table 1.2 describe the four different tones, the marks are usually above the only vowel or one of the vowels in a word. Tone 1 is also called a level tone, which is marked with a macron accent. The macron means the word is pronounced with a constant high pitch. The tone 2 is called a high rising tone, which is marked with an acute accent. Tone 2 is initially pronounced with a low pitch followed by a rise to a higher pitch with a slight crescendo. Tone 3 is called a low falling-rising tone, which is marked with a caron accent. The tone 3 starts with a low pitch and falls even lower, and then ascends into a high pitch. Tone 4 is called high falling tone, with a grave accent. The tone 4 is pronounced by starting with a high pitch, and then descending to a low pitch. Only tone 1 could be pronounced with the least stress, while the other three tones make the stress or accent on the vowels even stronger, especially tones 3 and 4. When Mandarin Chinese speakers produce tones 3 and 4, they usually use more glottal to make the tone descending and ascending, which causes the larynx to move more often than other languages. The four-tone system does not necessarily apply in singing, but the implication of each tone will affect Mandarin Chinese singers when they are singing. These implications involve the fast glottal onsets and occasional jaw tensions. A voice teacher from the UK mentioned that "even the completely untrained singers have natural resonance and very fast glottal stroke onsets" during an online discussion about this research. Most Mandarin Chinese singers or even untrained singers do have natural resonance and brighter timbre. I believe that

\footnotetext{
${ }^{1}$ The characters in Tone 1 means "soup;" in Tone 2 means "sugar;" in Tone 3 means "lying down;" and in Tone 4 means "hot."
} 
this phenomenon is also related to the four-tone system. When producing a tone with the pitches for speaking, it naturally makes people put extra tension for those pitches. Because the speaking voice is mostly chest voice, and with the ascending and descending tone changing in one word, singers must move their larynx and jaw to make it happen.

Music example 1. 1: Four-tone with actual pitches. (These tones are more suitable for men's voices, for women's voices, the pitches should be an octave higher). ${ }^{2}$

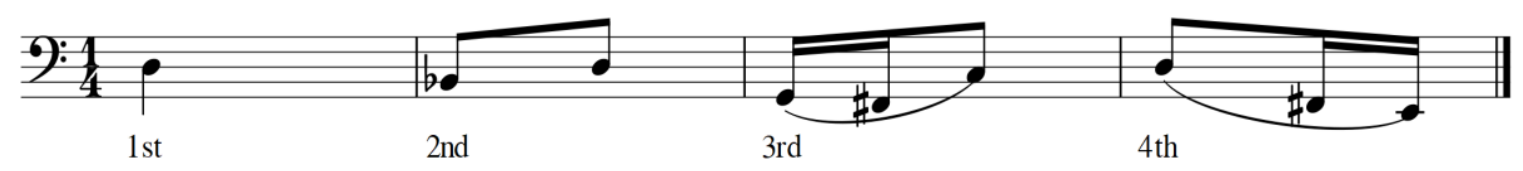

Music example 1. 2: excerpt from “The Rippling Brook” by Yin, Yigong, measures 5-6.

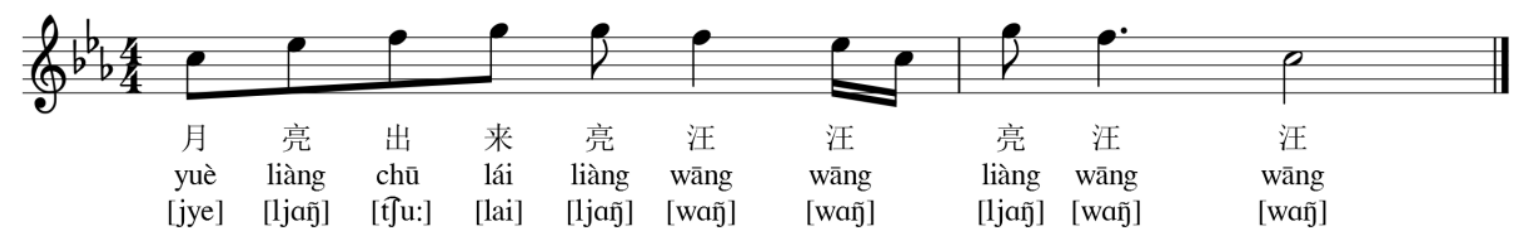

In music example 1.2, the fifth word liàng (亮) is pronounced [liañ], the grave mark on $a$ means the word is a tone 4, a high falling tone. When people speak this word, they will usually put an extra accent on it, because of the high falling tone motion. When Mandarin Chinese singers sing this phrase, the fifth word is in the middle of the measure, and the singers usually treat it as a strong beat partially because it is a higher note. The same situation happens at the second measure, first word. However, there is an exception that happens on the second word in the first measure, which is the same pronunciation as the fifth one, but this word holds different meaning than the other two liàngs. It is a part of a phrase yuè liàng (月亮), and these two words together mean "the moon." When certain words appear in a phrase as a supportive role (which

\footnotetext{
${ }^{2}$ Yuen Ren Chao, Mandarin Primer: An Intensive Course in Spoken Chinese (Cambridge: Harvard University Press, 1948 ), 85.
} 
usually happens in the end of the phrase), the pronunciation might change into a neutral tone without any accent. Therefore, the singers will usually put the accent on the first word yuè, and then another strong beat in this measure will be on the fifth note, the word liàng, and usually with a strong glottal onset. Another possible singing trick in music example 1.2 would be the fourth word, lái [lai], which is tone 2, the high rising tone. When people speak this word, they will start from a lower pitch and rise to a higher pitch. This situation might cause a habit of sliding up to a pitch to many Mandarin Chinese singers, when they try to sing the word lái the way that it is spoken. Because the meaning of Mandarin Chinese crucially depends on the fourtone system, most singers would like to make the diction clear, and they would add extra efforts to make the four tones more audible in singing.

The four-tone system causes the habit of sliding up a note, as well as placing extra accents on certain notes. These two kinds of situations occasionally affect Mandarin Chinese singers' vocal technique. The habit of sliding up a note often happens when Mandarin Chinese singers are producing a higher note, and with this motion, the consonant is often difficult to pronounce on the pitch. The extra accent on tone 4 and sometimes tone 3 causes a significant amount of unnecessary tension in singing, and hardly makes the legato lines work as well.

\subsection{Vowels}

\section{Single Vowels:}

Table 3: Six Mandarin Chinese single vowels.

\begin{tabular}{|l|l|l|l|l|l|}
\hline$a$ [a:] & $o[\mathrm{o}:]$ & $e$ [ə:] & $i[\mathrm{i}:]$ & $u[\mathrm{u}:]$ & $\ddot{u}[\mathrm{y}:]$ \\
\hline
\end{tabular}

From table 3, we can see that Mandarin Chinese has six single vowels: $a$ [a:], $o$ [o:], $e$ [ə:], $i$ [i:], $u$ [u:] and $\ddot{u}$ [y:], and there is no open version of vowels in Mandarin Chinese. All 
single vowels are closed when labeled with the IPA system. American voice teachers and vocal coaches might notice that some Mandarin Chinese singers have problems when pronouncing open vowels. This is simply because all the vowels in Mandarin Chinese are supposed to be closed unless, for some specific range, singers might need to modify the vowels and make them easier to sing. As mentioned earlier, vowels and consonants are pronounced consistently at most times, but vowels have more exceptions when in the case of vowel combinations. All possible pronunciations of each vowel are presented below.

\section{$a:$ [a:] and [a:]}

The letter $a$ in Mandarin Chinese is usually pronounced as a dark [a:], but the bright [a:] does exist in Mandarin Chinese when it appears in vowel combinations (which we will discuss more in Vowel Combinations). It is a similar situation to the bright [a:] in English that only exists in diphthongs. American voice teachers and vocal coaches might notice that some Mandarin Chinese singers have difficulty singing a bright [a:] as a single vowel from the four Western languages. In music example 1.3, the second word $\bar{a}$ (阿) in measure 1 is pronounced as the dark [a:]. However, in the first word ài (哎), the letter $a$ is pronounced as the bright [a:], or in spoken language, could be pronounced as [e:].

Music example1.3: excerpt from “The Rippling Brook” by Yin, Yigong, measures 17-18.

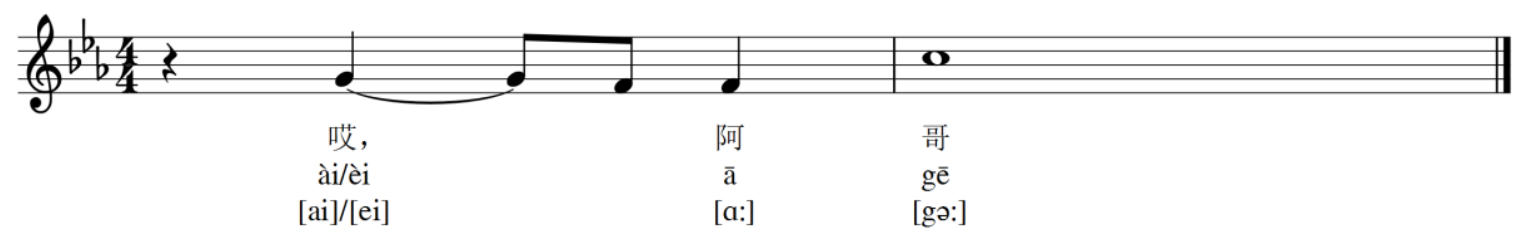

$o:\left[0:^{\bullet}\right]$

The $o$ vowel in Mandarin Chinese does not appear as a single vowel very often. When it does appear as a single vowel, it is pronounced with a brief [ə] following it, even though the 
spelling does not contain an $e$. In music example 1.4, the first word is spelled as wor, the pronunciation is [wo: ${ }^{\circledR}$. The small schwa is quickly blended with the [o:] (see more detail in Vowel Combinations). Mandarin Chinese singers might have a problem maintaining the [o] vowel when it appears as a single vowel in the four western languages as well.

Music example 1.4: excerpt from "I Live at the Source of the Yangtze River" by Qing, Zhu, measures 5-7.

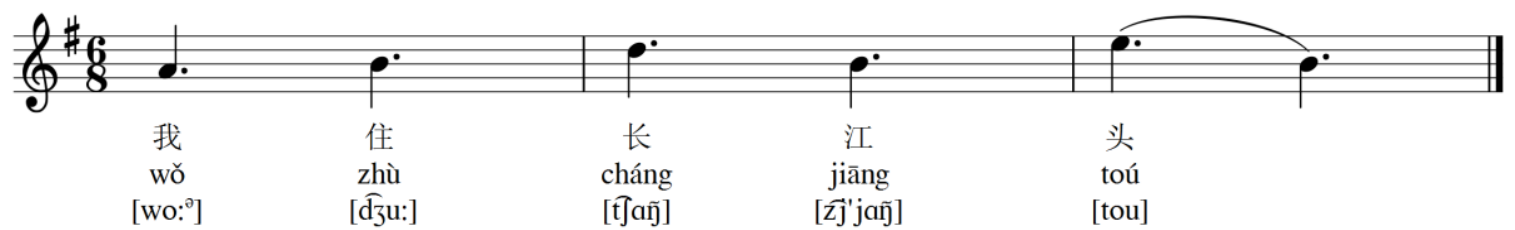

\section{$e:$ [ə:] and [e]}

The letter $\boldsymbol{e}$ has two pronunciations: [ə:] and [e]. The latter only exists in vowel combinations, or in the word ye when the $e$ follows the [i] vowel related glide $y$ [j]. The schwa [ə:] in the four Western languages is never stressed. However, in Mandarin Chinese, based on both single syllable rule and four-tone system, every single vowel is stressed, and the stress will be even stronger with the tone 3 and tone 4, except when some words are pronounced in the neutral tone. When the schwa is being stressed, the pronouncing process brings the jaw slightly forward and creates a tension in the back of the tongue. The stressed schwa also resonates in a lower position due to the forwarding jaw. This issue confuses many Mandarin Chinese singers when they sing the schwa in the four Western languages, especially in French.

In music example $1.5, g \bar{e}$ (哥) [gə:] in the second measure is a tone 1 , which is the mildest among the four tones. However, this word is being sung on a whole note and started from the downbeat of the measure. Therefore, for maintaining the [ə:], Mandarin Chinese singers 
will have to maintain the stressed sound through 4 beats with a slightly forwarded jaw and a pushed down back of the tongue.

Music example 1.5: excerpt from “The Rippling Brook” by Yin, Yigong, measures 17-18.

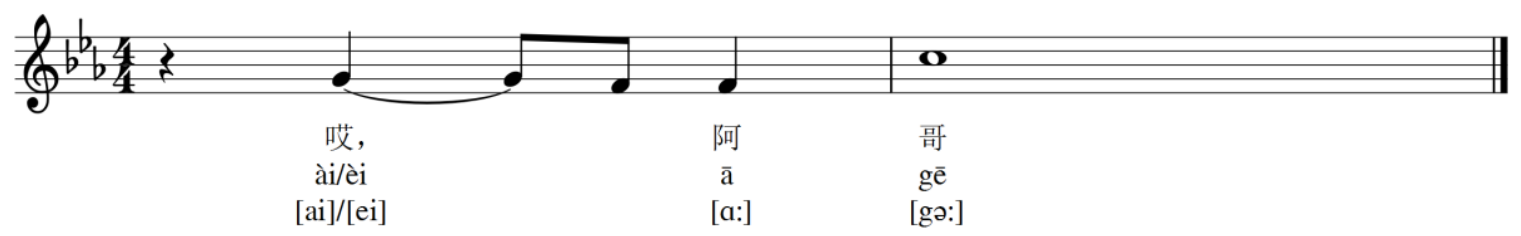

Mandarin Chinese rarely has unstressed syllables. Even when a neutral tone is being used for a vowel, Mandarin Chinese singers usually still treat it with a stress in singing. Therefore, for helping Mandarin Chinese singers to produce a better schwa, the stress issue needs to be explained distinctly. In addition, creating a correct articulator shape could be another way to help Mandarin Chinese singers with the schwa issue. When a Mandarin Chinese singer forwards their jaw while producing the schwa, they usually will not be able to round the lips. However, when the lips are rounder, it usually creates the state of a relaxed jaw. Therefore, for helping Mandarin Chinese singers to quit producing a stressed schwa, voice teachers and vocal coaches might ask them to make their lips rounder. Some voice teachers or vocal coaches might notice that some mature Mandarin Chinese singers try very hard to round their lips while producing the schwa, which is probably because those singers are trying to fix the schwa being sung in the lower position. Sometimes, the round lips look a bit overemphasized, but before a Mandarin Chinese singer gets used to the feeling of unstressed schwa, the round lips trick might be the best way to fix this problem.

\section{$i:[\mathrm{i}:],[\mathrm{j}]$ and [a:]}

When $i$ appears as a single vowel in Mandarin Chinese words, it could be pronounced in two ways. Based on the consonants that $i$ is following, the pronunciation changes. When $i$ 
follows the basic consonants, special consonants, and glide (see table 1.1), the pronunciation is [i:]. When $i$ is the first vowel of a vowel combination, it is pronounced as a glide [j] (we will discuss more in Vowel Combinations). However, it changes when it follows the curled-tongue consonants: $s h\left[\int\right], c h[\mathrm{t}]$ ], $z h[\mathrm{~d} 3]$ and $r$ [3], and the flat-tongue consonants: $s[\mathrm{~s}], c[\mathrm{ts}]$ and $z[\mathrm{z}]$. When $i$ is following these consonants, it will be pronounced as a [ə] but with the mouth closed. In other words, all the articulators remain the same shape from pronouncing the consonants and then produce a [ə:] sound. This closed-mouth [ə:] is difficult for singing, especially for the higher range. For less confusion, the closed mouth [ə:] will be labeled as [॰:] in this paper.

In a situation of the closed mouth [:] following the flat-tongue consonants $s[\mathrm{~s}], c$ [ts] and $z[\mathrm{z}]$, the tip of the tongue is touching the low teeth, and the upper and lower molars are approaching each other. Based on the articulator's shape, if Mandarin Chinese singers seek space inside their mouth while singing, they would usually choose to press down the middle of the tongue, which usually causes the back of the tongue to be raised. In a situation where the closed mouth [॰:] follows the curled-tongue consonants: $\operatorname{sh}\left[\int\right], \operatorname{ch}\left[\mathrm{t} \int\right], z h[\mathrm{~d} 3]$ and $r[3]$, the tongue must continue approaching the back of the alveolar ridge. The space inside the mouth might be bigger than the space in the flat-tongue consonants since there is a space for the tongue being curled. However, when the tongue is being curled, the space or resonance is usually aimed to the back of the mouth. Mandarin Chinese singers would usually press down the back of the tongue to create more space. I believe that many voice teachers and vocal coaching have noticed the issue that Mandarin Chinese singers generally have tongue tension either for raising the back of the tongue or pressing down the back of the tongue.

In music example 1.6, the vowels in the last two words are both spelled as $i$, but they are pronounced differently. si is pronounced [ $\mathrm{s}^{\mathrm{s}}$ :], after pronouncing the [s], all the articulators 
remain the same while pronouncing the schwa without opening the mouth. However, if the same word happens on a higher range, Mandarin Chinese singers usually do open their mouths. In the last measure, $i$ is following the glide $y$, which is pronounced as [i:].

Music example 1.6: excerpt from "I Live at the Source of the Yangtze River” by Qing, Zhu, measures 33-35.

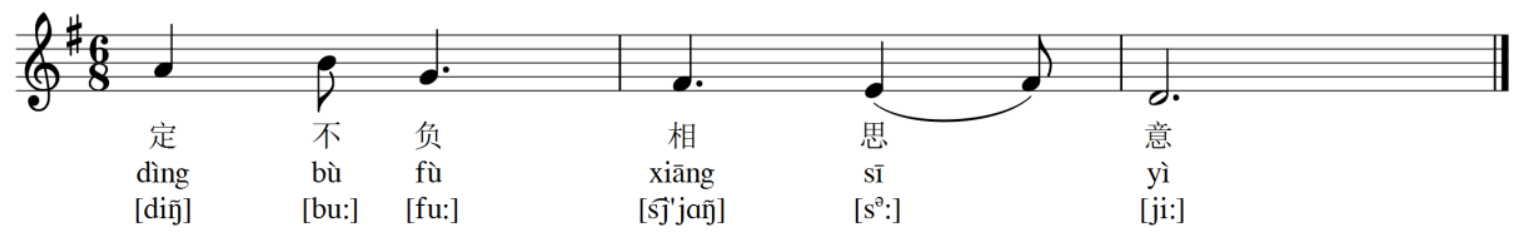

In music example 1.7, $i$ follows a curled-tongue consonant $s h\left[\int\right]$ as shí in the second measure second note. In producing this word, the tongue tip approaches the back of the alveolar ridge, and the airflow is stopped and goes through quickly. All the articulators then stay the same way while pronouncing a schwa without opening the mouth. When the tongue keeps approaching the back of the alveolar ridge, the schwa would sound like an American [I]. In the U.S, most voice teachers would recommend not to keep an American $[\mathrm{x}]$ for too long of a duration when American English singers sing it, but for this Mandarin Chinese word, singers must maintain this sound for the complete note duration.

Music example 1.7: excerpt from "I Live at the Source of the Yangtze River" by Qing, Zhu, measures 21-23.

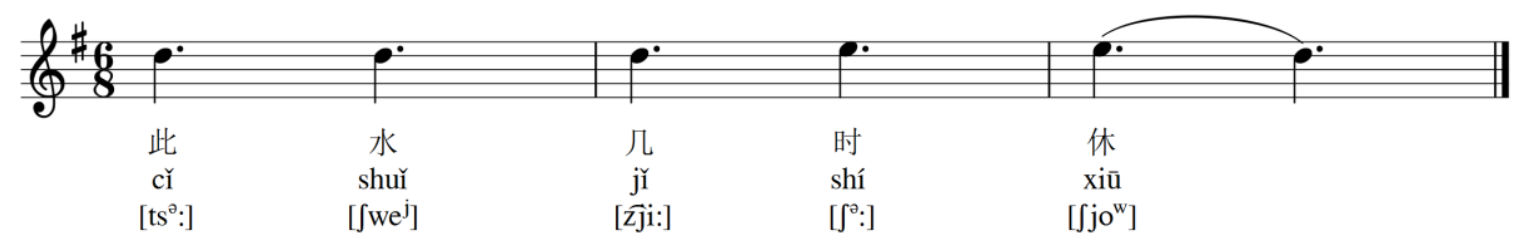




\section{$u:[\mathrm{u}:]$ and [w]}

In Mandarin Chinese, when $u$ appears as a single vowel, it is pronounced as [u:]. When $\mathrm{u}$ appears as the first vowel of a vowel combination, it is usually pronounced as a glide [w].

However, some voice teachers pointed out that when Mandarin Chinese singers pronounce a [u:] alone or when [u:] is the initial vowel, they usually add with a [w] in front of it. What causes this phenomenon is that in Mandarin Chinese, the vowels [a:] [ə:] and [o:] could be pronounced alone, which means some words initiate with these three vowels. However, there is no word initiated with [i] and [u] in Mandarin Chinese. In the Mandarin Chinese alphabet, the letters $w$ and $y$ are pronounced as [wu:] and [ji:], and these two pronunciations are considered the same as the letter $u$ and $i$ for Mandarin Chinese speakers. Therefore, the [u:] vowel in Mandarin Chinese is always pronounced with a [w] , and the [i:] vowel is always pronounced with a [j]. When [i:] is pronounced with a [j] (y), not much difference can be heard between [i:] and [ji:]. However, if the $[u]$ is pronounced with a $[w]$, this makes an audible difference when compared with the pronunciation of $[\mathrm{u}]$ without a $[\mathrm{w}]$ in front of it. In music example 1.8, wū in the first measure is pronounced as [wu:], which is also the same pronunciation of [u:] vowel for Mandarin Chinese speakers.

Music example 1.8: excerpt from “A Night-Mooring by the Maple Bridge” by Li, Yinghai, measures 6-9.

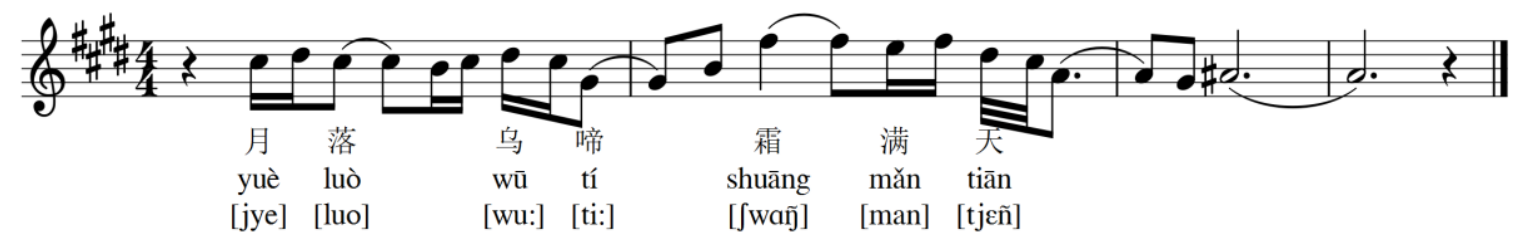




\section{ï: [y:]}

The umlauted $\ddot{u}[\mathrm{y}:]$ is no longer used very often in writing and typing in modern Mandarin Chinese, but the pronunciation still exists. Since computers began being extensively used in China and regular keyboards do not have a key for the umlauted $\ddot{u}$, people started using $v$ to replace $\ddot{u}$ for typing. Now, the umlauted $\ddot{u}$ might only be used for teaching children in elementary schools.

Mandarin Chinese does not have a consonant $v$, when letter $v$ is following a basic consonant, which is pronounced as $\ddot{u}$ [y:]. However, the $\ddot{u}$ is not always spelled as $v$; when the $\ddot{u}$ follows the special consonants $j, q, x$, and glide $y$, the $\ddot{u}$ will be spelled as $u$, which was a rule of the Mandarin Chinese pronunciation system before computers were widely used. This rule is based on the fact that the consonants $j, q, x$, and $y$ are never followed by a [u:] vowel in Mandarin Chinese, and so there will be no confusion about the pronunciations. Therefore, people omit the umlaut $\ddot{u}$ for an easier way to write. In fact, besides the special consonants $j, q, x$, and glide $y$, there are only two basic consonants that could be followed by the $\ddot{u}$ [y:], which are $n$ and $l$. Therefore, when the $\ddot{u}$ [y:] follows the special consonants $j, q, x$, and glide $y$, the spellings will be $j u, q u, x u$, and $y u$; but when the $\ddot{u}$ [y:] follows the consonants $\mathrm{n}$ and 1 , the spellings will be $n v$ and $l v$.

In music example 1.9, both spelling ways of $\ddot{u}$ [y:] appear. The first word $l \grave{v}$ (绿) ${ }^{3}$ is, in fact, lü but typed as this way it is pronounced as [ly:]. The second word yún (云) ${ }^{4}$ is pronounced as [jyñ] (the pronunciation of [ñ] will be discussed later in Vowel Combinations) but is spelled as

\footnotetext{
3 The character “绿” means "green."

${ }^{4}$ The character “云” means “cloud."
} 
$u$ when following the glide $y$. The last word live is also, in fact, lüe, but when typed this way it is pronounced as [lye].

Music example 1.9: excerpt from “Spring Nostalgia” by Huang, Zi, measure 8.

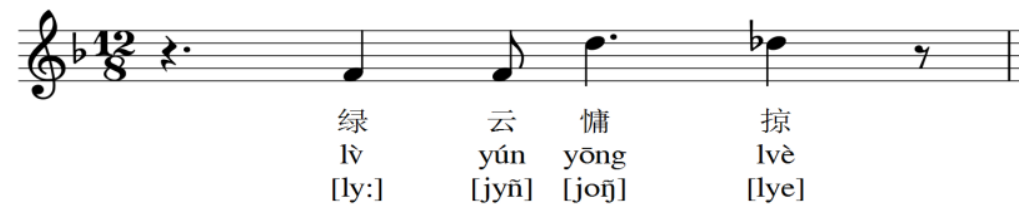

\section{Vowel Combinations:}

In the four Western languages, when multiple vowels appear in one word, which are often diphthongs or triphthongs. Based on the rule of diphthongs from English, Italian, and German, two vowels in a diphthong should be pronounced separately, and the first one should be longer than the second. For example, the English word high [haI]; the Italian word sei [se:i]; the German word Haus [haos]. For glides in English, Italian and French, the rule is that when a vowel follows $i[\mathrm{j}]$, or $u[\mathrm{w}]$, that vowel will be pronounced longer than the $[\mathrm{j}],[\mathrm{w}]$ or $[\mathrm{u}]$. For example, the English word use [juz]; the Italian word qui [kwi]; the French word lui [lyi]. Triphthongs in Italian are usually composed of a glide and a diphthong, such as suoi [swo:i]; in English, triphthongs are usually composed of a diphthong followed by the r-colored vowel [ə], such as hour [avo].

In Mandarin Chinese, when two or more vowels appear in one word, instead of being pronounced separately and clearly, the two vowels become a one-vowel combination, but not a mixed vowel. The two vowels are equally important, and are both pronounced quickly into a combined sound. If two vowels are being sung in a slow tempo, we can hear the combination more obviously. When two vowels appear together and the first one is $i$ or $u$, they are usually pronounced as glides, and combinations with glides have different rule as other vowel combinations (see later Combinations with glides). In table 1.4, we can see that some of the 
vowel combinations contain $r, n$ and $n g$ at the end. However, these consonants are not being considered as consonants, and are only a part of the vowel combinations. In other words, Mandarin Chinese does not have any final consonants, which we will discuss more in 2.4 Consonants.

Table 1.4: Mandarin Chinese Vowel Combinations

\begin{tabular}{|c|c|c|c|c|c|c|c|c|c|}
\hline$a$ & $\begin{array}{l}a n \\
{[a \tilde{n}]}\end{array}$ & $\begin{array}{l}a o \\
{[a o]}\end{array}$ & $\begin{array}{l}a i \\
\text { [ai] }\end{array}$ & $\begin{array}{l}\text { ang } \\
{[a \tilde{y}]}\end{array}$ & & & & & \\
\hline $\boldsymbol{O}$ & $\begin{array}{l}\text { ong } \\
\text { [ō̃] }\end{array}$ & $\begin{array}{l}\mathrm{ou} \\
{[\mathrm{ou}]}\end{array}$ & & & & & & & \\
\hline $\boldsymbol{e}$ & 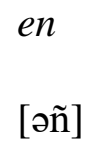 & $\begin{array}{l}e r \\
{[ə \partial]}\end{array}$ & $\begin{array}{l}e i \\
{[\mathrm{ei}]}\end{array}$ & 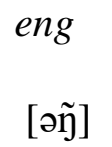 & & & & & \\
\hline$i$ & $\begin{array}{l}i a \\
{[\mathrm{ja}]}\end{array}$ & $\begin{array}{l}i u \\
{[j u]}\end{array}$ & $\begin{array}{l}i e \\
{[\mathrm{je}]}\end{array}$ & $\begin{array}{l}\text { in } \\
{[\mathrm{in} \tilde{n}]}\end{array}$ & $\begin{array}{l}\text { ing } \\
\text { [iñ ] }\end{array}$ & $\begin{array}{l}\text { iao } \\
\text { [jao] }\end{array}$ & $\begin{array}{l}\text { ian } \\
\text { [jहñ }]\end{array}$ & $\begin{array}{l}\text { iang } \\
\text { [jẫ] }\end{array}$ & $\begin{array}{l}\text { iong } \\
\text { [joñ] }\end{array}$ \\
\hline $\boldsymbol{u}$ & $\begin{array}{l}u a \\
\text { [wa] }\end{array}$ & $\begin{array}{l}\text { uan } \\
\text { [wañ] }\end{array}$ & $\begin{array}{l}\text { uo } \\
\text { [wo] }\end{array}$ & $\begin{array}{l}u i \\
\text { [wei] }\end{array}$ & $\begin{array}{l}\text { un } \\
\text { [uñ] }\end{array}$ & $\begin{array}{l}\text { uang } \\
\text { [wañ] }\end{array}$ & & & \\
\hline$\ddot{u}$ & $\begin{array}{l}\text { ve/ue } \\
\text { (ïe) } \\
\text { [ye] }\end{array}$ & $\begin{array}{l}\text { un } \\
(\text { ün }) \\
\text { [yñ] }\end{array}$ & & & & & & & \\
\hline
\end{tabular}

\section{Combinations with two vowels:}

Table 1.5: vowel combinations with two vowels

\begin{tabular}{|l|l|l|l|l|}
\hline ai: [ai] & ao: $[\mathrm{ao}]$ & ou: [ou] & $e i:[\mathrm{ei}]$ & ve/ue (üe): [ye] \\
\hline
\end{tabular}


When two vowels appear in a vowel combination, they are most likely pronounced in equal time durations, but are connected more closely and quicker. In speaking, these vowel combinations are not very different from the English diphthongs. In singing, however, after the first vowel is sung, Mandarin Chinese singers will keep the first vowel and quickly combine the second vowel with it, and then the combination will continue until the note duration is complete. In other words, the second vowel can barely be heard clearly and purely.

The $a$ vowel is a dark [a:] when appearing as a single vowel, but when it appears with [i:] in the vowel combination ai [ai], the dark [a:] becomes the bright [a]. We can consider that the bright [a] in $a i$ [ai] makes the articulators move less from [a] to [i], as when $a$ appears with $o$ in vowel combination ao [ao], which is still pronounced as the dark [a] and makes less articulator movement from [a] to [o]. In music example 1.10, ài (爱) ${ }^{5}$ [ai] in the second measure is being sung for 4 beats. Mandarin Chinese singers will usually sing the [a] briefly and add [i] into the combination. Therefore, there will be no time duration for a pure [i] vowel. The same situation will happen on yoú (游) ${ }^{6}$ [jou], the [o] vowel will be sung briefly, and then the $[\mathrm{u}]$ will be blended into the vowel combination.

Music example 1.10: excerpt from "The Three Wishes of a Rose” by Huang, Zi, measures 17-20.

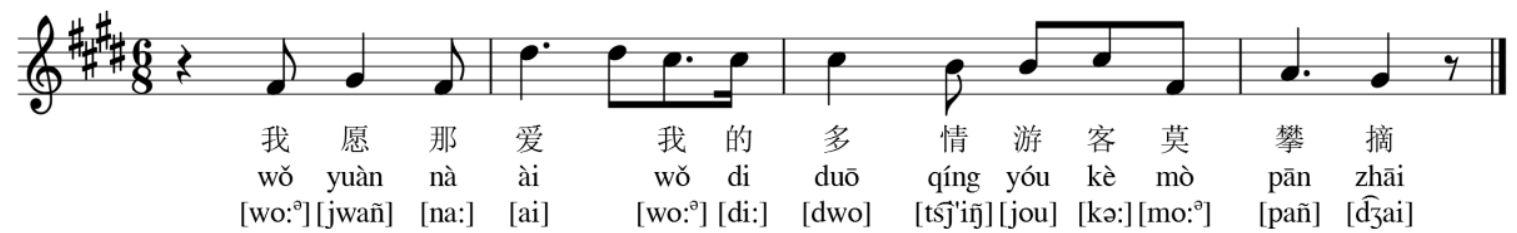

Among these combinations with two vowels, ei and velue (üe) need to be explained more. As mentioned previously, $e$ as a single vowel that is usually pronounced as [ə:]. The same

\footnotetext{
5 The character “爱” means “love.”

${ }^{6}$ The character “游” and the next character “客” make the phrase “游客” that means “tourist.”
} 
pronunciation also applies to a few combinations that end with $n$ and $n g$ (please see later in Combinations end with $n, n g$, and $r$ ). However, when $e$ appears with $i$, or $\ddot{u}$ (the spelling will be $v e$ or $u e$ ), the pronunciation will be [e]. In music example 1.11, the first word of the second measure wèi (未) follows the same combination rule. After [e] is quickly pronounced, the note will be sung as a combination of [e] and [i]. The velue (ïe) is the only exception from this combination rule. The $\ddot{u}$ in this combination plays a role more similar to a glide. Mandarin Chinese singers will sing the [y] quickly and the [e] longer, and remain on the [e] for the rest of the time duration. In music example 1.12, the first word yuè (月) [jye] has two eighth notes, so Mandarin Chinese singers will usually sing this vowel combination in a separate way, which means the first eighth note will be $[y]$ and the second eighth note will be [e] instead of a combination as others. If in any other rhythm, the velue (üe) will be treated the same way as glides, which means the second vowel will be sung longer than the first one. (See rules for combinations with glides below)

Music example 1.11: excerpt from "Spring Nostalgia" by Huang, Zi, measures 4-5.

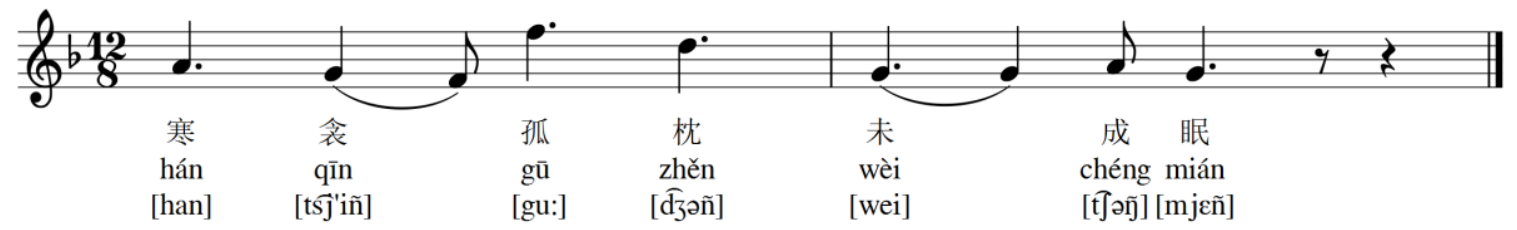

Music example 1.12: excerpt from "A Night-Mooring by the Maple Bridge" by Li, Yinghai, measures 6-9.

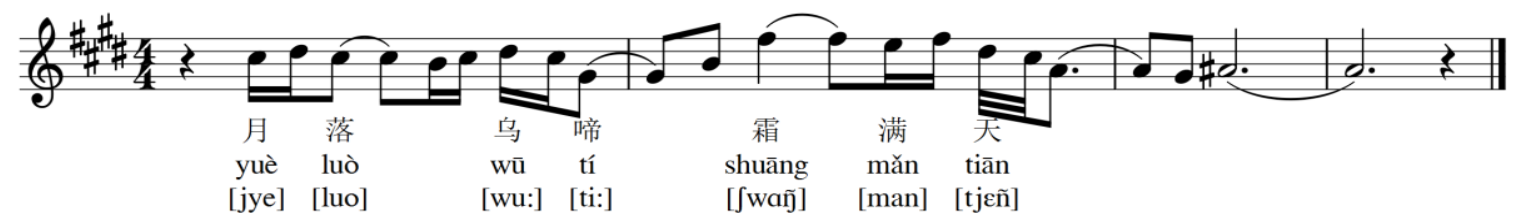




\section{Combinations with glides:}

Tables 1.6: vowel combination with glides

\begin{tabular}{|l|l|l|l|l|l|l|}
\hline$i a:[\mathrm{ja}]$ & $i e:[\mathrm{je}]$ & $u a:[\mathrm{wa}]$ & $u o:[\mathrm{wo}]$ & $i a o:[\mathrm{jao}]$ & $i u:[\mathrm{jo}]$ & $u i:[\mathrm{wei}]$ \\
\hline
\end{tabular}

In Mandarin Chinese, when $i$ and $u$ initiate a vowel combination, they are usually pronounced as glides [j] and [w], except when they are followed by $n$ and $n g$ (see Combinations ends with $n, n g$ or $r$ below). In combinations with glides, the vowel is more important than the glide, and it will be pronounced longer and clearer than the glide, such as ia: [ja], ie: [je], ua: [wa], and $u o$ : [wo]. In music example 1.13, the last word $h u \bar{a}(\text { 花 })^{7}$ is pronounced as [hwa]. When two vowels follow a glide, the two vowels will apply the rule for the combination for two vowels, such as iao: [jao]. In music example 1.14, the first word xiăo $(\text { 小 })^{8}$ is pronounced as [ $\widehat{\mathrm{sj}}$ 'jao] (the pronunciation of [ $\widehat{\mathrm{sj}}]$ will be discussed later in Special Consonants). After the consonant and glide are quickly pronounced, the [ao] follows the rule of combination with two vowels with the $[a]$ is being pronounced quickly and the [o] added in to make the combined sound.

Music example 1.13: excerpt from "The Three Wishes of a Rose" by Huang, Zi, measures 4-5.

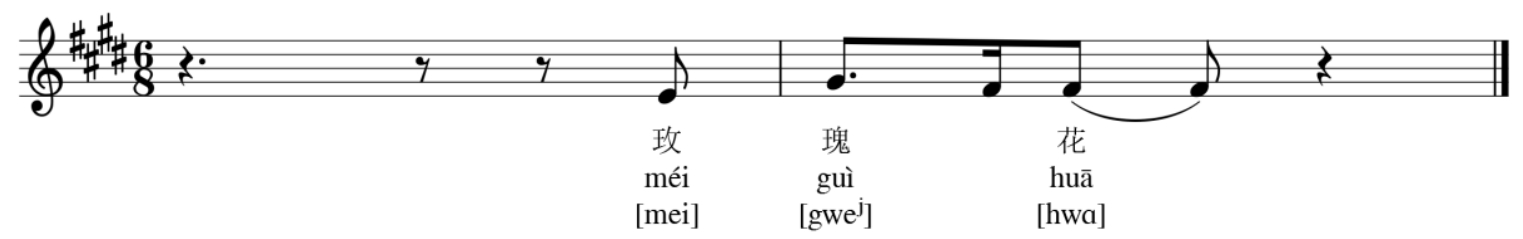

\footnotetext{
7 The character “花” means “flower.”

8 The character “小” means “small” or "little."
} 
Music example 1.14: excerpt from “Spring Nostalgia” by Huang, Zi, measures 11-12.

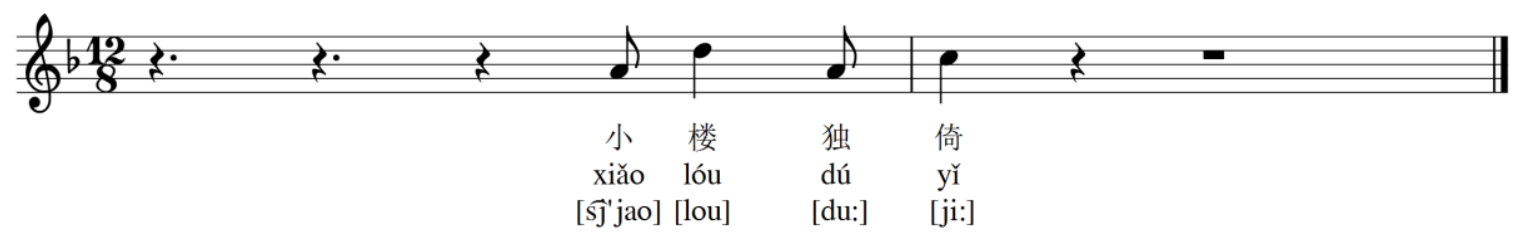

In Mandarin Chinese, vowels usually maintain consistent pronunciations, except when $i$ and $u$ are functioning as glides and when i follows the flat-tongue and curled-tongue consonants. However, there are two interesting exceptions in the category of combination with glides. When two glides combine as $i u$ and $u i$, which I will refer it as double-glides combinations, based on the spellings, people would assume that $i u$ should be pronounced as [ju], but in fact, the $u$ here is pronounced as [o], and then a very short [w] sound is added at the end, hence [jo $\left.{ }^{\mathrm{w}}\right]$; and instead of pronouncing $u i$ as [wi], the $i$ is pronounced as [e], and then a very short [j] sound is added, hence [wej]. From music example 1.15, we can see both double-glide combinations. In the first measure, the second word shur (水) ${ }^{9}$ is pronounced as [ $\left.\int \mathrm{we}^{\mathrm{j}}\right]$, as the consonant $\left[\int\right]$ and glide [w] quickly pass, the [ej] is the important part of the pronunciation of this word. In the last measure, $x i \bar{u}(\text { 休 })^{10}$ is pronounced as $\left[\widehat{\mathrm{sj}^{\prime}}{ }^{\mathrm{jo}}{ }^{\mathrm{w}}\right]$, after the consonant $[\widehat{\mathrm{sj}}]$ and glide [j] are quickly pronounced, the $\left[\mathrm{o}^{\mathrm{w}}\right]$ stays for two beats.

Music example 1.15: excerpt from "I Live at the Source of the Yangtze River" by Qing, Zhu, measures 21-23.

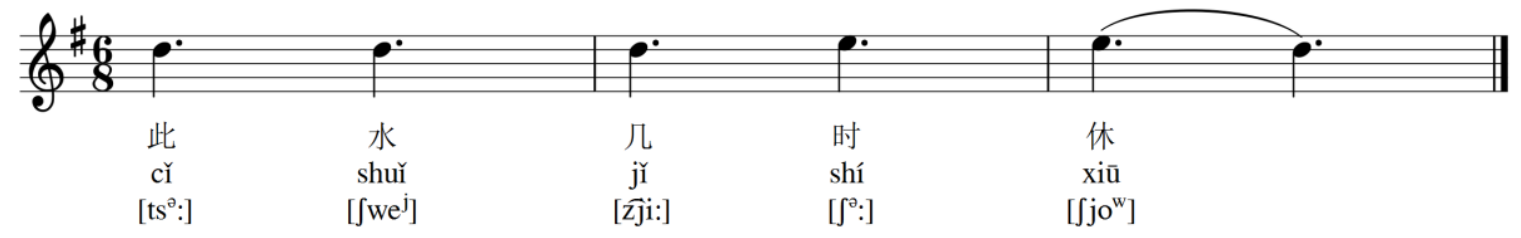

\footnotetext{
9 The character “水” means “water."

10 The character “休” means “stop.”
} 


\section{Combinations end with $n, n g$ and $r$ :}

Table 1.7: combination end with $n, n g$ and $r$

\begin{tabular}{|c|c|c|c|c|c|c|c|}
\hline$n$ & $\begin{array}{l}a n \\
\text { [añ] }\end{array}$ & $\begin{array}{l}\text { en } \\
\text { [əก̃] }\end{array}$ & $\begin{array}{l}\text { in } \\
\text { [iñ] }\end{array}$ & $\begin{array}{l}\text { ian } \\
\text { [jeñ] }\end{array}$ & $\begin{array}{l}\text { uan } \\
\text { [wañ] }\end{array}$ & $\begin{array}{l}\text { un } \\
\text { [uñ] }\end{array}$ & $\begin{array}{l}\text { velue (ïe) } \\
\text { [yñ] }\end{array}$ \\
\hline$n g$ & $\begin{array}{l}\text { ang } \\
\text { [añ] }\end{array}$ & $\begin{array}{l}\text { ong } \\
\text { [oñ] }\end{array}$ & $\begin{array}{l}\text { eng } \\
\text { [ə்̃] }\end{array}$ & $\begin{array}{l}\text { ing } \\
\text { [iñ̄] }\end{array}$ & $\begin{array}{l}\text { iang } \\
\text { [jañ] }\end{array}$ & $\begin{array}{l}\text { iong } \\
\text { [joñ] }\end{array}$ & $\begin{array}{l}\text { uang } \\
\text { [wañ] }\end{array}$ \\
\hline$r$ & $\begin{array}{l}\text { er } \\
{[ə \curvearrowright] /[a ð]}\end{array}$ & & & & & & \\
\hline
\end{tabular}

In Mandarin Chinese, there are three kinds of final consonants in spelling: $n, n g$, and $r$. In fact, these final consonants are not pronounced in the same way as they are when functioning as

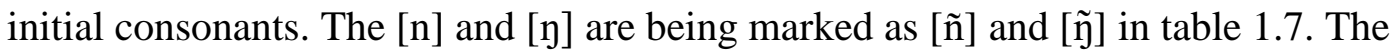
pronunciations are similar with the regular [n] and [ $\mathrm{n}]$, but without the tongue touching the hard or soft palate. When speaking or singing the final $n$, the tongue might sometimes touch the hard palate as the word is finishing and the mouth is closing. However, the touching movement will not involve a phonation, which is unlike in Western languages where [n] and [ $\mathrm{n}]$ are always voiced consonants. But in Mandarin Chinese, even if the tongue did touch the hard palate when closing the mouth, the $n$ would be not be pronounced as a voiced consonant. The $n g$, on the other hand, is never pronounced with the tongue touching the soft palate.

The vowel combinations end with $n$ is called front-nasal tone, and the vowel combinations end with $n g$ is called back-nasal tone. As their names imply, the pronunciations are more focusing on the nasal tone. The back-nasal tone is similar to the French nasal tone, in which the tongue does not touch the hard or soft palate either. However, as part of the vowel 
combinations, the back-nasal tone does not go as far as the French nasal vowels in the sense of nasal. The front-nasal and back-nasal are more like a direction for the vowels before them. Hence, the front-nasal tone brings the vowel before it more forward, and the back-nasal tone makes the vowel before it more backward. For example, in the vowel combination an [añ], the front-nasal tone $n$ makes the $a$ before it a bright [a] instead of the dark [a], just like the [i] does in the vowel combination [ai]. In the vowel combination ian [jeñ], because the $i$ already made $a$ a

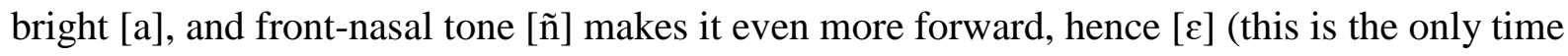
the open $[\varepsilon]$ is used in Mandarin Chinese). On the other hand, in the vowel combination iang [jã̃], the $a$ is pronounced as the dark [a], and even though the [j] made the $a$ a bright [a], the back-nasal tone $[\tilde{y}]$ brings it back to the dark $[a]$.

When $n$ appears at the end of a word, it is blended into the vowel or vowels before it, and then made the front-nasal tone. When $n$ is followed by a single vowel, such as an, the [a] will still be briefly pronounced as in combination with two vowels, and then blended with the [ñn]. Imagine the $[\tilde{\mathrm{n}}]$ is an [n] without letting the tongue touch the hard palate, but has a place of

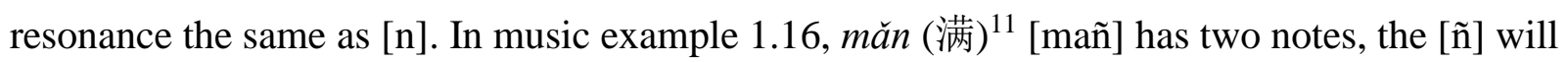
happen in the first one after a briefly pronounced [a], and the second note will be sung with the

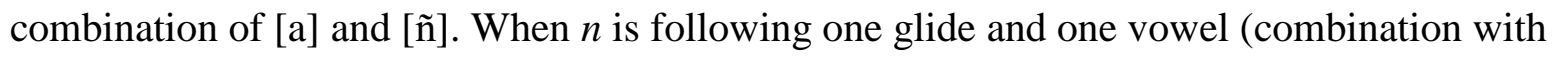
glides), the two will be pronounced as usual, and the $n$ will be blended in after these two are quickly pronounced. In music example 1.16, the last word tiān (天) [tjeñ] has five notes. Based on this rhythm, everything in [tjeñ] will be quickly pronounced in the first $32^{\text {nd }}$ notes and maintain the combination for the rest of the duration.

\footnotetext{
11 The character “满” means “full."
} 
Music example 1.16: excerpt from "A Night-Mooring by the Maple Bridge" by Li, Yinghai, measures 6-9.

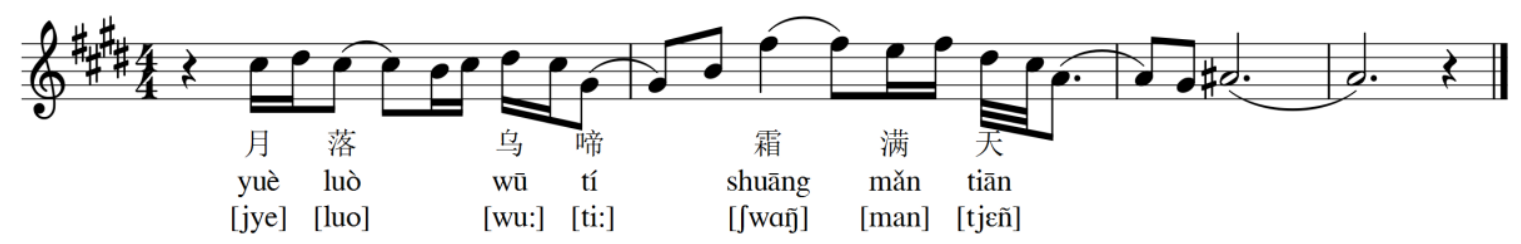

When the $n g$ appears at the end of a word, the same rule applies. A [ [̃] sound is blended into the vowel(s) before it, and all together make the back-nasal tone, but without the back of the tongue touching the soft palate. In music example 1.17, the two words cháng jiāng (长江) ${ }^{12}$ in the second measure are both back-nasal tone words. With this $6 / 8$ time signature, everything in each word is usually pronounced quickly within the first eighth note and stays in the vowel combination (back-nasal tone) for the rest of the duration.

Music example 1.17: excerpt from "I Live at the Source of the Yangtze River" by Qing, Zhu, measures 5-7.

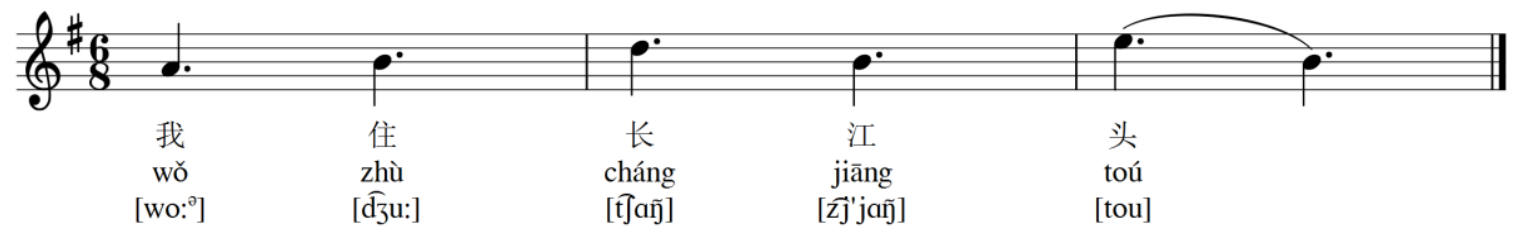

The final $r$ is pronounced as the r-colored vowel [r] in English, which could only be used in one spelling: $e r$ in Mandarin Chinese. However, er has two different pronunciations: the first one is [aə] (二); ${ }^{13}$ the second one is [əə] (儿). ${ }^{14}$ In music example 1.18, the third word in the first measure is ér (儿) [əə]. We can see that this word has three notes. Mandarin Chinese

\footnotetext{
12 The phrase “长江” means "Yangtze river."

13 The character “二” means "two."

14 The character “儿” means "son.”
} 
singers will usually finish the pronunciation in the first eighth note, and the two sixteenth notes will remain in the combination sound. Unlike the four Western languages, when singers sing the r-colored vowel [ə] , they should put it as late as they can in a note duration, but the vowel combination rule of Mandarin Chinese indicates that all vowels need to be pronounced quickly and stay in the combination for the rest of the duration. In this case, $[\propto]$ is already a combination of [ə] and $[x]$, and when we combine the [ə] and [ə] together, we can only hear the [ə] with a strong stress on the [ə] part. Therefore, this word ér (儿) [əə] has to remain in the sound of [ə] for all the notes as written, and the [ə] sound will start right after the [ə].

Music example 1.18: excerpt from Yunan folk song “Thinking of My Mother," measures 10-11.

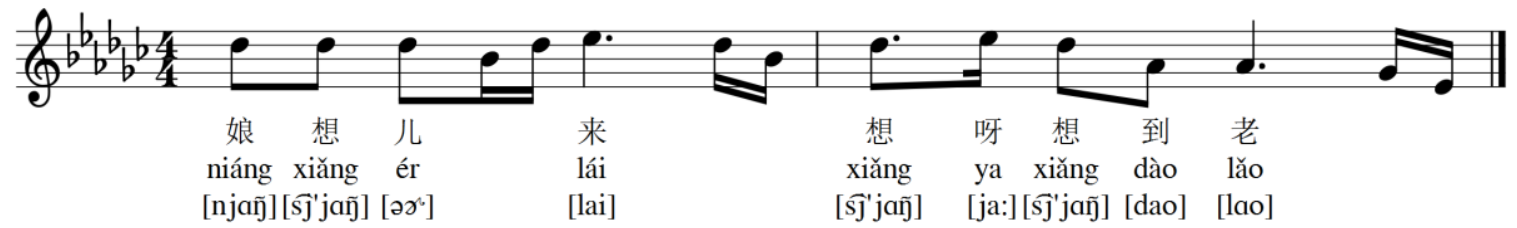

Many voice teachers in China declared that the diphthongs in the four Western languages are quite tricky for many of their students due to the habit of speaking Mandarin Chinese. Many voice teachers and vocal coaches in the U.S might also notice that Mandarin Chinese singers (especially for beginning singers) will often connect two vowels in a diphthong too close; they will usually not hold long enough for the first vowel, and the second one will either come too soon or barely be heard. The final $n$ and $n g$ also bring troubles to most of Mandarin Chinese singers. Voice teachers and vocal coaches in the North America need to understand that the final $n$ and $n g$ in Mandarin Chinese are entirely different than they are in the four Western languages. The tongue touching the hard or soft palates while phonating is the key that Mandarin Chinese singers need to master for producing a perfect final $n$ and $n g$ in the four Western languages (more discussion in Nonexistent vowels and consonant). 


\subsection{Consonants}

\section{Basic Consonants:}

Table 1.8: Mandarin Chinese basic consonants

\begin{tabular}{|l|l|l|l|l|l|l|l|l|l|l|}
\hline $\mathrm{b}[\mathrm{b}]$ & $\mathrm{p}[\mathrm{p}]$ & $\mathrm{m}[\mathrm{m}]$ & $\mathrm{f}[\mathrm{f}]$ & $\mathrm{d}[\mathrm{d}]$ & $\mathrm{t}[\mathrm{t}]$ & $\mathrm{n}[\mathrm{n}]$ & $\mathrm{l}[\mathrm{l}]$ & $\mathrm{g}[\mathrm{g}]$ & $\mathrm{k}[\mathrm{k}]$ & $\mathrm{h}[\mathrm{h}]$ \\
\hline
\end{tabular}

As in table 1.8, Mandarin Chinese uses these 11 consonants as the basic consonants, which are pronounced the same as when they are initial consonants in the four Western languages. In other words, these consonants are only used as initial consonants in Mandarin Chinese.

Flat-Tongue and Curled-Tongue Consonants:

Table 1.9: Mandarin Chinese Flat-Tongue and Curled-Tongue Consonants

\begin{tabular}{|l|l|l|l|l|}
\hline Flat-tongue & $z[\mathrm{z}]$ & $c[\mathrm{ts}]$ & $s[\mathrm{~s}]$ & \\
\hline Curled-tongue & $z h[\mathrm{~d} z]$ & $c h[\mathrm{t}]]$ & $s h\left[\int\right]$ & $r[3]$ \\
\hline
\end{tabular}

In Mandarin Chinese, there are two opposite groups of consonants that are called flattongue consonants and curled-tongue consonants. The flat-tongue consonants are $z[\mathrm{z}], c[\mathrm{ts}]$, and $s[\mathrm{~s}]$, which are all alveolar consonants; the curled-tongue consonants are $z h$ [dz], $c h\left[\mathrm{t} \int\right], \operatorname{sh}\left[\int\right]$ and $r$ [3], which are all postalveolar consonants. In table 1.9, the first three curled-tongue consonants are precisely the opposite of the flat-tongue consonants, in which the $h$ is silent and its only purpose is making the consonant before it a curled-tongue consonant. The $r$ [3] is an additional one, due to its postalveolar placement. The flat-tongue consonants barely cause any trouble for Mandarin Chinese singers when they sing. However, the curled-tongue consonants might cause tongue tensions due to the curling motion of the tongue. 
The letter $r$ has three different pronunciations in the four Western languages: the rolled $r$ $[\mathrm{r}]$, the flipped $r[\mathrm{r}]$, and the American $r[\mathrm{r}]$. However, in Mandarin Chinese, the $r$ is unexpectedly pronounced as [3]. The American $r[\mathrm{I}]$ is a retroflex consonant, which means the tongue tip is curled backward in the mouth, and while pronouncing it the articulators are further apart. The Mandarin Chinese $r$ [3] is a postalveolar consonant, which means the tongue is approaching to cross the alveolar ridge, and all articulators are close to each other. ${ }^{15}$ From the descriptions of these two consonants, we can see they share certain similarities, such as the fact that the tongue in both situations must be curled backward in the mouth, but the tongue when producing a retroflex consonant is further backward than in producing a postalveolar consonant. The articulators in both situations are not touching, but the articulators in producing a retroflex consonant are further apart than they are in producing a postalveolar consonant. Therefore, the motions in both situations are very similar, but the degrees are different.

Also, the letter $r$ is pronounced as [ $\left.3^{\circ}\right]$ in the Mandarin Chinese alphabet, in which [3] is following by a schwa without opening the mouth. The same pronunciation applies to the spelling of $r i$. As mentioned earlier, to phonate in this situation, Mandarin Chinese singers or speakers will usually choose to press down the back of the tongue to seek more space, and meanwhile, will curl the tongue even more backward to help press down the back of the tongue. Therefore, when producing a Mandarin Chinese $r$ [3], the tongue is in fact, further back than producing the [3] in the regular way, in which the tongue is backward passing the postalveolar ridge, and is almost like producing a retroflex consonant. Many Mandarin Chinese singers pronounce the American $r$ as a [3] since the spelling is the same as the American $r$. The similarities between

\footnotetext{
${ }^{15}$ Describing Consonants. Accessed March 27, 2019. https://home.cc.umanitoba.ca/ krussll/phonetics/articulation/describingconsonants.html.
} 
these two consonants means that this diction fault is not easy to recognize for many Mandarin Chinese singers and even some American voice teachers and vocal coaches.

In music example 1.19 , the first two words rì rì $\left(\right.$ 日日) ${ }^{16}$ are both pronounced as $\left[3^{\circ}\right]$. When Mandarin Chinese singers phonate with this postalveolar (retroflex feeling) consonant followed by a close-mouth [ə], they must press down the back of their tongue more than in other languages to make resonance. In this particular music example, the $\left[3^{\circ}\right]$ repeats twice; Mandarin Chinese singer cannot open their mouths while changing to the next note, so they have to press down the back of their tongues again to produce the second [3] and move their glottis to produce the second close-mouth schwa. Inevitably, there will be tongue and jaw tension caused by this kind of pronunciation. In music example 1.20, the second word rú (如) ${ }^{17}$ is pronounced as [зu:], very much like the French word jour without the flipped $r$. The implication of the Mandarin Chinese $r$ [3] might cause Mandarin Chinese singers to press down the back of their tongue more than they need to.

Music example 1.19: excerpt from "I Live at the Source of the Yangtze River" by Qing, Zhu, measures 13-16.

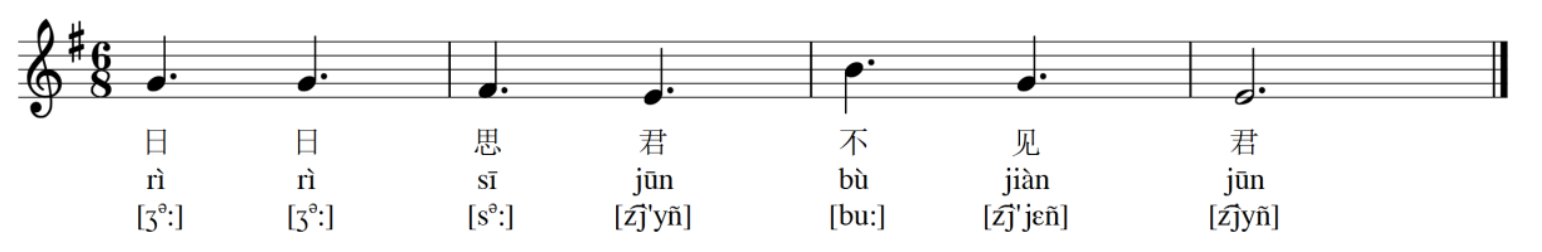

\footnotetext{
${ }^{16}$ The phrase of “日日” means “every day.”

17 The character “如” with the character before it “假” make the phrase “假如,” which means “if.”
} 
Music example 1.20: excerpt from "I Love This Land” by Lu Zaiyi, measures 10-11.

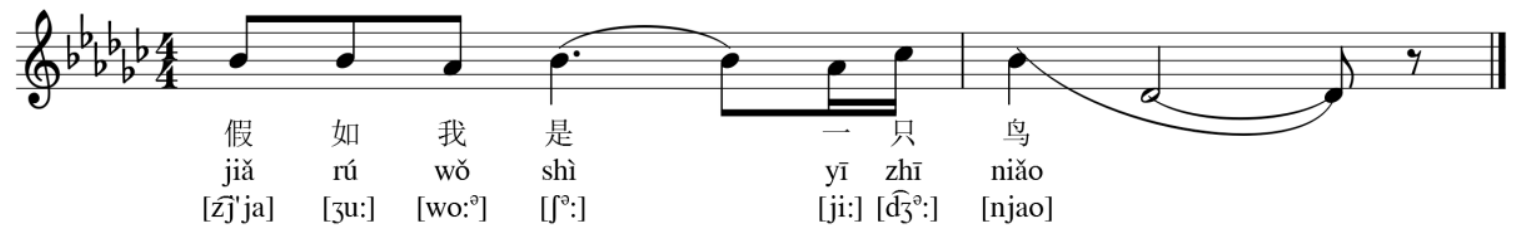

\section{Special consonants:}

Table 1.10: Mandarin Chinese special consonants

\begin{tabular}{|l|l|l|}
\hline$[\mathrm{d} 3]----\boldsymbol{j}^{-----[\mathrm{z}]}$ & {$\left[\mathrm{t} \int\right]$------ $\boldsymbol{q}$-----[ts] } & {$[\mathrm{J}]$----- $\boldsymbol{x}$------[s] } \\
\hline
\end{tabular}

Table 1.11: Comparing the curled-tongue and flat-tongue consonants with the special consonants

\begin{tabular}{|c|c|c|}
\hline Curled-tongue Consonants & Special Consonants & Flat-tongue Consonants \\
\hline$z h\left[\mathrm{~d}_{3}\right]$ : Postalveolar & $j[\widehat{\mathrm{zj}}]]:$ Alveolar & $z[\mathrm{z}]:$ Alveolar \\
\hline Affricate & Plosive & Fricative \\
\hline Voiced & Voiced & Voiced \\
\hline ch [t $\left.\int\right]$ : Postalveolar & $q$ [tsj]: Alveolar & $c$ [ts]: Alveolar \\
\hline Affricate & Plosive & Affricate \\
\hline Unvoiced & Unvoiced & Unvoiced \\
\hline $\operatorname{sh}\left[\int\right]$ : Postalveolar & $x[\widehat{\mathrm{sj}}]:$ Alveolar & $s[\mathrm{~s}]:$ Alveolar \\
\hline Fricative & Plosive & Fricative \\
\hline Unvoiced & Unvoiced & Unvoiced \\
\hline
\end{tabular}

In Mandarin Chinese, there are three special consonants $j, q$, and $x$ whose pronunciations do not exist in the IPA system. Western languages speakers usually pronounce the $j, q$ and $x$ in Mandarin Chinese as the curled-tongue consonants [dz], [t $\left.\int\right]$, [J] when these special consonants 
appear in Mandarin Chinese names. In fact, the pronunciations of $j, q$ and $x$ are between the curled-tongue consonants [dz], [t $\mathrm{f}],\left[\int\right]$ and the flat-tongue consonants [z], [ts], [s]. Based on the manners and places of articulation and voicing among these three kinds of consonants in table 1.11, we can see their specific differences. While pronouncing the $j, q$ and $x$ in Mandarin Chinese, instead of curling the tongue (being in postalveolar), the tongue needs to be flat (alveolar), and instead of letting a turbulence of airflow through the mouth (fricative or affricate), the tongue stops the airflow (plosive). Besides the tongue being flat, it is also towards the sides, which means the two sides of the tongue are approaching or touching the lower molars. Because of this motion, the upper and lower teeth are further apart than when producing the curled-tongue consonants and flat-tongue consonants, in which the upper and lower teeth (incisors and molars) are approaching each other. The tongue movement in producing $j, q$ and $x$ is like producing a glide [j]. Based on the places of articulation, $j, q$ and $x$ are all alveolar as the flat-tongue consonants. Therefore, I decided to use the glide [j] after [z], [ts], and [s], then becoming [ $\overline{\mathrm{zj}}$ [t $\widehat{\mathrm{tsj}}]$ and [ $\widehat{\mathrm{sj}}]$ for representing the Mandarin Chinese special consonants $j, q$ and $x$. When pronouncing these three consonants, consider that the first consonant is representing the mouth (teeth) shape and the second [j] is representing the tongue position. The mouth (teeth) shape is first ready for the first consonant but remains silent, then the tongue positions as the [j] ready to stop the airflow. When the preparations of both consonants are ready at the same time, the phonation starts.

Like most Western languages speakers, Mandarin Chinese speakers or singers (most likely for beginning learners of Western languages) are sometimes confused by the difference between the curled-tongue consonants [dz], [t $]$ ], [ $]$ ] and the special consonants $j, q$ and $x$ in Mandarin Chinese, which causes certain problems when Mandarin Chinese speakers or singers 
pronounce [d]], [t]], [J] in Western languages, such as English words jeep, cheese, and shimmer, or the Italian words gia, cielo, sciolto. Even Mandarin Chinese has [d]], [t]], [J] as curled-tongue consonant, which are never followed by vowel [i:] or glide [j]. However, the special consonants $j$, $q$ and $x$ are always followed by vowel [i:] or [y], and glide [j]. Therefore, when Mandarin Chinese singers are just starting to learn Western languages, they might get confused when [d3], [t $\left.\int\right]$, and [S] are followed by vowel [i] and glide [j].

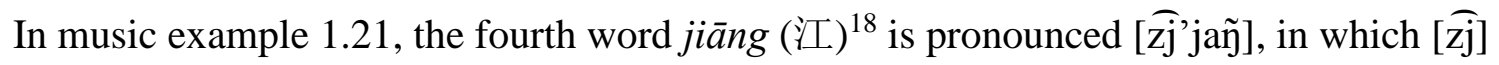
is directly followed by another [j] glide, but the pronunciation will only show the second one because the $[\mathrm{j}]$ in the $[\overline{\mathrm{zj}}]$ only represents the tongue position. In music example 1.22 , the last word $q \grave{u}(\text { 去 })^{19}$ is pronounced [tsj'y]. The letter $u$ here is in fact, a $\ddot{u}$, but is spelled as a $u$ because it follows a special vowel. In music example 1.23, the last word $x i \bar{u}$ (休) is pronounced [ $\widehat{\mathrm{sj}}$ 'jo], in which the [j] glide is pronounced only once, as well as in music example 1.21. Music example 1.21: excerpt from "I Live at the Source of the Yangtze River" by Qing, Zhu, measures 5-7.

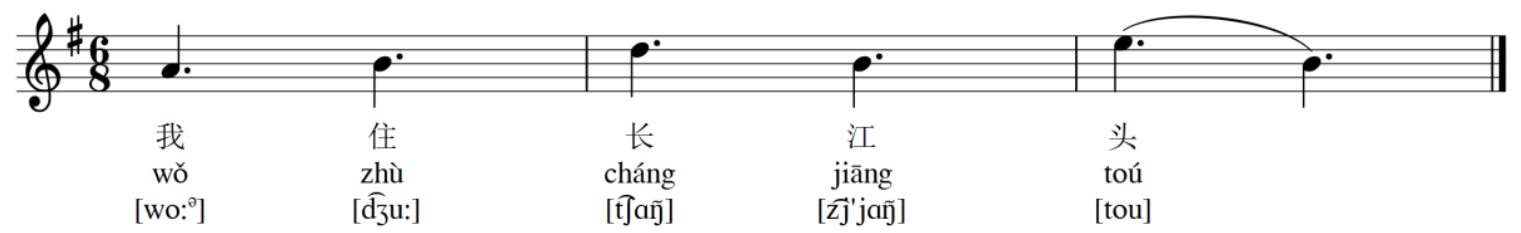

Music example 1.22: excerpt from "Homesickness" by Huang, Zi, measures 23-25.

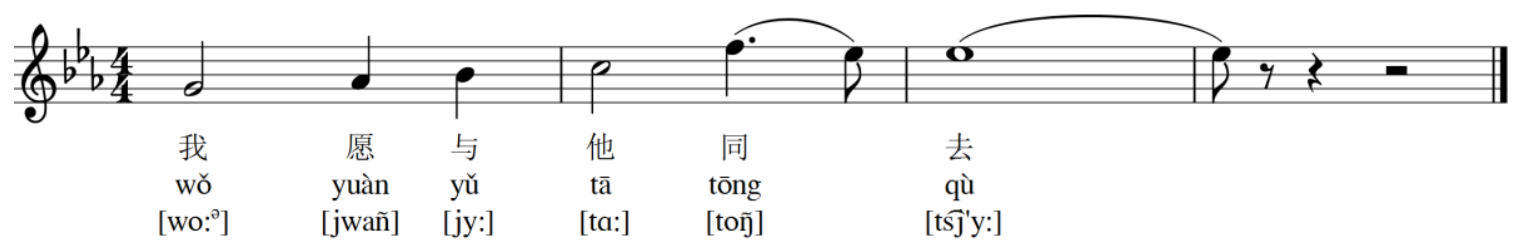

\footnotetext{
18 The character "江” means "river."

19 The character “去” means “go.”
} 
Music example 1.23: excerpt from "I Live at the Source of the Yangtze River" by Qing, Zhu, measures 21-23.

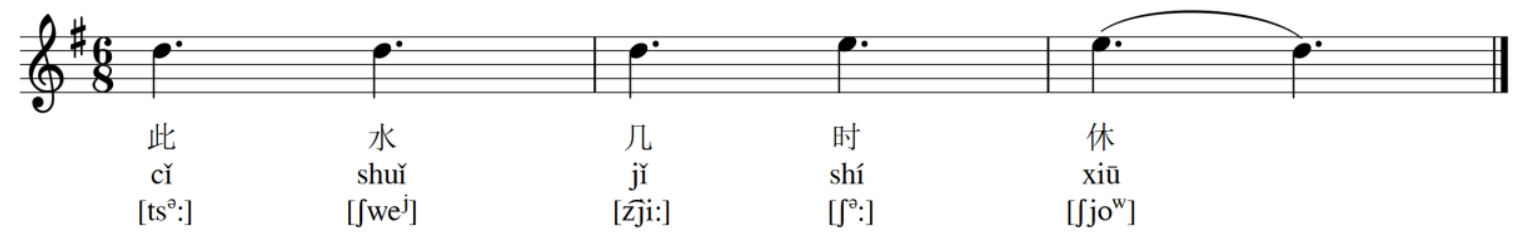

\subsection{Nonexistent Vowels and Consonants from Western Languages}

Every language has certain unique sounds that do not exist in other languages. After introducing the pronunciation system of Mandarin Chinese, we can see that some sounds that exist in the four Western languages do not exist in Mandarin Chinese. How can Mandarin Chinese singers learn and sing these sounds? What are the difficulties and how can Mandarin Chinese singers conquer them? We will try to find out.

\section{Nonexistent Vowels:}

Table 1.12: Vowels that do not exist in Mandarin Chinese

\begin{tabular}{|l|l|}
\hline Open Vowels & {$[\varepsilon][\odot][\mathrm{I}][\mho]$} \\
\hline Mixed Vowels & {$[œ][\varnothing]$} \\
\hline Nasal Vowels & {$[\tilde{a}][\tilde{\varepsilon}][\tilde{o}][\tilde{œ}]$} \\
\hline R-colored Vowels & {$[\varkappa][\varkappa]$} \\
\hline Paired Central Vowels & {$[\Lambda][ə]$} \\
\hline English Special Vowel & {$[æ]$} \\
\hline
\end{tabular}




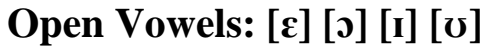

As mentioned previously, Mandarin Chinese does not have the open version vowels. Therefore, when most Mandarin Chinese singers start singing foreign languages, some of the open vowels become quite a challenge.

[ع]: Most Mandarin Chinese singers do not have a big problem with it because the [e] in Mandarin Chinese is pronounced slightly more open than the [e] in Western languages, but not quite as open as the $[\varepsilon]$. In fact, the $[\varepsilon]$ does appear in the vowel combination ian [tjeñ] because, as mentioned earlier, the front-nasal tone [ñ] makes the vowel before it a more forward vowel. Mandarin Chinese does not have the [e] sound as a single vowel; the [e] sound is always a part of the vowel combinations, and it usually appears with a [j] or [i] before or after it. The [j] or [i] can make the [e] sound not as close as the [e] in German, French and Italian. Mandarin Chinese singers will usually open the [e] more than is needed after or before the [i] or [j]. In real singing, Mandarin Chinese singers might have problems with producing both $[\mathrm{e}]$ and $[\varepsilon]$ which means the close version is not close enough and the open version is not open enough.

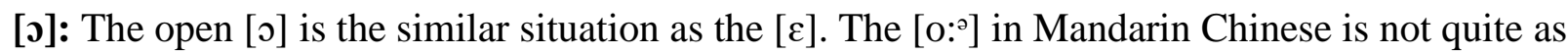
close as it is in Western languages, but it is not as open as [0] either. When Mandarin Chinese singers first try to produce the closed [o], they might feel it is too close and too similar to the [u:]; and when they first try to produce the open [0], they might find that is too open and with a slight feeling of [a]. To teach Mandarin Chinese singers to produce a correct [o], voice teachers or vocal coaches could ask them to try combining the sensations of [o] and [a].

[ซ]: Many Mandarin Chinese singers have a problem with the open [ซ]. Joan Wall and Robert Caldwell list the open [ซ] as a special vowel in English in Diction of Singers. ${ }^{20}$ The open [ซ] is a

\footnotetext{
${ }^{20}$ Joan Wall, and Robert Caldwell, Diction for singers: A Concise Reference for English, Italian, Latin, German French, and Spanish Pronunciation (Redmond, WA, Diction for Singers.com), 18.
} 
short vowel, which cannot be sung comfortably for a long duration. From observing American English beginning singers, when the $[\mho]$ is sung for a long duration, it will change into or combine with a sound between $[0]$ and $[\Lambda]$. Mandarin Chinese singers are not used to producing a combination sound without all the vowels presented. To teach Mandarin Chinese singers to produce a correct [ซ], voice teachers could try to ask them to combine the sensations of [o] and $[\Lambda]$.

[I]: The open [I] is the same situation as the open [U], which is also a short vowel. When it is sung for a long duration, the sound might change into or combine with $[\varepsilon]$ and $[\Lambda]$. Voice teachers and vocal coaches might ask Mandarin Chinese singers to combine the $[\varepsilon]$ and $[\Lambda]$ to find the feeling of an open [I].

\section{Mixed Vowels: [œ] [ø]}

These two mixed vowels exist in German and French. The [œ] is mixed by a $[\varepsilon]$ tongue position with a $[0]$ mouth shape, and $[\varnothing]$ is mixed by the same $[\varepsilon]$ tongue position but with a [o] mouth. The only difference between this pair of mixed vowel is the mouth shape. As mentioned previously, Mandarin Chinese does not have open vowels. The open version [œ] might be more difficult for Mandarin Chinese singers than the close version [ $\varnothing]$. When teaching Mandarin Chinese singers to produce the open version [œ], voice teachers and vocal coaches might ask them to make their mouth shape a rectangle. In addition, the open version [œ] might be a solution to fix the stressed [ə] for Mandarin Chinese singers. The open [œ] is more comfortable when produced in a higher position with a rounder mouth shape, which helps Mandarin Chinese singers fix the problem. Moreover, the [œ] does not exist in Mandarin Chinese, Mandarin Chinese singers can learn it without a reference from their native language. 


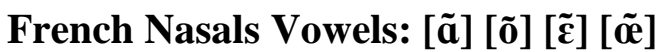

The most important three principles of pronouncing these French nasal vowels are: 1. do not over nasalize these vowels; 2 . the basic vowels are the distinctive feature of each nasal vowel, not the nasalization part; 3 . any $m$ or $n$ that follows the nasalized vowel letter is silent. ${ }^{21}$ Frist, Mandarin Chinese singers usually do not over nasalize the French nasal vowels, but they often place the nasal sound in the back of mouth. The back-nasal tone $n g$ in Mandarin Chinese is the reference when their singers learn the French nasal vowels. The sound might be similar, but the placement is different. The Mandarin Chinese back-nasal tone is placed closer to the soft palate, the French nasal vowels are closer to the hard palate. Even Mandarin Chinese singers do not use the tongue to touch the hard palate in back-nasal tones, when the sound ends and the mouth closes, the tongue might touch the hard palate accidentally. This brings us to the third principle, using back-nasal tone as a reference to pronounce the French nasal vowels causes Mandarin Chinese singers to sometimes add an $n$ or $n g$ sound after the French nasal vowels. For the second principle, most Mandarin Chinese singers are aware the important part is the basic vowel. In Mandarin Chinese, [a] and [o] in could be followed by the $n g$ and become the back-nasal tones.

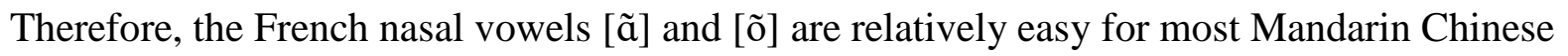
singers. However, the $[\varepsilon]$ and [œ] are more difficult than the other two, since Mandarin Chinese does not have these two open vowels. Based on the fact that the Mandarin Chinese [e] is usually pronounced more open, with a nasal sound added, the nasal vowel [ $\tilde{\varepsilon}]$ is still workable for most Mandarin Chinese singers. The [œ] does not exist in Mandarin Chinese at all, and with a nasal

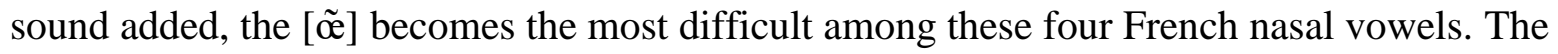
primary challenge of French nasal vowels for Mandarin Chinese singers might still be the

${ }^{21}$ Thomas Grubb, Singing in French: A Manual of French Diction and French Vocal Repertoire (Belmont CA, Schirmer, 1979), 54-55. 
placement issue that comes from the Mandarin Chinese back-nasal tone. Voice teachers and vocal coaches might need to explain more about the placement to help Mandarin Chinese singers to produce correct French nasal vowels, especially without an $n$ or $n g$ sound in the end.

\section{R-colored Vowels: [3] [a]}

Mandarin Chinese does have the close version [ə] , but not the open version [з]. However, since the difference between these two English r-colored vowels [3] and [ə] is the stressing, and the $[\vartheta]$ is Mandarin Chinese is a stressed vowel. Mandarin Chinese singers usually do not have obvious trouble producing them when singing. Only possible issue might be overstressing the $[\curvearrowright]$ sometimes.

\section{Paired Vowels: [A] [ə]}

Mandarin Chinese singers might have never considered $[\Lambda]$ and $[ə]$ as paired vowels. As mentioned previously, the [ə] is pronounced as a stressed vowel in Mandarin Chinese, which makes the [ə] sound often being a low position when singing. Mandarin Chinese singers usually consider the $[\Lambda]$ as similar to the [a] vowel. Changing the $[\Lambda]$ into an [a] vowel might be good for singing, but it is still not the correct pronunciation. To teach Mandarin Chinese singers this pair of vowels, voice teachers and vocal coaches should focus on asking singers to differentiate the stressed one and unstressed one.

\section{English special vowel: [æ]}

This special vowel only exists in English. Mandarin Chinese singers might get confused with the English diphthong [ar] or the Mandarin Chinese vowel combination [ai]. Mandarin Chinese does not ever have any vowels as forward and open at same time as the [æ], which will cause some difficulty at first. To teach Mandarin Chinese singers to produce a correct [æ], voice 
teachers and vocal coaches might start with a correct mouth shape first, then focus on preventing the blending in of [I] or [i].

\section{Nonexistent Consonants:}

Consonants that do not exist in Mandarin Chinese are listed in table 1.13. Mandarin Chinese does not have any final or medium consonants; the four consonants on the list of final or medial consonants are the most problematic ones. Other special consonants from different languages will also be discussed.

Table 1.13: Nonexistent Consonants from Western Languages.

\begin{tabular}{|l|l|}
\hline Final or Medial Consonants & {$[\mathrm{n}][\mathrm{y}][\mathrm{m}][\mathrm{l}]$} \\
\hline English Paired Fricative Consonants & {$[\theta]$ and $[\mathrm{\delta}]$} \\
\hline Enya (Italian and French) and Elya & {$[\mathrm{n}]$ and $[\kappa]$} \\
\hline German Ichlaut and Achlaut & {$[\mathrm{c}]$ and $[\chi]$} \\
\hline Flipped and Rolled $r$ & {$[\mathrm{c}]$ and $[\mathrm{r}]$} \\
\hline The Mandarin Chinese Missing [v] & {$[\mathrm{v}]$ vs. [w] } \\
\hline
\end{tabular}

Final or Medial Consonants: [n] [y] [m] [l]

[n] and [y]: As mentioned previously, Mandarin Chinese does not have any final or medial consonants. When the spelling of $n$ or $n g$ appears at the end of a word, it is considered as a part of the vowel combination. The vowel combinations end with $n$ and $n g$ are called front-nasal tone and back-nasal tone in Mandarin Chinese. As the names refers, the focusing of these two sounds

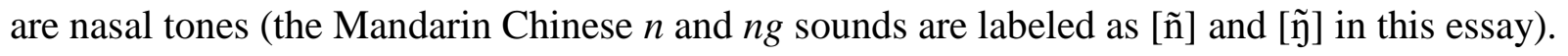
In the pronouncing process, the tongue is not required to touch either the hard or soft palate. Even when the tongue and palates accidentally touch each other while the mouth is closing, there 
will be no phonation involved. The final and medial [n] and $[\mathrm{n}]$ in the four Western languages are produced by letting the tongue touch the hard or soft palate while the phonation continues, which is a very important and challenging part for Mandarin Chinese singers. Mandarin Chinese singers often treat the final and medial $[\mathrm{n}]$ and $[\mathrm{y}]$ in the four Western languages as the same way

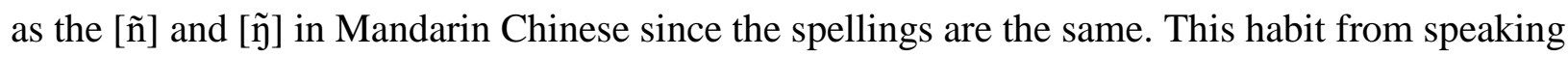
Mandarin Chinese brings tons of problems to Mandarin Chinese singers.

Many voice teachers and vocal coaches might notice that the problem is because the singers did not use their tongue to touch the palates. However, after asking Mandarin Chinese singers to touch the palates with their tongues, the problem does not always resolve completely. The reason is when Mandarin Chinese singers do use their tongue to touch the palates, the phonation has already stopped. This tongue movement did not work to make an audible difference. Also, some voice teachers noticed that some Mandarin Chinese singers have trouble to differentiate between [n] and [n]. Mandarin Chinese singers sometimes will sing a [n] instead of an [n]. In Mandarin Chinese, the back-nasal tone [n] means a greater amount of nasal sound than the front-nasal tone [n]. When a voice teacher asks a Mandarin Chinese singer to produce a correct [n], the singer might try to emphasize the nasal sound more by producing the $[\mathrm{\eta}]$ instead. Mandarin Chinese does have [n] as an initial consonant. Voice teachers and vocal coaches should try asking Mandarin Chinese singers to produce the final or medial [n] using the same way as when it as an initial consonant, especially making the phonation longer. For [ $\mathrm{\eta}]$, asking Mandarin Chinese singers to use the back of their tongue to touch the soft palate is the key, as well as making sure the phonation continues during this tongue movement.

[m] and [I]: The letters $m$ and $l$ in Mandarin Chinese only appear as initial consonants, which means there will always be vowels following these two voiced consonants. In the four Western 
languages, these two voice consonants often appear as final or medial consonants without any vowels to follow. When these two voiced consonants appear without any vowels following, Mandarin Chinese speakers usually pronounce them shorter than they are supposed to be or make them as unvoiced sounds. In Italian and German, we can sometimes add a [ə] after [m] and [1], but it is usually not an option for English. Voice teachers and vocal coaches could try to make Mandarin Chinese singers sing only on these two consonants with pitches and exaggerate and slow down the movements of involved articulators until the singer has mastered how to pronounce $[\mathrm{m}]$ and $[1]$ alone as voiced consonants.

\section{English Paired Fricative Consonants: $[\theta]$ and [ð]}

The th sounds [ $\theta]$ and [ð] are dental fricative consonants in the unvoiced and voiced versions, which are distinctly English consonants and do not appear in the other three Western languages. The $[\theta]$ and $[ð]$ are also the only two dental consonants in English, which involve the tongue blade or tip approaching or touching the upper teeth. Mandarin Chinese does not have any dental consonants, and the motion of the tongue touching the upper teeth could be very unfamiliar for Mandarin Chinese singers, which causes plenty of troubles for them, especially when voiced. They would often substitute the unvoiced $[\theta]$ with [s], and the voiced [ð] with [d], but the substitute for the unvoiced one usually happens to singers who are beginners of learning English. These consonants are both fricative consonants, which means there will be an airflow going through the mouth. However, when a phonation happens at the same that the tongue must touch the upper teeth, adding an airflow that goes through the mouth is not easy to accomplish, since the tongue is almost blocking the air. These two dental fricative consonants create more pressures than other fricative consonants, especially the voiced one. For helping Mandarin Chinese singers to produce these consonants correctly, voice teachers and vocal coaches need to 
explain the articulator movements in detail, and also assure them the extra pressure is normal and necessary for making them correctly. Practicing these two consonants in a slow motion and singing the voiced one on a pitch will be helpful for Mandarin Chinese singers as well.

\section{Italian Enya and Elya: [n] and [K]}

These new sounds from Italian and French (French only has Enya) bring some challenges to Mandarin Chinese singers. The Enya $[\mathrm{n}]$ is similar as the Mandarin Chinese word $n \check{\iota}(\text { 你 })^{22}$ [ni:]. The [ni:] requires two articulatory movements, in which [n] requires the tip of tongue touch the alveolar ridge and [i:] requires the tongue being lowered and touching the lower teeth. The enya $[\mathrm{n}]$ only requires one movement, in which the tip of tongue approaches the upper teeth, and the blade of the tongue touches the alveolar ridge. ${ }^{23}$ The elya $[\Lambda]$ is more difficult for Mandarin

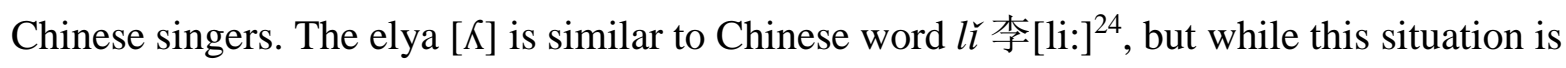
similar to the enya [n], the articulatory movements are different. The [li:] requires two movements for [1] (the tip of tongue touches the alveolar ridge) and [i:] (the tip of tongue approaches the lower teeth), but the elya $[\kappa]$ only requires one, in which the tip of tongue approaches the lower teeth, and the blade of tongue touches the boundary between the alveolar ridge and hard palate. The single articulatory movement in enya $[\mathrm{n}]$ and elya $[\kappa]$ is in fact, combining two articulatory movements, which makes the producing process longer than other consonants. This characteristic of a long producing process goes against the Mandarin Chinese pronunciation rule, in which all consonants are pronounced quickly, and the phonation always relies on the vowels. Again, practice in a slow motion and with pitches will help Mandarin Chinese singers greatly.

\footnotetext{
22 The character of “你” means "you."

${ }^{23}$ Wall, and Caldwell, Diction for singers, 66.

${ }^{24}$ The character of “李” is a Chinese surname.
} 


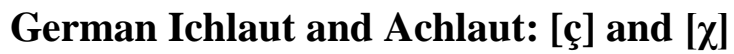

These two special German consonants brought a few confusions to Mandarin Chinese singers. Among Mandarin Chinese beginning singers, the Ichlaut [ç] is often substituted with the Mandarin Chinese special consonant $x[\widehat{\mathrm{sj}}]$, or the curled-tongue consonant $s h\left[\int\right]$. The Ichlaut [ç] is an unvoiced palatal fricative, which means the body of the tongue is approaching or touching the hard palate. It is not same as the Mandarin Chinese special vowel $x[\widehat{\mathrm{sj}}]$, in which the tip of the tongue is approaching or touching the hard palate. Moreover, the tongue position in Ichlaut [ç] is also not as curled as the [S]. Once the voice teacher or vocal coaches can make a Mandarin Chinese singer understand the correct tongue position, the pronunciation issue will be solved. The Achlaut $[\chi]$ is in fact, not too difficult for Mandarin Chinese singers. The pronunciation of $[\chi]$ is very similar with the Mandarin Chinese $h$ in the alphabet, which is pronounced as [hə:]. The Mandarin Chinese [hə:] is an unvoiced consonant with a stressed [ə] following, and the sensation of placement is very similar as the Achlaut $[\chi]$.

\section{Flipped and Rolled $r$ : [r] and [r]}

The flipped and rolled $r$ do not make too much difference for Mandarin Chinese singers, since the diction class in most conservatories and universities in China do not teach that there are two kinds of $r$ in the four Western languages, but only the rolled $r$ [r]. For every singer who does not have the flipped and rolled $r$ in his or her native language, the learning process takes a while. When the learning is completed, a rolled $r$ might become more accessible than the flipped $r$ at least for Mandarin Chinese singers. When the tongue is trilled, Mandarin Chinese singers might have difficulty making the time duration as short as the flipped $r$. Also, the correct time duration for a flipped $r$ is too similar to the Mandarin Chinese le when it is pronounced as [lə:] in a neutral 
tone (without stress). Therefore, many Mandarin Chinese singers intend to pronounce all the $r$ in Italian, German and French as the rolled $r$.

\section{The Mandarin Chinese Missing [v] vs. [w]:}

Mandarin Chinese does not have [v] as a consonant, and the letter $v$ is only used for representing the letter $\ddot{u}$ under certain circumstances. In the four Western languages, the [v] is a voiced labiodental fricative consonant, which means the lower lip is approaching or touching the upper teeth, and there is still an airflow going through the mouth. The unvoiced version of the labiodental fricative consonant is [f]. These two consonants are the only labiodental consonants in the four Western languages. As the discussion above about the dental fricative consonants [ $\theta]$ and [ð] indicates that Mandarin Chinese singers or speakers often have trouble with consonants that involve dental, especially those that are voiced. The airflow is barely getting through when the upper teeth and lower lip are approaching or touching. A phonation in the meanwhile will make some extra pressure around the lips and jaw and makes the production process longer than other non-dental or non-labiodental voiced consonants. The characteristics of the voiced dental and labiodental consonants bring a new sensation that has never existed in Mandarin Chinese. Voice teachers and vocal coaches might notice that Mandarin Chinese singers have trouble producing a $[\mathrm{v}]$ in two different ways, in which they either pronounce it without using the upper teeth to touch the low lip or having the motion in a too short time duration. The reason for these two ways is that Mandarin Chinese singers are trying to avoid extra pressure on the lips. 


\section{Chapter II}

\section{The Pronunciation of North American English and Its Beginning Singers}

In the early $17^{\text {th }}$ century, the English and British colonization of the Americas brought the language of English into North America. Later, immigrants from West Africa and other European countries settled in North America. With all the influences from West African, Native American languages, German, Dutch, Irish, Spanish, and other languages of immigrants, American English developed its own accent and dialects. The different dialects certainly affect singers in general, but we will only focus on the standard American English accent in this research. The North American English accent is normally considered as the standard American English accent, which is being used in both the United States and Canada. The North American English accent is widely used in Classical style singing for $20^{\text {th }}$ and $21^{\text {st }}$ centuries' music. North American English contains the most vowels and consonants out of the other three Western singing languages, but some of them might pronounce differently. There are also a few vowels and consonants that do not exist in North American English, but exist in the other three Western languages. This chapter will discuss briefly the pronunciations of vowels, diphthongs, glides and consonants in North American English, the nonexistent vowels and consonants found in the other three Western languages, and all the common and possible diction issues and vocal faults caused by the pronunciation of North American English. 


\subsection{Vowels}

\section{Single vowels:}

Chart 2.1: The Vowel Chart ${ }^{25}$

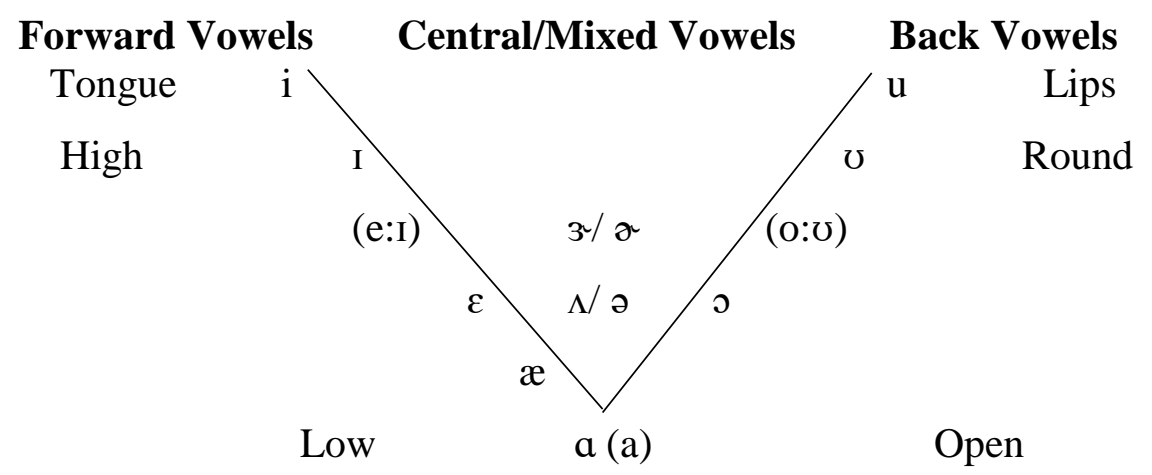

As figure 1 presents, English contains 12 single vowels that are categorized based on the places of articulation as forward vowels, central/mixed vowels, and back vowels (the vowels in brackets only exist in diphthongs, we will discuss later in Diphthongs) Joan Wall and Robert Caldwell defined these single vowels as pure vowels in their book Diction of Singers, which states "a pure vowel is a sound that can be sustained indefinitely without movement of the articulators. ${ }^{26}$ However, as the most significant characteristic of the North American accent, the r-colored vowels $[3]$ and $[x]$ do need the articulators to move when being sung for a long duration. Based on the pronouncing procedure of the r-colored vowels [3] and [ə], the tongue needs to be curled to make the American [I] sound, which tongue position should not be sustained as the same length as the singing duration. In Kathryn LaBouff's Singing and Communicating in English-A Singer's Guide to English Diction, she considers [־], [ə], $[\Lambda]$ and [ə] as mixed vowels. The mixed vowels usually contain two vowel sounds, so considering the

\footnotetext{
${ }^{25}$ Kathryn LaBouff, Singing and Communicating in English: A Singer's Guide to English Diction, (New York, Oxford University Press, 2008), 35.

${ }^{26}$ Wall, and Caldwell, Diction for singers, 17.
} 
two r-colored vowels [अ] and [^] as mixed vowels does make sense since they contain the main vowels [3] and [ə], and the [I] sound. The $[\Lambda]$ and [ə] on the other hand do not contain two vowel sounds, and therefore will be considered as central vowels in this research.

In Manual of American English Pronunciation, the author Clifford H. Prator, Jr. mentioned that the five fundamental vowels [a], [e], [i], [o], and [u] in American English do not pronounce as pure as they are in the other European languages. The author labels them as /a/, /ey/, /iy, /ow/, and /uw/ and explains that the /y/ and /w/ are being used to represent diphthongization, an upward movement of the tongue in the production of the vowel sound. ${ }^{27}$ The /ey/ and /ow/ are obviously indicating the diphthongs [er] and [ov]. However, the /iy/ and /uw/ bring an interesting insight into some common singing habits of American English beginning singers producing [i] and [u], and we will discuss them later. The 12 single vowels in figure 1 contain four paired vowels, in which [i] and [I], or [u] and [ซ] are close and open versions, and $[\Lambda]$ and $[ə],\left[{ }^{\Im}\right]$ and $[\curvearrowright]$ are stressed and unstressed versions. The $[\varepsilon],[\supset]$ and $[a]$ are not in pairs. We can see from figure 1 that English does not have the close [e] and [o], or the bright [a] as single vowels. However, the close [e] and [o], and the bright [a] do exist in diphthongs, which we will discuss later in "Diphthongs."

\section{Forward Vowels:}

\section{[i] and [I]:}

In German, the pronunciation rule specifically indicates that if the vowels are long vowels, they will be close vowels and if the vowels are short vowels, they will be open vowels. This rule generally applies to English as well, such like the words seat [si:t] and sit [sit], or heat [hi:t] and hit [hit], although, not every English diction book has mentioned this rule.

\footnotetext{
${ }^{27}$ Clifford H Prator, Manual of American English Pronunciation (New York, Rinehart and Winston, 1972), 10.
} 
The close [i:] usually does not affect American English beginning singers very much, unless they overspread it in the higher register. This spreading habit of the [i] vowel might not only be because of the singing technique, which could have some connection with the pronunciation of American English accent. Prator explains his labels /iy/ for [i] in Manual of American English Pronunciation that the /y/ represents the tongue moves upward toward the front of the mouth. ${ }^{28}$ This movement of the tongue restrains American English beginning singers from releasing their jaw when singing in long note duration, especially in their higher register. Prator also states in his book "this upward movement in the making of these vowel sounds is a characteristic which distinguishes English vowels from the so-called pure vowels of many European languages." ${ }^{29}$ In music example 2.1, the last [i] vowel in the word eternity happens on an F\#. If the singer adds a [j] glide after pronouncing [i], the sound might get tensed due to the middle of the tongue is trying to lean forward for the [j].

Music example 2.1: excerpt from "The Chariot” by Aaron Copland, measures 50-56.

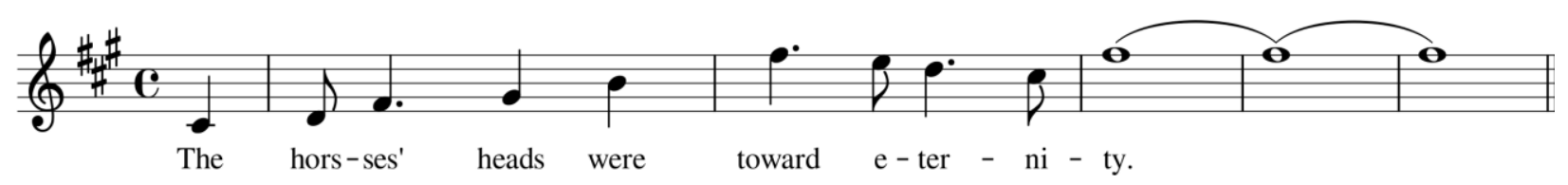

The open [I] might bring more issues to American English beginning singers than the close [i] does. The open [I] could be pronounced in a short duration in speaking, and then a consistent sound could be easily made. However, when the open [I] is being sung for a longer note duration, it is more difficult to maintain consistently than the close version.

The open [I] vowel generally has a lower tongue position than the close [i], and the mouth is slightly more open. For making an obvious difference between the open [I] and close [i],

\footnotetext{
${ }^{28}$ Prator, Manual of American English Pronunciation, 10.

${ }^{29}$ Prator, Manual of American English Pronunciation, 10.
} 
many American English beginning singers phonate the open [I] in a much lower position and create a sensation or resonance under the tongue. The most obvious difference between the open [I] and close [i] is not only the mouth being more opened, but the tongue position. The tongue position in producing the close [i] is arched and forward toward the hard palate, but in producing the open [I], the tongue is less arched and forward toward the hard palate, which often causes a gap between the sides of the tongue and the upper molars. However, the sides of the tongue touching the upper molars is the essential action for producing both the open [I] and close [i]. Without this action the vowel will sound mushy. This diction issue commonly happens among American English beginning singers. Moreover, when an open [I] vowel is produced with a gap between the side of the tongue and the upper molar, that means the space inside the mouth is more than the vowel needs, which can cause the singer to have a hard time concentrating and also causes the low sensation and resonance under the tongue. The most common solution will be modifying the open [I] to the close [i], or at least in a closer version. In music example 2.2, the last word slip has an open [I] with a long duration, if the singer does not modify it to a closer version, the vowel might sound mushy.

Music example 2.2: excerpt from "Now Sleeps the Crimson Petal” by Roger Quilter, measures $19-20$.

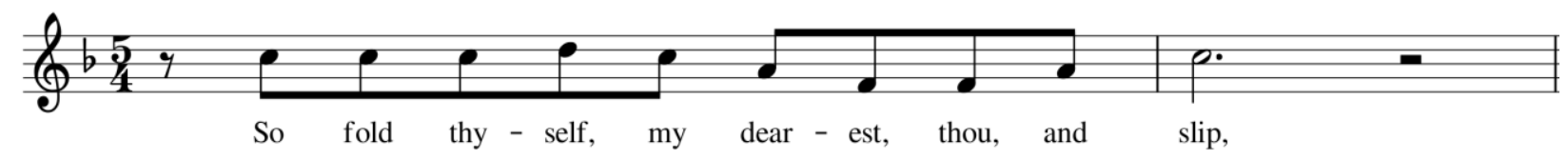

$[\varepsilon]:$

The open $[\varepsilon]$ rarely appears in any words without a following consonant in American English, which could be either a long or short vowel. It often appears as a stressed syllable, such as: many, head, said. The pronouncing procedure of this vowel is such that the tip of the tongue 
should be in contact with the lower front teeth, the front of the tongue is slightly arched toward the soft palate, and sides of the tongue are touching the upper molars. ${ }^{30}$ American English beginning singers often are able to pronounce the open $[\varepsilon]$ well. The only occasional issue is that since the open $[\varepsilon]$ vowel is often followed by a consonant, beginning singers might change the tongue position for the following consonant too early, which can cause the sides of the tongue to leave the upper molars while the $[\varepsilon]$ is still being sung. If the sides of the tongue do not touch the upper molars, the vowel will sound more like an [æ].

[æ]:

The vowel [æ] is a distinct English vowel, which is not found in Italian, German, and French. The [æ] is always a long vowel sound in duration. ${ }^{31}$ The tongue position of this vowel is similar to the $[\varepsilon]$ with less arched tongue blade, but the sides of the tongue are aligned with the lower molars instead. In other words, the jaw needs to drop more to make space so that the tongue can touch the lower molars without touching the upper ones, and the lips should not be spread. Many American English beginning singers spread their lip while producing the [æ], which can cause jaw tensions and lower resonance. As the vowel chart in figure 1 indicates, the tongue position of $[æ]$ is lower than $[\varepsilon]$, and the lips move more open from $[\varepsilon]$ to [æ]. If a singer produces an [æ] vowel with a lower tongue position but without a properly opened mouth shape, the back of the tongue has to be pressed more to seek space for the resonance, and the resonance would usually stay where the tongue is being pressed. The word passed in music example 2.3 is pronounced [pæst] in North American Standard English. With this word being sung on an F\#, singers might need more space to resonate. Beginning singers sometimes choose to spread the [æ] instead of open their mouth more vertically. American voice teachers and vocal coaches often

\footnotetext{
${ }^{30}$ LaBouff, Singing and Communicating in English, 51.

${ }^{31}$ LaBouff, Singing and Communicating in English, 53.
} 
suggest beginning singers to modify the $[æ]$ with a more vertical mouth shape for a healthier sound.

Music example 2.3: excerpt from "Now Sleeps the Crimson Petal" by Roger Quilter, measures $31-36$.

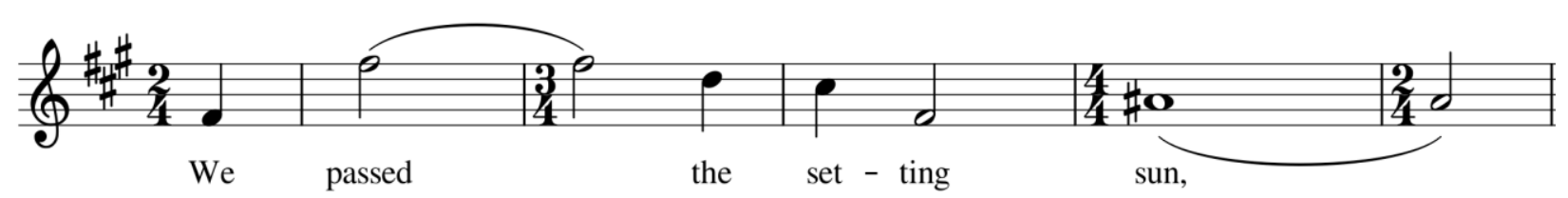

[a]:

In American English, only the dark [a] is used as a single vowel; the bright [a] is only used in diphthongs. In many diction books, the dark [a] is considered as a back vowel. The dark [a] surely has the lowest tongue position and most open mouth or lips, but these two articulator positions do not necessarily make the dark [a] a back vowel. The vowel chart in figure one is created by LaBouff and clearly visualizes the tongue positions from high to low and the lips from round to open, and the dark [a] meets in the middle. If the mouth/lips are open properly with the lowest tongue position, the dark [a] should sound like a forward vowel. However, in spoken American English, people do not open the mouth as much as in singing, which makes opening the mouth properly a difficult task for many beginning singers. With the lowest tongue position, but the mouth not opened properly, it could cause the dark [a] to sound like a back vowel.

\section{Central/Mixed Vowels:}

These two paired vowels $[\Lambda]$ and $[ə]$, and $\left[{ }^{-}\right]$and $[\curvearrowright]$ in this category are not very friendly for singing. Even mature singers would usually find substitutes for them when singing in certain registers. The $[\Lambda]$ and $[ə]$ are categorized as central vowels in this research, and the $[3]$ and $[ə]$ are considered as mixed vowels as LaBouff states in her book Singing and Communicating in English- A Singer's Guide to English Diction. 


\section{$[\Lambda]$ and [ə]:}

In American English, $[\Lambda]$ and [ə] are pronounced almost the same; $[\Lambda]$ might be slightly more open than [ə]. The most significant difference between them is the stressing, in which the $[\Lambda]$ is only used in stressed syllables, and the [ə] is always used in unstressed syllables.

As mentioned previously, [ə] brings troubles to Mandarin Chinese singers, but in American English, $[\Lambda]$ is more troublesome than [ə]. In Diction for Singers, the authors mention that "people make this sound when they can't think of what to say (as uh)," which is saying that the $[\Lambda]$ is a very common sound, and English speakers use it even when not in a word. The authors also state that "singers should practice this vowel with vibrant vocal resonance because it can become dull in tone quality," 32 which perfectly indicates the common singing habit of many American English beginning singers when they are singing $[\Lambda]$. When $[\Lambda]$ is being produced, the jaw is slightly forward, and because the $[\Lambda]$ sound is used too often in speaking, the resonance gets easily stuck under the tongue by many beginning singers. When the $[\Lambda]$ is sung on a high note, beginning singers often hold and tense the jaw to maintain the $[\Lambda]$ sound. Many voice teachers and vocal coaches might ask beginning singers to substitute the $[\Lambda]$ with an $[a]$ for releasing the jaw tension on the higher register, and making an easier resonance as well. The word love in music example 2.4 is pronounced $[\mathrm{h} \Lambda \mathrm{v}]$, but when it is being sung for a long duration, the $[\Lambda]$ vowel often forces beginning singers to forward their jaws. Modifying or substituting the $[\Lambda]$ with $[\mathrm{a}]$ often works well for beginning singers.

Music example 2.4: excerpt from "Love Has Eyes" by Sir Henry Bishop, measures 26-28.

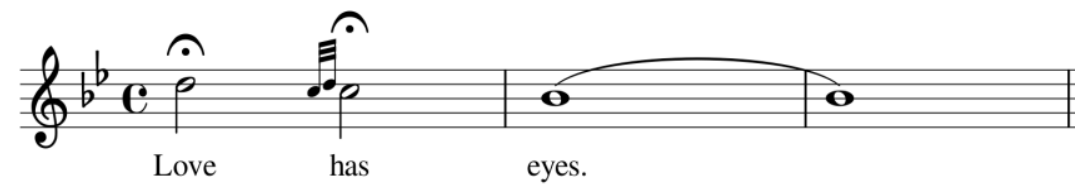

${ }^{32}$ Wall, and Caldwell, Diction for singers, 18. 
Since this pair of vowels are very similar, some voice teachers would ask beginning singers to substitute the $[ə]$ with the $[\Lambda]$ for creating a slightly bigger space. However, this trick sometimes creates unnecessary tension if beginning singers produce it in a stressed manner. In some French diction books, authors suggest using the French mixed vowel [œ] to substitute the [ə], which usually helps singers to release more tension in the back of the tongue, and also makes it easier to bring out the resonance. This trick might not work for some American English beginning singers if they are not familiar with the French diction. However, using the $[\Lambda]$ to substitute [ə] does not work well without changing the correct pronunciation of the word, especially when singing in low ranges. In music example 2.5 , if the [ə] in word the is being substituted with $[\Lambda]$, it might cause the lyric to be delivered unclearly.

Music example 2.5: excerpt from "Early in the Morning" by Ned Rorem, measures 5-6.

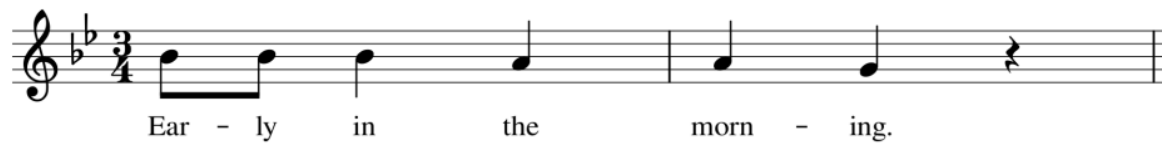

The vowel [a] also exists in German and French, but even though the IPA label is the same, the pronunciation among American English, German and French is slightly different. In German, the [ə] is regularly used for final $e$, but when it is in prefixes ge-, and be-, and endings -

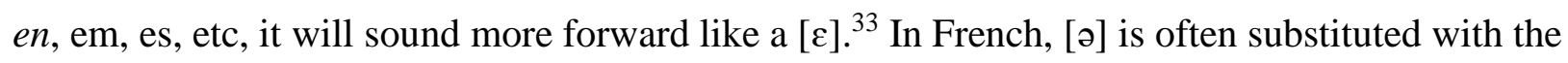
short and unstressed [œ] ([œ] in French has two versions: long and stressed [œ:], short and unstressed [œ]), and the genuine [ə] can be only sung at the end of the phrase, and on a very short note ${ }^{34}$ These sounds or substitutes in German and French are all labelled as [ə]. If American English beginning singers treat [ə] in German and French as same as the American

\footnotetext{
${ }^{33}$ William Odom, and Benno Schollum, German for Singers: A Textbook of Diction and Phonetics (Belmont CA, Schirmer, 1997), 45.

${ }^{34}$ Grubb, Singing in French, 43.
} 
English [ə], the sound quality might get affected due to the different placements among [ə], $[\varepsilon]$ and [œ]. After beginning singers get familiar with the French [œ], this vowel might help American English beginning singers to sing [ə] on a long note more comfortably.

\section{[3] and [o]:}

These vowels are considered as mixed vowels in this research since they contain more than one sound: the vowel and the $\mathrm{r}$ coloring. In American English, when $r$ appears at the end of a word that belongs to an $\mathrm{r}$-colored vowel [3] or [ə]. The $\mathrm{r}$ coloring itself is pronounced the same as the American [x], which is produced in the very back of the tongue, and includes curling the front of the tongue and the jaw moving slightly forward. In the r-colored vowels [з] and [ə], the $\mathrm{r}$ coloring is mixed with the vowel [3] or [a] when spoken. However, in singing, the r-colored vowels should not be treated as other mixed vowels; the two sounds need to be pronounced separately, unless for a very short duration. The r-colored vowels happen when $r$ is followed by a consonant or is final, and it is always after a vowel. ${ }^{35}$ The $r$ and vowel before it make the $r$ colored vowel, when an r-colored vowel (a vowel and $r$ ) is being sung on a long note, it should be treated the same way as in a diphthong which means the vowel sound should be sung longer, and the $r$ coloring should be sung at the last moment and in a very short duration. LaBouff considers that when a vowel is followed by the unstressed $r$-colored vowel [ə], they make an $r-$

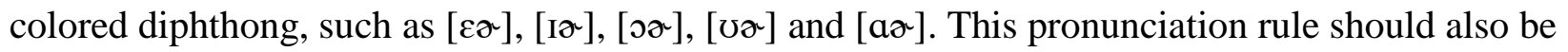
like the other diphthongs of English: the first vowel of the r-colored diphthongs should be sustained, then the secondary vowel sound, and the $\mathrm{r}$ coloring, is added at the very last moment. ${ }^{36}$ The same rule should apply for when stressed r-colored vowels [3] follow a vowel as well.

\footnotetext{
${ }^{35}$ LaBouff, Singing and Communicating in English, 106.

${ }^{36}$ LaBouff, Singing and Communicating in English, 93.
} 
In singing, difference between the stressed and unstressed versions is not very audible.

Composers usually will set the stressed version on a strong beat, and the unstressed version on a weak beat, such as the two examples in music examples 2.6. The stressed [з] in the word bird's starts from the second beat of the measure; the unstressed [ə] in the word labour happens on the last beat of the measure. For singing them, pronouncing the $r$ coloring too early is usually the main trouble for beginning singers.

Music examples 2.6: excerpts from "Under the Greenwood Tree" by Douglas Moore, measures 13-16; and "The Chariot" by Aaron Copland, measures 19-20.
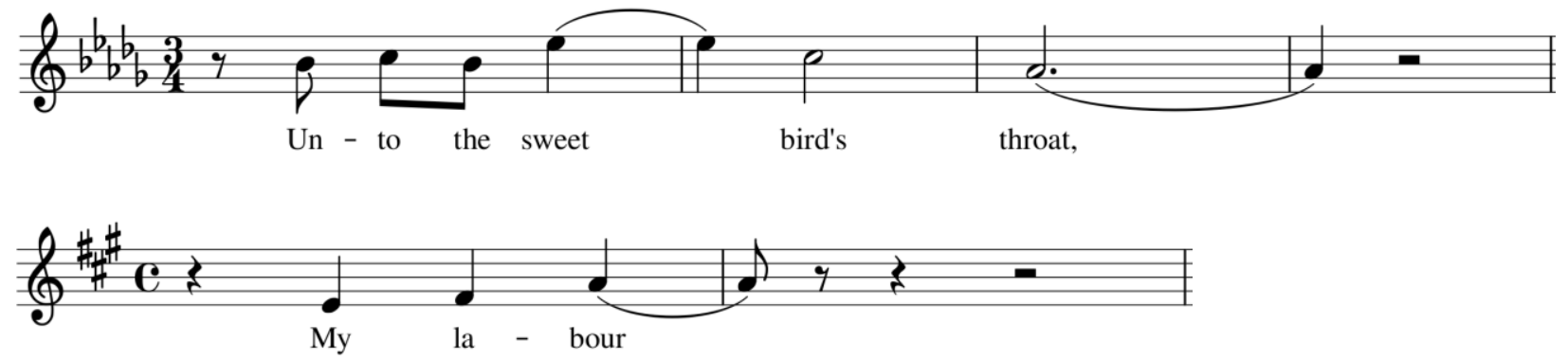

Because of the spelling of the r-colored vowels (a vowel followed by $r$ ), many American beginning singers have trouble when similar spellings appear in the other three Western languages. In the other three European languages: Italian, German, and French, the letter $r$ appearing after a vowel is usually a flipped $[r]$ or rolled $[r]$. Being able to pronounce a flipped $[r]$ or rolled [r] could be one of the problems, but willing to pronounce the vowel before the $r$ long enough is the most common trouble among American beginning singers. Some American English beginning singers are able to pronounce a flipped $[r]$ or rolled $[r]$, but when the flipped $[r]$ or rolled [r] appears after a vowel at the end of a word, the impression of American English rcolored vowels makes them prepare the tongue for the flipped $[r]$ or rolled $[r]$ too early, the same as they do with the r-colored vowels. With the tongue preparing the flipped $[\mathrm{r}]$ or rolled $[\mathrm{r}]$ too soon, the vowel before it is usually cut off too soon, and then an r-colored vowel-like sound will 
appear before the flipped [r] or rolled [r] is pronounced. In music example 2.7, the word cor happens on a half note. Beginning singers sometimes start preparing the rolled [r] too early, which can change the [o] vowel into a [ə] sound before the rolled [r] has taken place.

Music example 2.7: excerpt from "Caro mio ben" by Tommaso Giordani, measures 33-34.

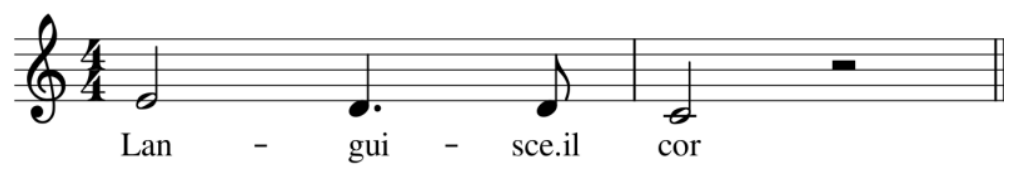

\section{Back Vowels:}

\section{$[u]$ and [o]:}

This pair of vowels sometimes causes trouble for American English beginning singers.

First of all, the close [u] vowel is often sung too close. In Manual of American English Pronunciation, Prator uses a /uw/ to represent the American English [u], in which "the /w/ glide indicates that the tongue moves upward toward the back of the mouth" as he stated. ${ }^{37}$ This tongue movement from $[\mathrm{u}]$ to $[\mathrm{w}]$ causes the space in the mouth to be smaller than the $[\mathrm{u}]$ in the other three Western languages. As mentioned earlier, Mandarin Chinese singers usually pronounce the $[\mathrm{u}]$ vowel with a $[\mathrm{w}]$ in the front of it, but American English is the opposite. The [w] glide involves lips movement, which also makes American English beginning singers reduce the space in their mouths when the $[\mathrm{w}]$ is added after $[\mathrm{u}]$. This issue usually sounds more obviously or strangely when American English beginning singers perform in foreign languages, but the /uw/ does sound normal and healthy in the musical theatre genre. The musical theatre genre usually involves a higher amount of chest voice and lower position of resonance than the classical style of singing does. That being said, the /uw/ sound works for chesty voice well like when spoken, but when singers need to sing more head voice and have a higher position of

\footnotetext{
${ }^{37}$ Prator, Manual of American English Pronunciation, 10.
} 
resonance, the /w/ sound retrains them to do so by shutting down the space inside their mouths. However, the American English [u] vowel does bring a benefit to singers, which is that most American English beginning singers do not have the issue of the $[\mathrm{u}]$ vowel being too dark. In music example 2.8, if a singer pronounces the word rue as [.tuw] that means their lips will tend to approach each other while singing, which causes the lack of space inside the mouth. As the word rue is sung on a $\mathrm{C \#}$, singers might need a taller space inside the mouth, but a $[\mathrm{w}]$ sound at the end of the word will not allow singers to shape the space they need.

Music example 2.8: excerpt from "With Rue My Heart is Laden” by Samuel Barber, measures 25.

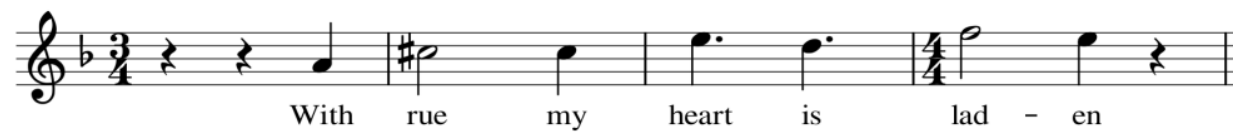

Among the four Western languages, the open [ひ] only exists in English and German. In German, the open [ [] is always a short vowel that is usually followed by more than two consonants, which is normally sung on a short note as well. The open [ $]$ ] in spoken English is often a short vowel as well and rarely vocalized, such as could, full, and cook. ${ }^{38}$ However, when composers set it on longer notes, the vowel is hard to maintain for a consistent sound. Beginning singers sometimes substitute it with $[\mathrm{u}]$ on certain registers, or sing on a distorted sound like a $[\Lambda]$, the latter of which is more common. The open [ $]$ should be able to vocalize with long notes. Comparing with the close $[u]$, the open $[\mho]$ has the back of the tongue as less arched toward the soft palate; the lips are less rounded; and the jaw is slightly dropped from the [u] position. In other words, the space inside the mouth for the open [ $\mathrm{\mho}]$ is slightly bigger than the close $[u]$, but the other articulation movements are the same. Singers should never not substitute the open [ ]

\footnotetext{
${ }^{38}$ LaBouff, Singing and Communicating in English, 64.
} 
with the $[\Lambda]$, but during the passaggio we could consider to substitute it with the close $[\mathrm{u}]$ (depending on voice types). In music example 2.9, the word look happens twice for two beats each. Beginning singers often pronounce it like the sound $[1 \Lambda \mathrm{k}]$, especially for the second one. The second look happens on an F, which is one of the notes during passaggio for high voice singers. The wiser way will be to modify the open $[\mho]$ with the close $[u]$, which could help to maintain the healthy way to sing through the passaggio and make the diction clearer.

Music example 2.9: excerpt from "Everywhere I Look" by Molly Carew, measures 65-69.

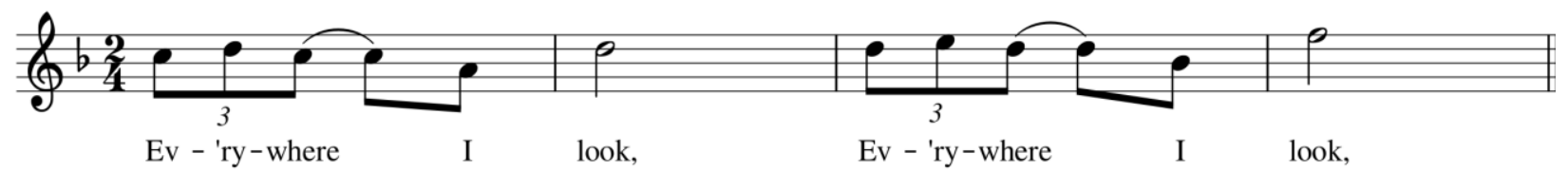

[?]:

As an open vowel, [0] is not as difficult as [ซ] or [I] when maintained on a long note, but it is easy to start on a lower resonant position if the singer tends to produce it in the spoken way. In spoken American English, the open [o] is often substituted by the dark [a], such like water [wotə] being substituted by [watə], or broad [bıod] as [b.ıad]. This phenomena is in fact, an effect from one of the American dialects, but it is very common among beginning singers. From the vowel chart, we can see the mouth shape and tongue position of [o] and [a] are similar, but it does not mean they are the same. The articulator movements for [0] are such that the back of the tongue is slightly arched, and the lips are protruded forward; for [a], the middle of the tongue is slightly arched, and lips are not protruded forward. In music example 2.10, the word paused is often pronounced [pazd] instead of [pozd]. Beginning singers should pay more attention to make sure that they are singing a pure [o], which helps them to have a vertical space as well. 
Music example 2.10: excerpt from "Everywhere I Look" by Molly Carew, measures 65-69.

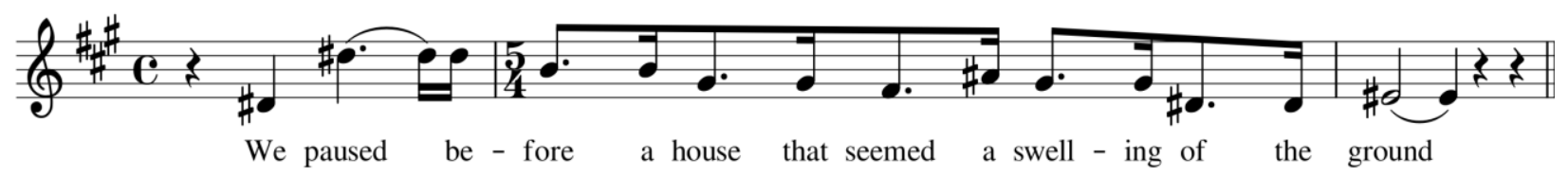

\subsection{Diphthongs}

Table 2.1: Diphthongs in English.

\begin{tabular}{|l|l|l|l|l|}
\hline [eI] & [oo] & [aI] & [ao] & [эI] \\
\hline
\end{tabular}

As table 2.1 indicates, English contains 5 diphthongs. We could notice that all the second vowels in these diphthongs are the open version vowels. When they appear in spoken American English, people might substitute the second vowels with the close versions. These diphthongs in table 2.1 are more specifically for singing, because the open version of the second vowels makes the articulators move less between the two vowels.

Diphthongs in American English use the same rule as the other three Western languages. A diphthong contains two vowels, the first vowel will be pronounced longer than the second one in singing. In spoken English, people usually pronounce both vowels with the same length and in a quick speed. Many American beginning singers use the spoken way to sing a diphthong, in which the first vowel is sustained briefly and then the second vowel is started too soon and sustained too long. This common issue does not cause any vocal faults, but it does make the lyrics difficult to understand by the audience. The most significant problem that the English diphthongs bring to beginning singers is the confusion when the close [e] and [o] appear as single vowels in the other three Western languages. In English, the close [e] and [o] only exist in diphthongs as [er] and [ov]. Many beginning singers have a hard time pronouncing these two 
vowels alone in singing the other three Western languages. The bright [a], on the other hand, also only exists in diphthongs as [aI] and [av], in which the bright [a] is often pronounced over-spread. [er] and [oo]:

As mentioned earlier, the close [e] and [o] only exist in diphthongs [eI] and [ov]. American English beginning singers often have trouble when the close [e] and [o] appear alone in the other three Western languages. The most common issue is that beginning singers often pronounce a single [e] as [eI], and a single [o] as [ov]. In other words, singing the [e] without a following [I], or the [o] without a [ $\mathrm{J}]$ to follow is often difficult for beginning singers. In music examples 2.11, the word sole in the first melody is pronounced as [sole], but many beginning singers pronounced it as [solei]. The word sento in the second melody is pronounced as [sento], but which commonly being pronounced as [sentov] instead by beginning singers.

Music examples 2.11: excerpts from "Gia il sole dal Gange” Alessandro Scarlatti, measures 7-9; and from "Nel cor piu non mi sento" by Giovanni Paisiello, measures 8-10.
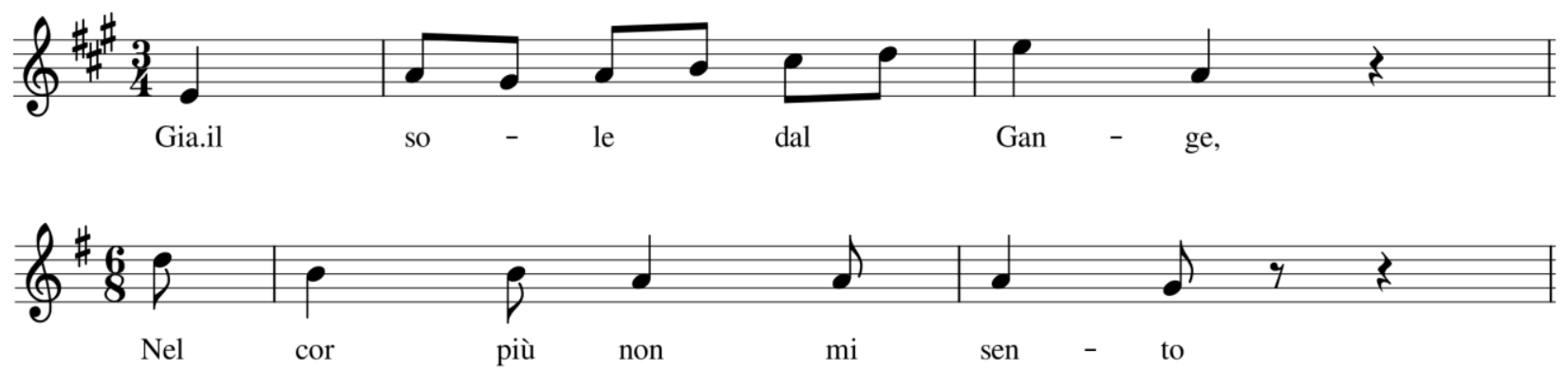

[ar] and [ao]:

The bright $[\mathrm{a}]$ in these two diphthongs usually helps beginning singers to sing more forward than the dark [a]. However, the bright [a] of [aI] and [av] in American English is usually more spread than they are supposed to be, which is often pronounced more like a $[\varepsilon]$ or sometimes even a [æ]. These kinds of substitutes are in fact, come from certain dialects. However, they are quite common for American English beginning singers. In music examples 
2.12, the word eyes in the first example is often sung with a spread mouth shape. The word how in the second example is sometimes pronounced as [hæo] instead of [av].

Music examples 2.12: excerpts from "Love Has Eyes” by Sir Henry Bishop, measures 26-28; and "How Beautiful are the Feet" from Messiah, by George Frideric Handel, measures 6-7.

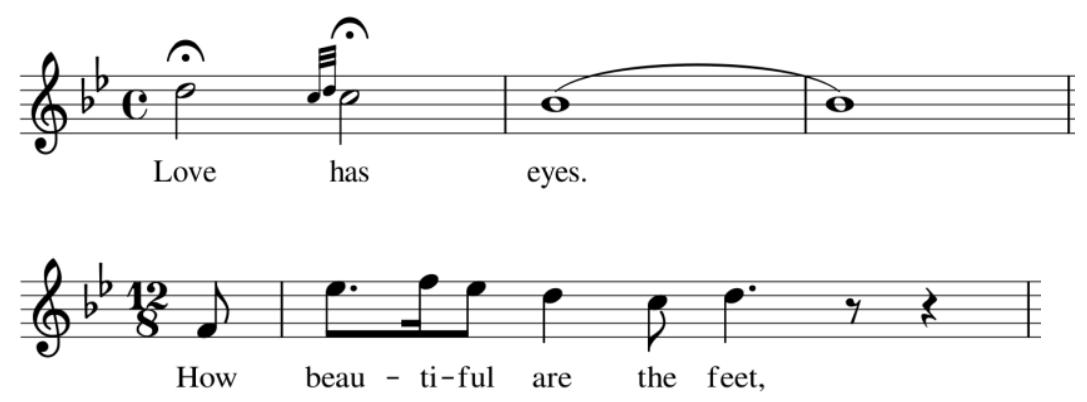

[эI]:

The two vowels in diphthong [गI] also exist as single vowels. American English beginning singers usually can pronounce this diphthong well, unless they substitute the [I] with [i] or pronounce the $[\mathrm{I}]$ too early in singing.

\subsection{Glides}

Table 2.2: Three semi-vowel glides:

\begin{tabular}{|l|l|l|l|}
\hline Manners/Places & Labial/Velar & Palatal & Retroflex \\
\hline Approximant & {$[\mathrm{w}]-[\mathrm{u}]$} & {$[\mathrm{j}]-[\mathrm{i}]$} & {$[\mathrm{I}]-[\mathrm{a}]$} \\
\hline
\end{tabular}

The three consonants in table 2.2 are considered as semi-vowel glides in American English, but their true identities are still consonants. LaBouff explains as: "a semi-vowel glide is a consonant that is produced during the movement from its initial articulatory position to another position that is formed by the oncoming vowel. In other words, it is the action of gliding from the related vowel sound to another vowel following that causes the consonant to be created and 
sounded. ${ }^{39}$ For example, when people produce the words wed, yes, and red, we produce the vowel sounds [u], [i] and [ə] first, and then produce the glide sounds [w], [j] and [I] right before the oncoming vowels. ${ }^{40}$ Because of these three semi-vowel glides $[w],[j]$ and $[\mathrm{I}]$ are originally related to the vowels $[u]$, [i] and [ə].

These three semi-vowel glides can appear before or after a consonant. Because the related vowels $[\mathrm{u}]$ and [i] of glides [w] and [j] are fairly easy to produce, when [w] and [j] appear either before or after a vowel or consonant, American English beginning singers usually can easily handle it well. However, the glide [r], also known as the American $r$ often brings troubles to beginning singers. Since a glide is a process between the original related vowel and the vowel following it, a glide itself often easily gets affected by the vowel or consonant around it, especially the American [I] glide. The American [I]'s related vowel [ə] itself is already not easy to sing in an appropriate way for many beginning singers, when the American $[x]$ glide appears after a consonant or before a vowel, some difficulties or inappropriate pronunciations would happen to beginning singers. The most significant incorrect pronunciations will be the two situations below.

\section{$[t . I]$ and $[\mathrm{d} . \mathrm{I}]$ :}

When the American [I] glide appears after the letters $t$ and $d$, and before a vowel, the length of the glide will be very short. The preparation of the American [.I] glide will often start while the $[t]$ and $[\mathrm{d}]$ are still in process, which means the tongue is being curled over the alveolar ridge during the pronouncing process of the initial consonants. Because of this, the initial $[\mathrm{t}]$ and [d] are usually cut off too soon before they have been heard clearly enough. Hence, the [t. $\mathrm{t}$ and $[\mathrm{d} x]$ are often pronounced as $\left[\mathrm{t} \int\right]$ and [dz]. In spoken English, these two situations might not

\footnotetext{
${ }^{39}$ LaBouff, Singing and Communicating in English, 99.

${ }^{40}$ LaBouff, Singing and Communicating in English, 99.
} 
sound very obvious, but they can make a big difference in singing. In music examples 2.13 , these two situations are presented by the words tree and drove. Beginning singers should be careful to pronounce them as the correct ways [t.ii:] and [d.ıov $]$ but not $[\mathrm{t} f \mathrm{i}:]$ and $[\mathrm{d} z o v]$

Music examples 2.13: excerpts from "Under the Greenwood Tree" by Douglas Moore, measures 3-6; and "The Chariot" by Aaron Copland, measures 14-16.
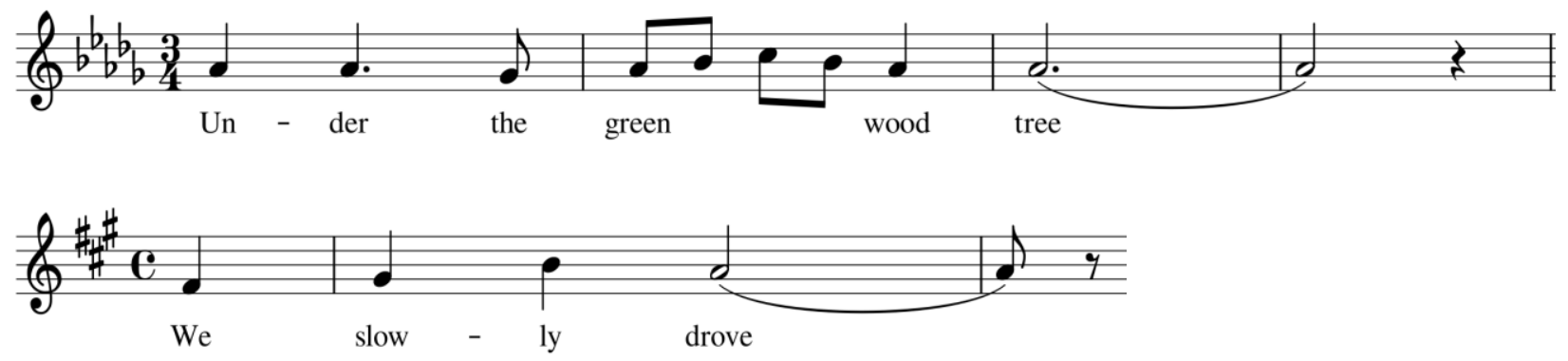

\section{[.I] Followed by Vowels:}

When the American $[\mathrm{x}]$ glide is followed by vowels, the tongue movement and mouth shape of the $[\mathrm{I}]$ often makes a $[\mathrm{w}]$ glide sound between it and the following vowel, except for [u] and $[\mho]$ which are the related vowels of [w]. Meanwhile, this added [w] glide sound also makes the $[\mathrm{I}]$ take a longer time than it is supposed to as an initial consonant, which means the tongue is being curled for a longer time than it needs to be. In other word, the process of the articulatory positions moving from the American [x] glide to another vowel creates a short [w] sound, and this [w] sound does not even exist in the IPA labels. Also, the longer singers hold the American $[\mathrm{I}]$, the longer the $[\mathrm{w}]$ will be presented. The examples below present the IPA labels of these words and the actual sounds of them.

Words Examples: [x] followed by vowels.
Raw [ıอ]--- [.เพอ]
$\operatorname{Read}[\mathrm{si}: \mathrm{d}]-[\mathrm{Iwi}: \mathrm{d}]$
$\operatorname{Red}[\mathrm{I} \varepsilon \mathrm{d}]---[\mathrm{Iw} \varepsilon \mathrm{d}]$
$\operatorname{Rush}\left[\mathrm{I} \Lambda \int\right]-\left[\mathrm{IW} \Lambda \int\right]$
Rat [.ıæ]--- [.ıwæd]
Rose [..ovz]---[..1wovz] 
This is a very common phenomenon among American English speakers or singers, which usually sounds fine in English songs. If singers can consider making the initial American [I] glide very short in singing, the [w] sound will be decreased, which might help the tongue release more for the following vowel as well. However, when this situation happens when American English beginning singers are singing in the other three Western languages, even those that can make the rolled [r] and flipped [r], the following vowels often get changed by adding a [w]. This speaking habit usually brings the [w] to follow the rolled [r] and flipped [r]. Hence, [ra], [re], [ro], [ri] or [ra], [re], [ro], [ri] in the other three Western languages are often pronounced as [rwa], [rwe], [rwo], [rwi] or [rwa], [rwe], [rwo] and [rwi]. This situation does not only happen among beginning singers but mature singers as well.

\subsection{Consonants}

Table 2.3: English consonants

\begin{tabular}{|c|c|c|c|c|c|}
\hline Manners & Plosive & Fricative & Affricate & Approximant & Nasal \\
\hline Bilabial & {$[\mathrm{p}][\mathbf{b}]$} & & & & {$[\mathrm{m}]$} \\
\hline Labiodental & & {$[\mathrm{f}][\mathrm{v}]$} & & & \\
\hline Dental & & {$[\theta][ð]$} & & & \\
\hline Alveolar & {$[\mathrm{t}][\mathbf{d}]$} & {$[\mathrm{s}][\mathbf{z}]$} & & [1] (lateral) & [n] \\
\hline Postalveolar & & [S] [3] & {$[\widehat{\mathrm{t}}][\widehat{d} \mathbf{d}]$} & & \\
\hline Velar & [k] [g] & & & & [n] \\
\hline Glottal & & {$[\mathrm{h}]$} & & & \\
\hline
\end{tabular}


The table 2.3 lists all consonants in English based on their places and manners. English contains most of the consonants that also exist in the other three Western languages, except for [ $\theta]$ and [ð] that only exist in English. From the aspect of the manners of consonants, plosive and fricative consonants are usually easy to produce. The articulators either touch each other and stop the airflow, or only approach each other and make a turbulence airstream. For the manner of affricate consonants, the articulators have more tasks to do for producing a consonant, in which the articulators have to stop the airflow first, and then make a turbulence airstream. In approximant consonants, articulators stay further apart and make a turbulence airstream. As mentioned earlier, [w], [j] and [I] in the category of approximant are also considered as semivowel glides. Another one that belongs to the categories of approximant and lateral is [1]. Because of the tongue movement, [1] brings some troubles to American English beginning singers, which we will discuss below. Lastly, the nasal consonants in American English often bring trouble when they appear as medial or final consonants.

\section{Final and Medial [n] and [m]:}

Furthermore, $[\mathrm{n}]$ and $[\mathrm{m}]$ are usually easy to produce when they appear as initial consonants in English. The tip of the tongue touches the hard palate to make a [n]; [m] requires the mouth to be closed. However, when these two voice consonants appear at the end or middle of a word, many American beginning singers usually have the urge to produce them or prepare them. Hence, the premature preparation often affects the vowel before these two consonants. In Italian, the [n] and [m] rarely appear at the end of a word; in German, they are often followed by a vowel or pronounced with a shadow $e$ when they appear as a medial or final consonant; in French, the medial and final $[\mathrm{n}]$ and $[\mathrm{m}]$ are often produced as a silent or nasal sound. When the [n] and [m] appear as the final or medial consonants in English, they often follow a vowel or 
consonant. Both $[\mathrm{n}]$ and $[\mathrm{m}]$ require the mouth to be in a closing motion or totally closed.

Therefore, when a vowel is followed by a $[\mathrm{n}]$ or $[\mathrm{m}]$, beginning singers often prepare the $[\mathrm{n}]$ and [m] too soon by closing their mouths, and this mouth movement will change the vowel or make it sound distorted.

In music examples 2.14, the word sun [s $\mathrm{s}$ ] sustains for six beats, if a beginning singer starts preparing the $[\mathrm{n}]$ too soon that might cause the $[\Lambda]$ is being sung while the mouth is closing. Or if a beginning singer pronounces the [n] too soon, the vowel will cut off and the sound of the word will sound strange. The same situation happens to the word seemed, since the letter $e$ between $m$ and $d$ is silent, the [m] is considered as the final consonant, even though it is not the last letter of the word. In this case, beginning singers often close their mouths completely to pronounce the [m] right after the [i] vowel, which causes the vowel not to be sustained long enough.

Music examples 2.14: excerpts from "The Chariot" by Aaron Copland, measures 31-36 and 3739.
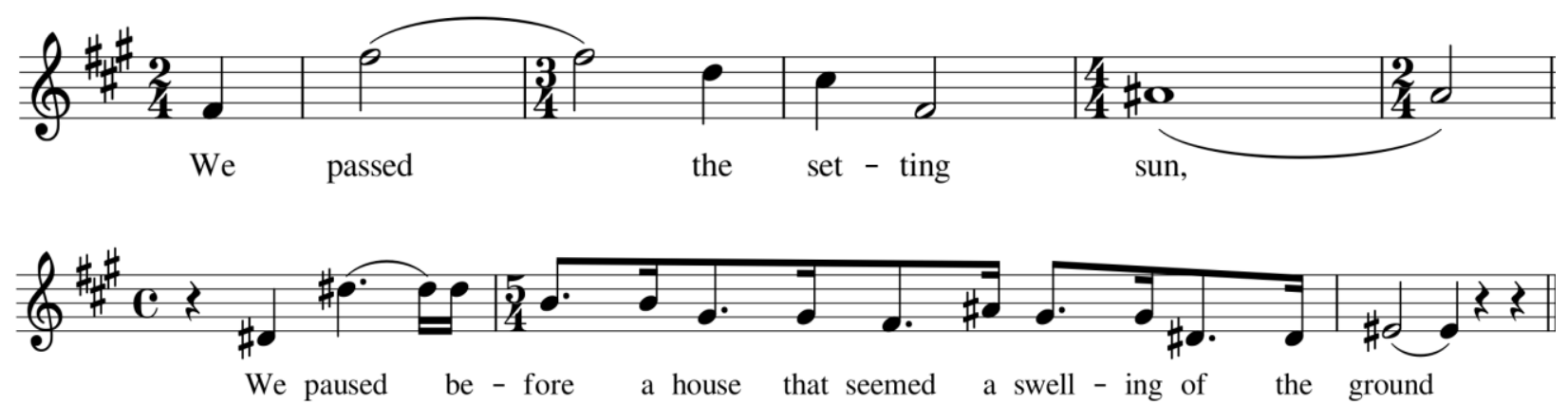

Final and Medial [1]:

The [1] is the only lateral approximant (manner) consonant in English, which means only the lateral of the articulators are further apart. In other words, the sides of the tongue stay apart from the molars, but the tip of the tongue is still touching the alveolar ridge. When the tongue 
touches the alveolar ridge but still keeps the sides away from the molars, the jaw must be slightly dropped. If the articulatory movements of [1] are sustained for a long time duration, a tension will be created and affect the vowel before or after it. Also, when producing an [1] for a long duration, singers will seek space in their mouths by pressing down the back of their tongues since the tip of the tongue is touching the hard palate.

LaBouff states that there are the two types of [1]'s in spoken English. The two types of [1]'s are: light and clear [1] that is often used as the initial one, and the dark and back [1] that is often used as the final or medial one. ${ }^{41}$ Instead of the tip of tongue touching the upper gum ridge as the light and clear [1] does, the dark and back [1] requires the middle of the tongue raises and approaches toward the palate, which often causes tongue tension due to the back of tongue being pushed down. In music examples 2.15 , both the [1] as a final consonant and a medial one are presented. In the word feels, the [1] sound is often sung for more than half of the duration by beginning singers, which causes the tongue to be tensed and creates a strange sound. In the word swelling, the same situation often happens, especially in this case where the double $l$ are being edited under the first G\#, but in fact, the [1] sound should be pronounced on the second G\#. Beginning singers usually will prepare their tongue for the [1] or already pronounce the [1] before the second G\# happens.

Music examples 2.15: excerpts from "The World Feels Dusty," measures 2-4; and "The Chariot," measures 37-39, by Aaron Copland.

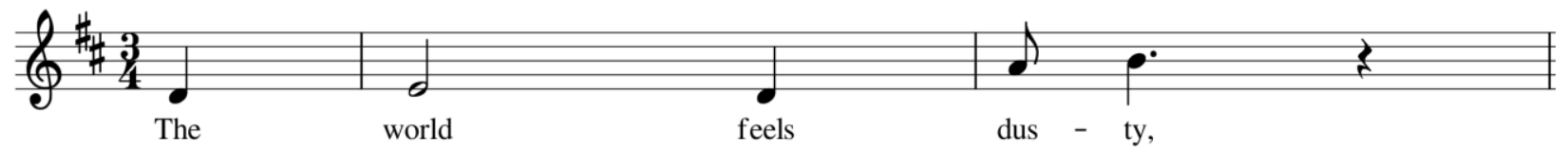

${ }^{41}$ LaBouff, Singing and Communicating in English, 180. 


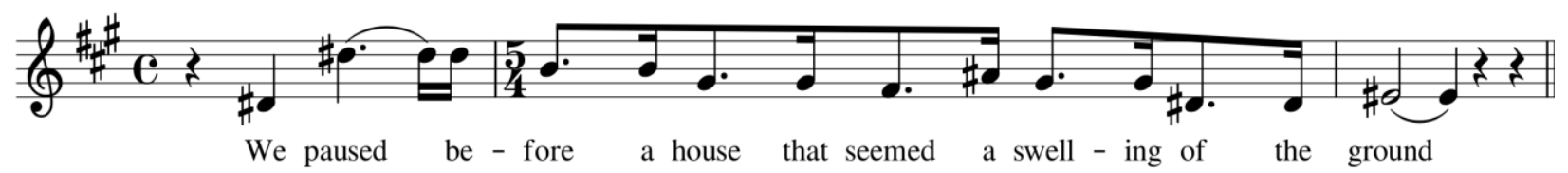

\subsection{Nonexistent Vowels and Consonants}

When American beginning singers start learning other three Western languages, those nonexistent vowels and consonants can be a challenge. English contains most of the vowels and consonants that also exist in the other three Western languages, but there are still a small number of new vowels and consonants that American English beginning singers have to deal with.

Table 2.4: Nonexistent Vowels and Consonants

\begin{tabular}{|c|c|}
\hline Mixed Vowels & [ø:] [œ]; [y:] [y] (only in German) \\
\hline French Nasal Vowels & {$[\tilde{a}][\tilde{\varepsilon}][\tilde{o}][\tilde{\alpha}]$} \\
\hline Enya and Elya & [n] (Italian and French) and $[K]$ \\
\hline German Ichlaut and Achlaut & {$[\mathrm{ç}]$ and $[\chi]$} \\
\hline Flipped and Rolled $r$ & {$[\mathrm{r}]$ and $[\mathrm{r}]$} \\
\hline
\end{tabular}

\section{Mixed Vowels:}

Mixed vowels only exist in German and French, and each of them contains two different elements which are lips and tongue position from two different vowels.

\section{[ø:] and [œ]:}

The $[\varnothing:]$ and $[œ]$ are a pair of mixed vowels in the close and open versions. They both appear in German and French. The close [ø:] contains a $[\varepsilon]$ tongue position and a [o] lips position. In producing it, the position of the lips is more important than the tongue position, especially for the middle and lower register. The lips position insures the formation of this vowel, while the 
tongue position is more helpful for the upper register when the lips have to relax. ${ }^{42}$ For many American English beginning singers, making the correct tongue position is more difficult than the position of the lips. Since the lip position is a [o] position, beginning singers often want to make a [o] tongue position as well, or press down the back of the tongue to go against the [ع] tongue position.

The open [œ] has the same tongue position $[\varepsilon]$, but with a more open lips position [o]. In other word, the only difference between these two mixed vowels is the lips position. Beginning singers often get confused between these two mixed vowels by making a difference on the tongue position.

\section{$[y]$ and $[\mathbf{Y}]$ :}

The $[\mathrm{y}]$ and $[\mathrm{y}]$ are also in the close and open versions, but the open version $[\mathrm{Y}]$ only exists in German. The close version [y] contains two elements, which are the tongue in a [i] position, and the lips in $[\mathrm{u}]$ position. Thomas Grubb states in his book Singing in French: A Manual of French Diction and French Vocal Repertoire that "the most important ingredient of a good [y] is [i], especially in the higher register."43 Many beginning singers get confused between these two elements. The most common fault of this mixed vowel is the [i] tongue position being fused with the [o] tongue position. With the lips position, beginning singers might have a hard time shaping a different tongue position at the same time. Sometimes, beginning singers can shape the tip of the tongue into almost the right position, but often lower the back of the tongue.

The open version [Y] only appears in German, in which the tongue position is in the open [I] position, and the lips are still in the [o] position. The same as the close [y], the common

\footnotetext{
${ }^{42}$ Grubb, Singing in French, 40.

${ }^{43}$ Grubb, Singing in French, 39.
} 
problem that happens among beginning singers is still the tongue position. Beginning singers often have a problem with the articulators shaping two elements that form different vowels.

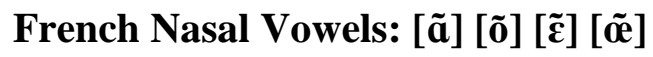

These four nasal vowels are distinctive French vowels. The most important three principles of pronouncing these French nasal vowels are: 1 . do not over nasalize these vowels; 2 . the basic vowels are the distinctive feature of each nasal vowel, not the nasalization part; 3 . any $m$ or $n$ that follows the nasalized vowel letter is silent. ${ }^{44}$ These principals are also the common faults that often happen to beginning singers.

American English does not contain any nasal vowels. When beginning singers first start learning these French nasal vowels, they might get confused about how much nasal sound they should produce. In the low register, the French nasal vowels can sometimes help beginning singers to sing more forward. However, in the higher register, if beginning singers over nasalize these French nasal vowels, the resonance might get stuck inside their nose and cause tensions. Some voice teachers suggest avoiding the nasalization part when these French nasal sounds occur on a higher register.

The second principle also happens very commonly among beginning singers as a diction issue. The $[\tilde{a}]$ and [õ] might sound similar in singing. Some beginning singers treat these two French nasal vowels as the same. There are two possible reasons for this confusion: 1, beginning singers might only focus on the nasalization part but the basic vowels; 2 . there is no close [o] as a single vowel in American English, beginning singers might use the open [o] as the basic vowel for [õ]. The dark [a] and open [o] are very similar as we can see from the vowel chart. When the nasalization part is added on a vowel, the sound usually will become more vertical and more

\footnotetext{
${ }^{44}$ Grubb, Singing in French, 54-55.
} 
backward. If beginning singers add the nasalization part on the dark [a] and open [0] that will create even more similar sounds. For helping American English beginning singers to

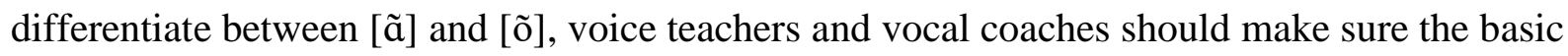
vowel of [õ] is the close [o]. The third principle usually does not bother American English beginning singers much, only occasionally the silent $n$ might be presented as [n].

\section{Enya and Elya: [n] (Italian and French) and [ $\mathcal{k}]$ :}

As discussed previously in the Mandarin Chinese chapter, the enya [n] and elya $[K]$ are distinctive vowels that exist in Italian and French (French only has the enya [n]). For any singers whose native language does not have them, the pronunciations will be tricky. For many American English beginning singers, the enya [n] is similar or equal to [ni], but they are completely different pronunciations. Instead of two articulatory movements like in [ni], the [n] only requires one. Instead of using the tip of the tongue to touch the alveolar ridge like [n], the blade of the tongue touches the alveolar ridge for [n], and unlike the tongue touching the lower teeth in [i], the tip of the tongue approaches the uppers teeth in [n]. However, this diction issue is not very audible sometimes, and many beginning singers might not realize it.

On the other hand, the elya $[K]$ brings more obvious troubles to beginning singers. The pronunciation of $[K]$ is considered as similar or the same as [li] by beginning singers. Some voice teachers might allow beginning singers to use [li] to substitute $[K]$ when they cannot imitate and pronounce the correct sound. However, unlike using [ni] to substitute [n], if a singer substitutes $[K]$ with [li], the difference between these two sounds is much more audible than the other one. The [li:] requires two movements, the tip of the tongue touching the alveolar ridge when producing [1], while [i:] requires the tip of the tongue to approach the lower teeth. The elya $[K]$ 
only requires one tongue movement where the tip of tongue is approaching the lower teeth, and the blade of the tongue is touching the boundary between the alveolar ridge and hard palate.

From the tongue movements for both enya $[\mathrm{n}]$ and elya $[\kappa]$, we can see that using the blade of the tongue to touch the alveolar ridge or be near to the hard palate is the key of pronouncing these two special consonants. If an American English beginning singer could fully understand the tongue movement, she/he should be able to pronounce them correctly.

\section{German Ichlaut [ç] and Achlaut $[\chi]$ :}

These two German consonants occasionally confuse beginning singers. The Ichlaut [ç] is an unvoiced palatal fricative consonant, which means there is air going through the mouth, and the hard palate is involved. The tongue position is the same as that of [j], but with the air going through, and then producing a hissing sound. ${ }^{45}$ Most American English speaking singers can pronounce $[c ̧]$ well, because the pronunciation is similar as the initial sound in English words human, or huge ${ }^{46}$ However, some American beginning singers are confused by the difference between $\left[\int\right]$ and $[c ̧]$, because they might be trying to imitate the sound by listening to recordings, but without a correct understanding of the pronunciation process. To fix this issue, explaining the tongue position will be helpful. On the other hand, most American English beginning singers are able to pronounce the Achlaut $[\chi]$, unless they sometimes substitute it with $[\mathrm{k}]$.

\section{Flipped and Rolled $r$ : [r] and [r]:}

The flipped [r] and rolled [r] are mainly used in Italian, German and French repertoires, as well as some British English repertoires. However they should never be used in music by North American composers with North American texts as Kathryn LaBouff states in her book. ${ }^{47}$

\footnotetext{
${ }^{45}$ Odom, and Schollum, German for Singers, 29.

${ }^{46}$ Odom, and Schollum, German for Singers, 29.

${ }^{47}$ LaBouff, Singing and Communicating in English, 107.
} 
For oratorio and repertoire that originates from British Isles, or a North American song or opera that has a text by an English poet, the flipped [r] and trilled [r] could both be considered as appropriate. $^{48}$

In Italian, German, and French, the flipped [r] and rolled [r] are usually pronounced quickly and take place in the front of the tongue. Many American English beginning singers cannot produce the flipped $[\mathrm{r}]$ and rolled $[\mathrm{r}]$ at first, so they would usually substitute them with the American $[\mathrm{I}]$. As mentioned earlier about the American $[\mathrm{I}]$ itself, its tongue movement changes the vowel following it. When beginning singers substitute the flipped $[r]$ or rolled [r] with the American $[x]$, the following vowel often gets changed as well. The same situation often continues even after they are able to pronounce the flipped [r] and rolled [r]. The examples will be when [ra], [re], [ro], [ri] or [ra], [re], [ro], [ri] appear in the other three Western languages and are being pronounced as [rwa], [rwe], [rwo], [rwi] or [rwa], [rwe], [rwo] and [rwi] by American English beginning singers. Beginning singers should understand the specific difference among the tongue movements of the American [I], flipped $[\mathrm{r}]$ and rolled [r]. The flipped $[\mathrm{r}]$ and rolled $[\mathrm{r}]$ are intended to be pronounced very quickly, and then the following vowel added in.

${ }^{48}$ LaBouff, Singing and Communicating in English, 108. 


\section{Chapter III}

\section{Data Analysis of Surveys}

For gathering pedagogic suggestions and advice from other voice teachers, vocal coaches, and professional singers, three surveys haven been conducted for this research. Two of the surveys are about teaching Mandarin Chinese (beginning) singers. ${ }^{49}$ One of them is in Mandarin Chinese, and it gathered responses from voice teachers, vocal coaches, and professional singers who speak Mandarin Chinese as their native language. Another one is in English, and that was responded to by voice teachers, vocal coaches, and professional singers who speak American English as their native language. Based on the cultural norms and customs, the questions in these two surveys were slightly different. The third survey is in regard to teaching American English beginning singers, which were sent to American voice teachers, vocal coaches, and professional singers for gathering responses. 12 participants have completed the English version survey of teaching Mandarin Chinese (beginning singers); 37 participants have completed the Chinese version survey of teaching Mandarin Chinese beginning singers; and 27 participants have completed the survey of teaching American English beginning singers. Each survey contains 2526 questions about how much difficulty beginning singers have when producing certain vowels or consonants, which include most of vowels and certain problematic consonants from the four Western singing languages (English, Italian, German, and French). Lastly, an open-ended question was given to the participants for providing any significant problem their students have that were not addressed in the surveys.

\footnotetext{
49 The English version survey is not only focusing on Mandarin Chinese beginning singers, mature singers are also the targets. The Chinese version survey is mainly focusing on their beginning singers.
} 
We will discuss the reports from these three surveys in this chapter. First, we will compare two reports between the two surveys of teaching Mandarin Chinese (beginning) singers from two different perspectives of Chinese and American voice teachers, vocal coaches, and professional singers. Second, we will discuss the report from the survey of teaching American English beginning singers.

\subsection{Mandarin Chinese Surveys Reports}

This research is mainly focused on beginning singers who speak Mandarin Chinese and North American English as their native languages. However, American voice teachers and vocal coaches in fact do not meet real Mandarin Chinese beginning singers very often. Many Mandarin Chinese singers came to the U.S. to study after they had at least three years or longer of voice training in China, and most of them came to the U.S. for their graduate level study. For those Chinese singers who started their first voice lesson in the U.S., they might not speak Mandarin Chinese as their native language or at least not their first language. Therefore, the English survey version of teaching Mandarin Chinese singers is more focused on Mandarin Chinese singers who are mature, or young singers with at least 3 years of voice training in China. The main participants of the Chinese version of the survey are Chinese voice teachers and vocal coaches who have taught undergraduate level singers or younger singers who applied for undergraduate study. Therefore, the Chinese version survey is more focused on Mandarin Chinese beginning singers specifically.

Both American and Chinese voice teachers and singers participated and offered insightful feedback and suggestions. The questions from these two surveys are almost the same, but with a few differences. Based on the Chinese culture and custom, every question only has three options, but each question in the English version has five options. Among these participants, over 50\% of 
them have been working with more than 20 Mandarin Chinese beginning singers for over 10 years. Chinese voice teachers and American voice teachers responded to some questions with similar answers, but they obviously have totally different insights about some questions as well.

\section{Similar Feedbacks:}

\section{Dark [a]:}

The bright [a] does not exist as a single vowel in Mandarin Chinese, which only exists in vowel combinations. Both Chinese and American participants agree that the dark [a] brings a little trouble to Mandarin Chinese (beginning) singers, but more American participants believe that there is no trouble at all. In fact, most Mandarin Chinese singers and voice teachers believe that the pronunciation of the letter $a$ in Mandarin Chinese is consistent as the dark [a]. Mandarin Chinese (beginning) singers often produce the dark [a] in an over-dark timbre, which is another reason behind the aesthetic standard of timbre. In China, the voice department of most musical institutions is divided into two branches: classical style and folk-song style. The main characteristic of the folk-song style is the bright timbre and forward resonant position, which sometimes requires a higher amount of chest voice for female singers than the classical style does. The repertoires of folk-song style are mostly focused on high voice types (sopranos and tenors). Based on the difference between these two styles of singing in China, singers developed an aesthetic standard that the classical style singers should produce a darker timbre, and the folksong style singers should produce a brighter timbre. This aesthetic standard causes Mandarin Chinese beginning singers who study in Classical style to often try to avoid the bright timbre in their voices by pulling the forward vowels back or reduce the brightness in all vowels. This issue often makes the dark [a] to be too dark. From chart 3.1, we can see both Chinese and American 
participants agreed that Mandarin Chinese singers have a little difficulty to produce the dark [a], but not many participants think there is a lot of problems.

Chart 3.1: Question of "how much difficulty do you think Mandarin Chinese singers have producing the dark [a] vowel?"

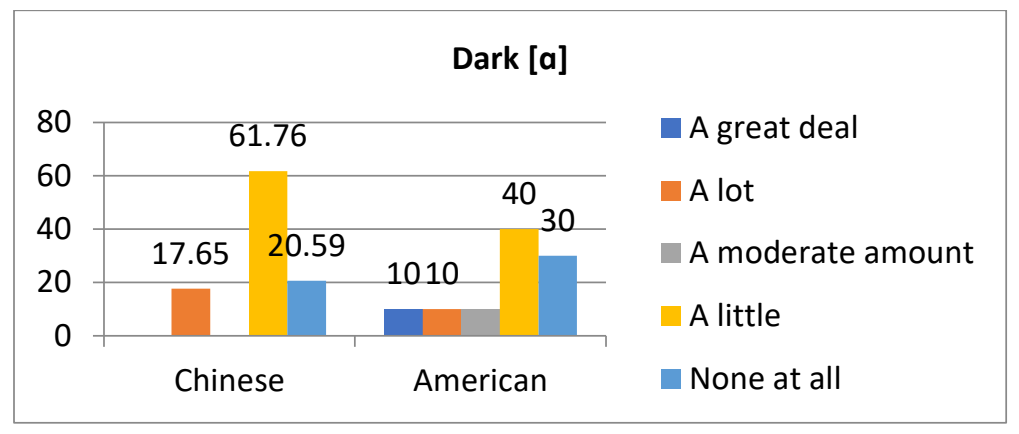

\section{Special English Vowel [æ]:}

As mentioned earlier, this distinctive English vowel does bring troubles to Mandarin Chinese singers, both Chinese and American participants do agree with it. We can see from chart 3.2 that there are still a few Chinese participants choosing "none at all," but there are no American participants who think that Mandarin Chinese singers do not have trouble with this special English vowel. Mandarin Chinese singers and speakers are easily confused between the [ai] and [æ] before they can speak English well.

Chart 3.2: question of "how much difficulty do you think Mandarin Chinese singers have producing [æ]?”

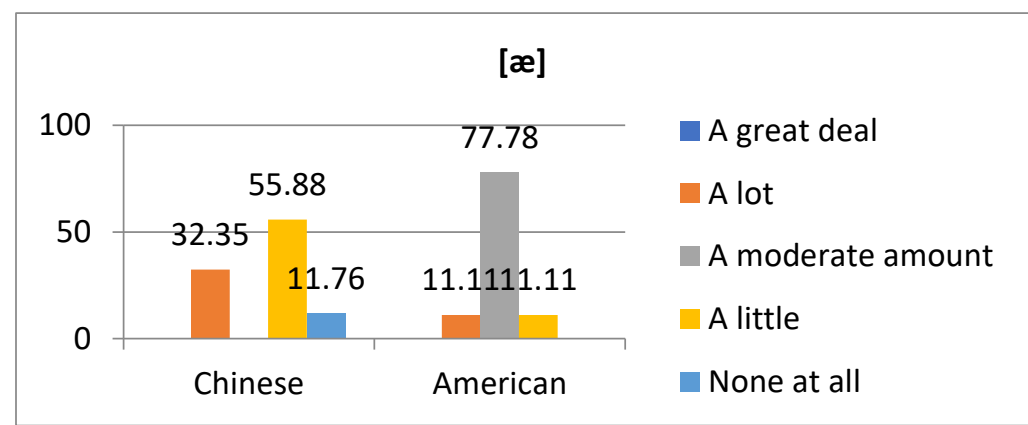




\section{Close [o] vs. Open [o]:}

As we know from earlier, Mandarin Chinese does not have the open version [o], but the close version [o] in Mandarin Chinese is not as close as it is in the four Western singing languages. From chart 3.3, we can see both Chinese and American participants think that Mandarin Chinese singers do have difficulty producing both of them.

Chart 3.3: Question of "how much difficulty do you think Mandarin Chinese singers have producing the closed [o] and open [0] vowel?"

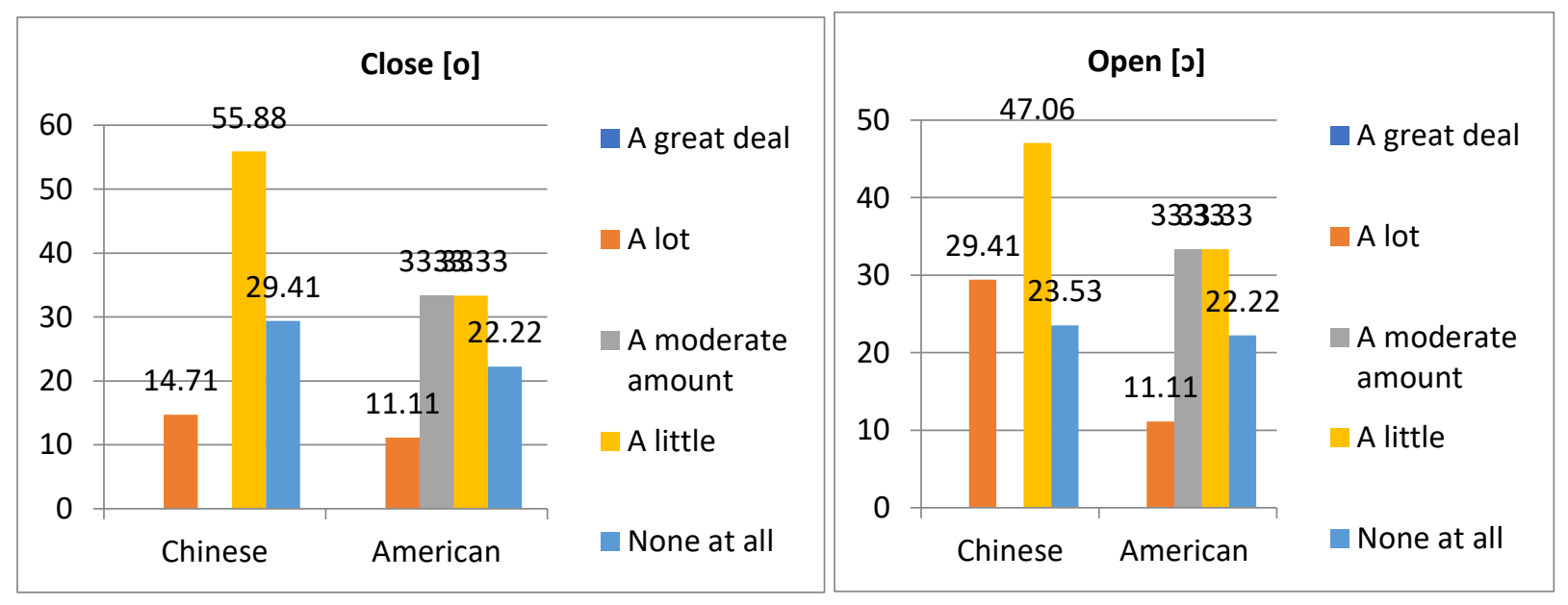

\section{Close [u] vs. Open [u]:}

From chart 3.4, we can see the overall results are similar. Both Chinese and American participants think these two vowels bring a little trouble to Mandarin Chinese (beginning) singers. However, there is a little difference between the reports from American and Chinese participants. The American participants believe that Mandarin Chinese singers have more trouble with the close $[\mathrm{u}]$ than with the open [v], but the Chinese participants think the opposite. As discussed earlier, Mandarin Chinese singers or speakers have a hard time producing the close $[\mathrm{u}]$ without a [w] in front of it, because the letter $u$ and $w$ in the Mandarin Chinese alphabet are both pronounced as [wu]. Mandarin Chinese singers and speakers rarely notice this issue, but it makes an obvious difference for the four Western languages. From the perspective of Chinese 
participants, the open $[\mho]$ is more difficult than the close one because it does not exist in Mandarin Chinese. Mandarin Chinese singers or speakers usually substitute the open one with the close one, because they are not familiar with the pronunciation process of the open [ $\mho]$. In singing, substituting the open one with the close one usually turns into a delightful result, because the open $[\mho]$ is somehow difficult to sing on longer notes or through the passaggio. Chart 3.4: Question of "how much difficulty do you think Mandarin Chinese singers have producing the closed $[\mathrm{u}]$ and open $[\mho]$ vowels?"

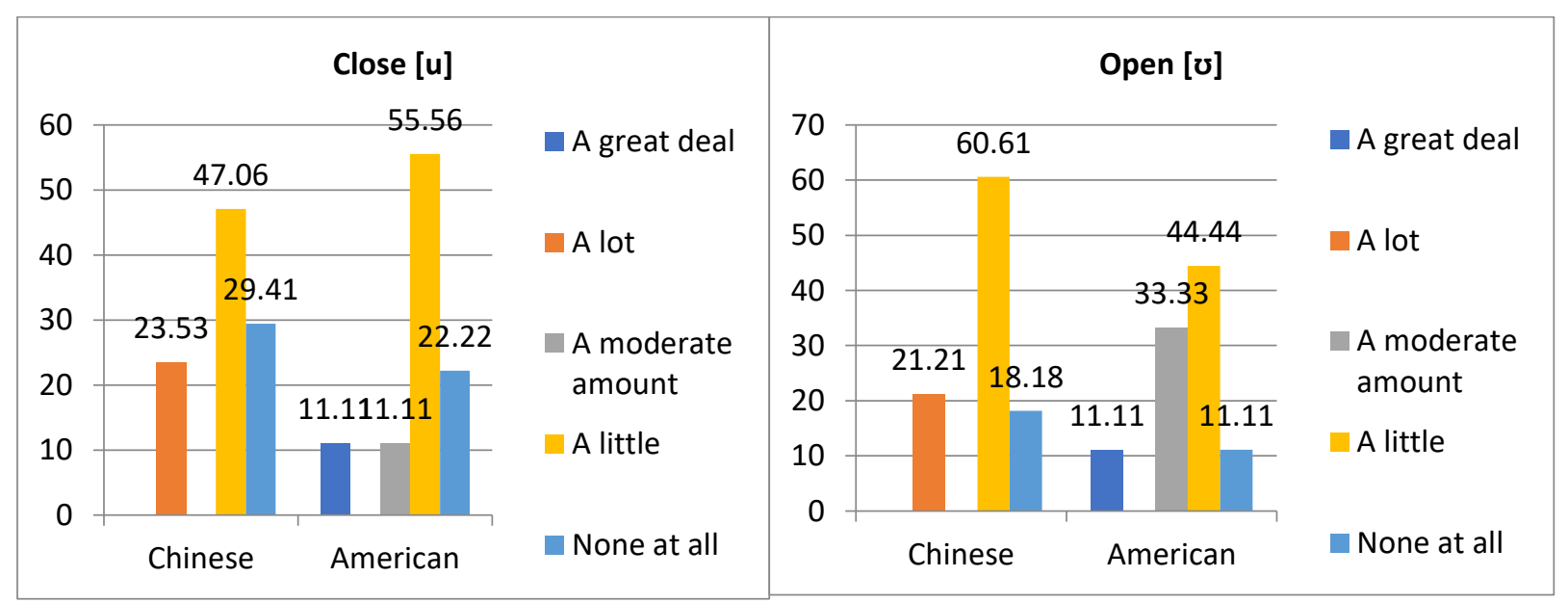

\section{Diphthongs:}

For this question, both American and Chinese participants gave very similar responses. Most participants in both surveys believe that the diphthongs are a little difficult for Mandarin Chinese singers. As discussed earlier, Mandarin Chinese does not have the diphthongs that are in the four Western languages. In the four Western languages, the two vowels in a diphthong are pronounced separately. In singing, the first one should be sustained longer than the second one, and the second one usually should only be pronounced at the end of the word. In Mandarin Chinese, when two vowels appear together in a word it is called a vowel combination, in which two vowels are pronounced as a combination sound instead of being pronounced separately. In a Mandarin Chinese vowel combination, the first vowel will be briefly pronounced before quickly 
adding in the second vowel to make the combination sound, which causes confusions for Mandarin Chinese singers when they sing diphthongs in the four Western languages. Mandarin Chinese singers usually have a hard time maintaining the first vowel long enough and pronounce the second vowel at the end of the note duration.

Chart 3.5: question of "how much difficulty do you think Mandarin Chinese singers have producing diphthongs?"

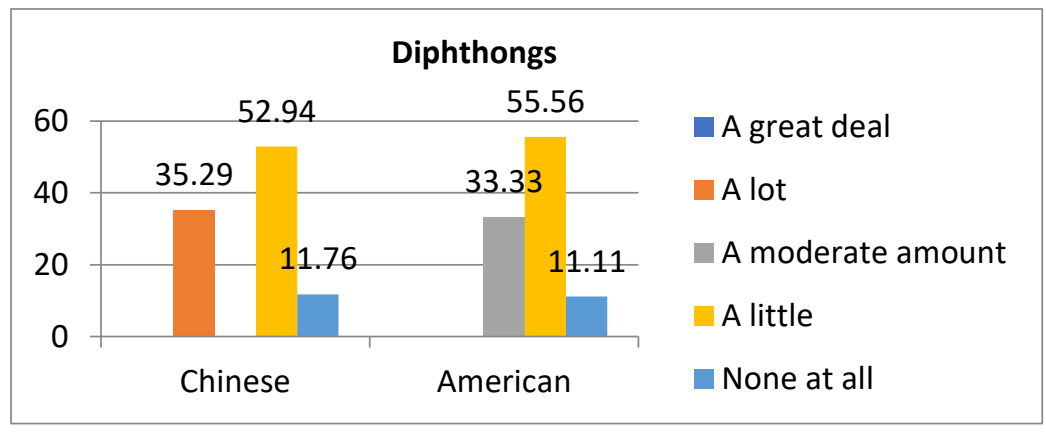

Final and Medial $[\mathbf{n}]$ and $[\eta]$ :

The most common diction issues among Mandarin Chinese singers are these two consonants. Mandarin Chinese do have $n$ and $n g$ as a spelling at the end of words, but instead of functioning as consonants they are in fact, a part of vowel combinations. When the letter $n$ appears as an initial consonant in Mandarin Chinese, the pronouncing procedure is the same as it is in the four Western languages, which means the tip of the tongue will touch the hard palate. However, when $n$ appears at the end of a word in Mandarin Chinese, it is always a part of a vowel combination. In this case, the $n$ will be blended with the vowel(s) before it, and there is no tongue movement required for the $n$. Chinese participants might not notice the problem of the missing tongue movement, but most of them think the final and medial [n] brings a little trouble to their young singers. On the other hand, many more American participants think it brings a lot of trouble to Mandarin Chinese singers. For the final and medial [n], since Mandarin Chinese does have it as an initial consonant, singers usually will be able to pronounce it the same as the 
initial one, voice teachers and vocal coaches just need to explain the importance of the tongue movement.

The [n] might be trickier than [n] for Mandarin Chinese singers, because it only appears at the end of words and it is always treated as a part of vowel combination, which means the tongue movement (the back of the tongue approaching or touching the soft palate) is omitted completely. From chart 3.6, we can see that the [n] has a higher percentage for being "a lot," "a moderate amount" and "a little" than the [n] does in the reports from both Chinese and English surveys. The tongue movement in [ $\mathrm{n}]$ is difficult for Mandarin Chinese singers to learn at first, but most of them are able to make the correct tongue movement.

Chart 3.6: question of "how much difficulty do you think Mandarin Chinese singers have producing the final and medial $[\mathrm{n}]$ and $[\mathrm{n}]$ ?"

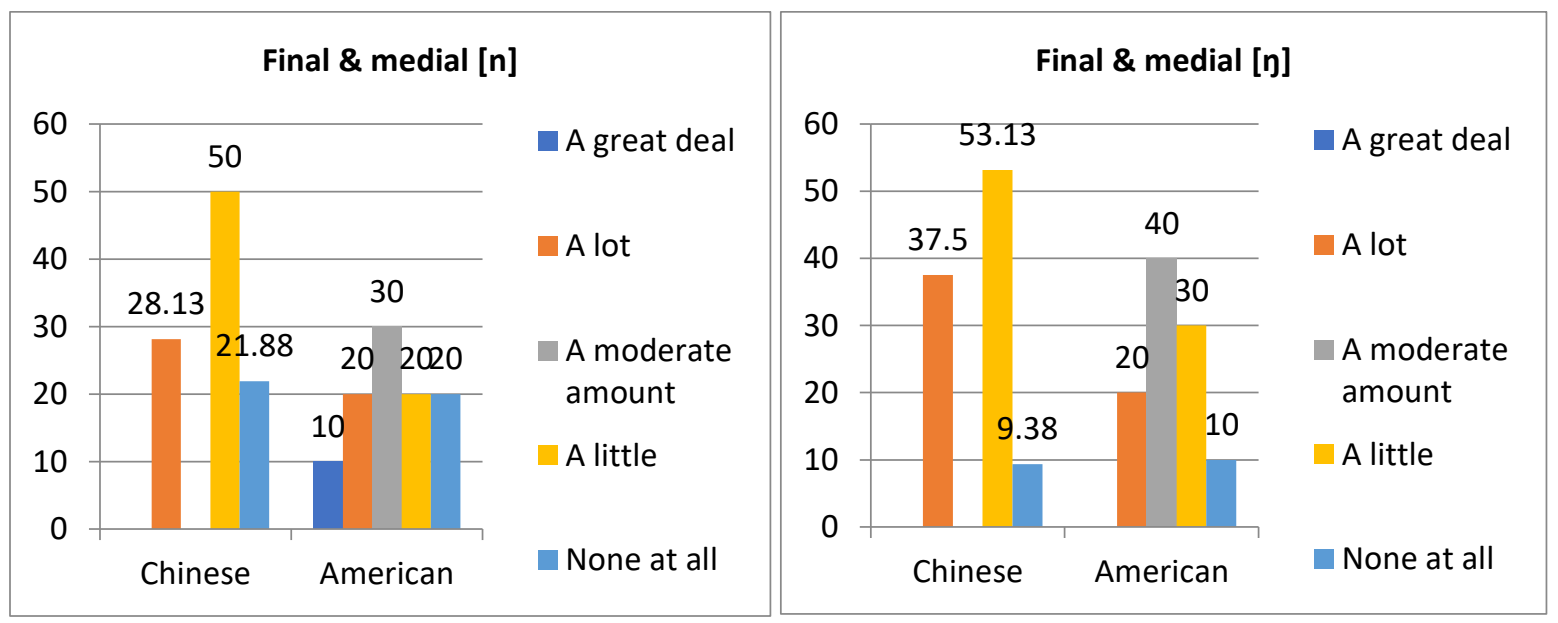

\section{Final and Medial [m]:}

Unlike [n], [m] only appears as an initial consonant in Mandarin Chinese, which is always followed by one or two vowels. When [m] appears as a final consonant in the four Western languages, Mandarin Chinese singers usually have trouble to pronounce it. When a consonant is pronounced alone at the end of a word, the pronouncing progress might need to be 
longer to make it more audible, which might occasionally bring tension. In the case of [m] being a final or medial consonant, the nasal sound needs to last longer when there is no following vowel, and the mouth needs to be closed for a short time that somehow scares Mandarin Chinese singers, especially when there is another word coming right after a final [m]. In Mandarin Chinese, words always end with the mouth open. When Mandarin Chinese singers have to close their mouths for a short time to produce a final [m], they usually choose to shorten the time duration for the consonant. This issue causes Mandarin Chinese singers' final [m] to often be inaudible, which is not caused by an incapability of pronouncing the [m], but only as a habit. In the case of $[\mathrm{m}]$ being a medial consonant, the issue might vary depending on if the medial $[\mathrm{m}]$ is followed by a vowel or not. If so, there will be no issue; if not, the same issue as the final [m] will occur. From chart 3.7, we can see both Chinese and American participants believe that the final and medial $[\mathrm{m}]$ bring difficulty to Mandarin Chinese singers, but apparently a higher percentage of American participants think there is more than "a little" difficulty that the final and medial $[\mathrm{m}]$ cause.

Chart 3.7: Question of "how much difficulty do you think Mandarin Chinese singers have producing or sing the final or medial $[\mathrm{m}]$ ?"

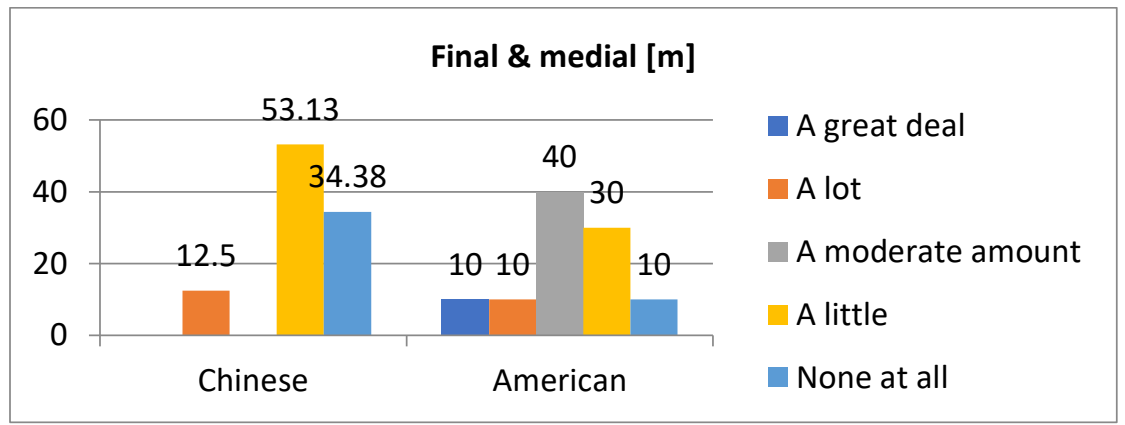




\section{$[\theta]$ and [ð]:}

These two distinctive English consonants normally bring troubles to all non-native English speakers. Mandarin Chinese singers have definitely encountered some difficulty in English repertoires. Chinese participants respond with the same percentage of results for both of them. More American participants think the voiced one is harder than the unvoiced one for Mandarin Chinese singers. As mentioned previously, both $[\theta]$ and $[ð]$ are dental fricative consonants. When the fricative consonants involve the tongue and teeth blocking the air at the same time, the airflow is hard to get through, which causes more pressure during the pronouncing progress. In Mandarin Chinese, all consonants are initial consonants and always produced very quickly without too much pressure. The feeling of extra pressure when producing $[\theta]$ and [ð] are very unfamiliar to Mandarin Chinese singers.

Chart 3.8: question of "how much difficulty do you think Mandarin Chinese singers have producing $[\theta]$ and [ð]?”

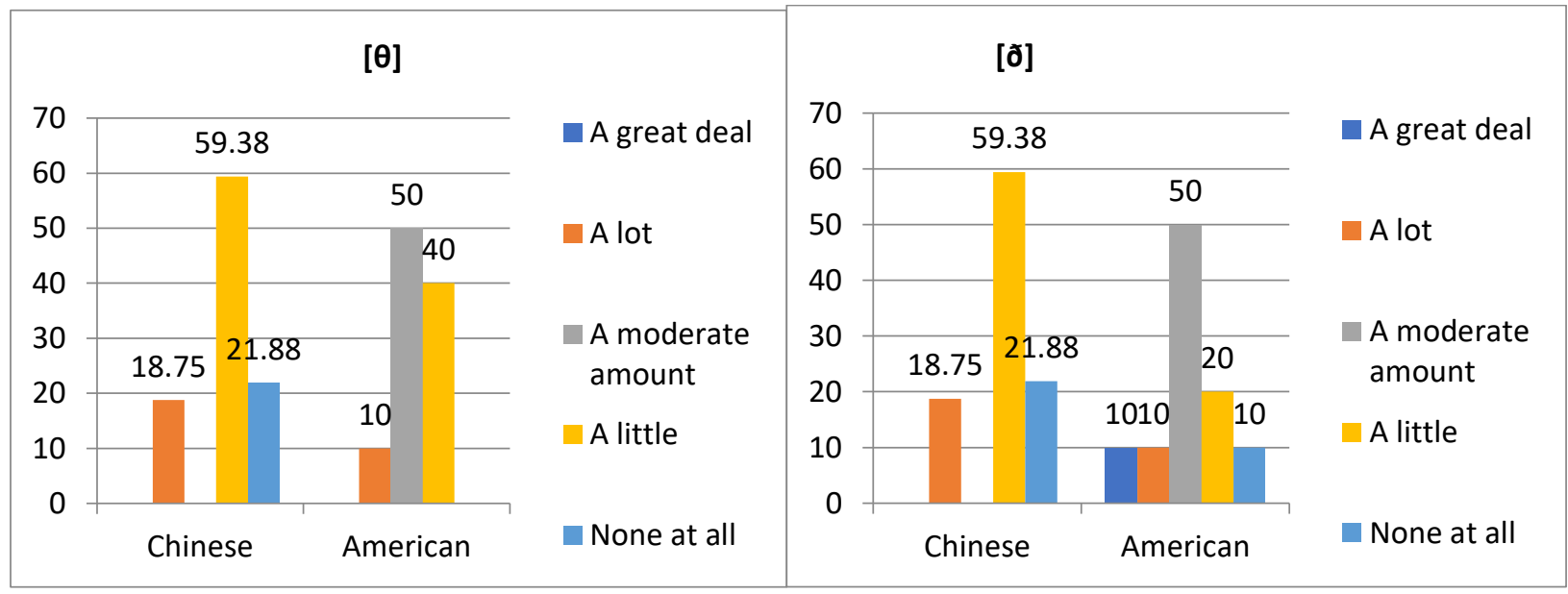




\section{Different Feedbacks:}

\section{Schwa [ə]:}

The most interesting one among the different feedbacks is about Mandarin Chinese singers producing [ə]. The question in the Chinese version of the survey is asked as "do you think that Mandarin Chinese singers having trouble to differentiate the French and Chinese [ə]?" From chart 3.9, the majority of Chinese participants think that Mandarin Chinese beginning singers have trouble to differentiate the French and Chinese [ə], and only a very small percentage of participants chose "none at all." In the English version, the question is asked as "how much difficulty do you think Mandarin Chinese singers have producing [ə]?" In the view of American participants, the troubles that the [ə] brings to Mandarin Chinese singers are quite a bit less than Chinese participants think. It is interesting to see that $33 \%$ of American voice teachers find that Mandarin Chinese singers do not have any difficulty pronouncing the schwa [ə]. As we discussed in the previous chapter about Mandarin Chinese and singers, instead of always being unstressed in the four Western languages, [ə] is always stressed in Mandarin Chinese. Mandarin Chinese singers often have trouble differentiating the stressed and unstressed ones.

In regards to the following question in the Chinese version "what is the most common reason that Mandarin Chinese singers having trouble to differentiate the French and Chinese [ə]?," three options are available: 1 . differentiation between stressed and unstressed; 2. high/low position; and 3. mouth shape. The question in the English version is "what is the most common issue of Mandarin Chinese singers producing [ə]?,” The English version has four options as: 1. dark/bright production issue; 2. high/low position issue; 3. mouth shape issue; and 4. differentiation between stressed and unstressed issue. From chart 10, because the "dark/bright production" issue was not addressed in the Chinese version, most Chinese participants believe it is the mouth shape and high/low position issue. The majority of American participants think the 
dark/bright production issue mainly causes the problem for Mandarin Chinese singers.

Unsurprisingly, the option of "differentiation between stressed and unstressed" issue has the least supporters in both surveys. Because most Chinese participants do not realize the [ə] in French and the other three Western languages is pronounced unstressed all the time, and most American participants do not realize the [ə] could be a stressed vowel in other languages. Even though all these options could affect Mandarin Chinese singers' abilities to produce a good [ə], the last one is the essential one. When a [ə] is being pronounced as a stressed vowel, the blade and the back of the tongue will be pressed down, and the jaw will often lean forward. These articulatory movements will cause the tone production being dark, the resonant position being low, and the mouth shape being wrong. If Chinese and American voice teachers and vocal coaches could help Mandarin Chinese (beginning) singers to fully understand the difference between an unstressed and stressed [ə], this diction issue and the vocal fault that come along with it will be solved. Chart 3.9: question: "How much difficulty do you think Mandarin Chinese singers have producing [ə]?” Chinese version question: "do you think that Mandarin Chinese singers having trouble to differentiate the French and Chinese [ə]?”

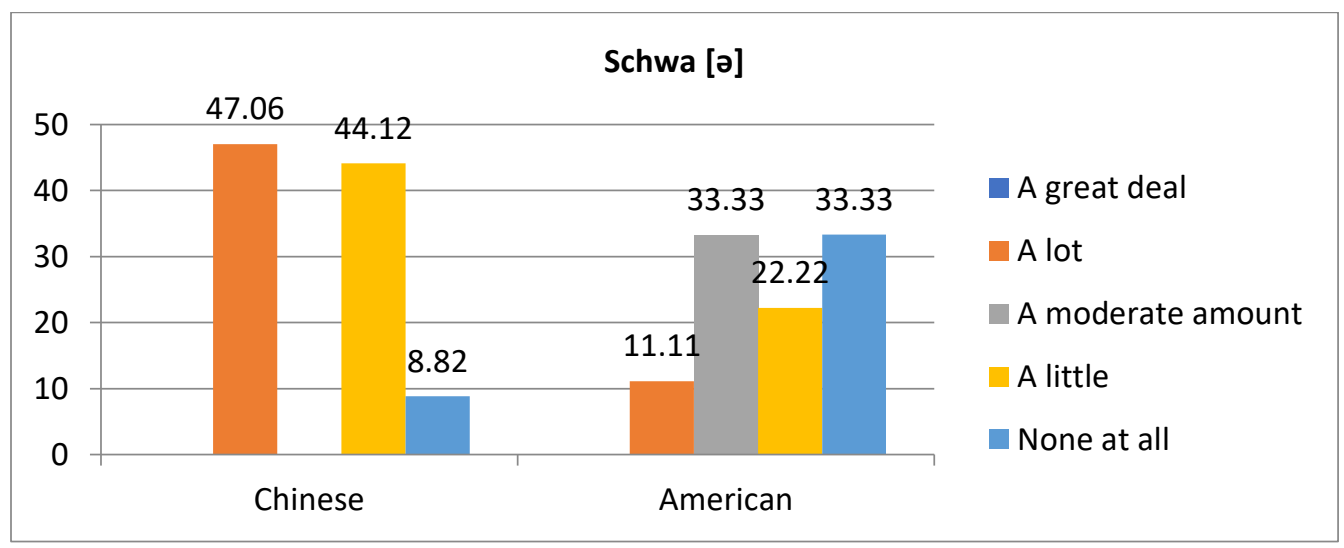


Chart 3.10: Question of "what is the most common issue of Mandarin Chinese singers producing [ə]?" The Chinese question: "what is the most common reason that Mandarin Chinese singers having trouble to differentiate the French and Chinese [ə]?”

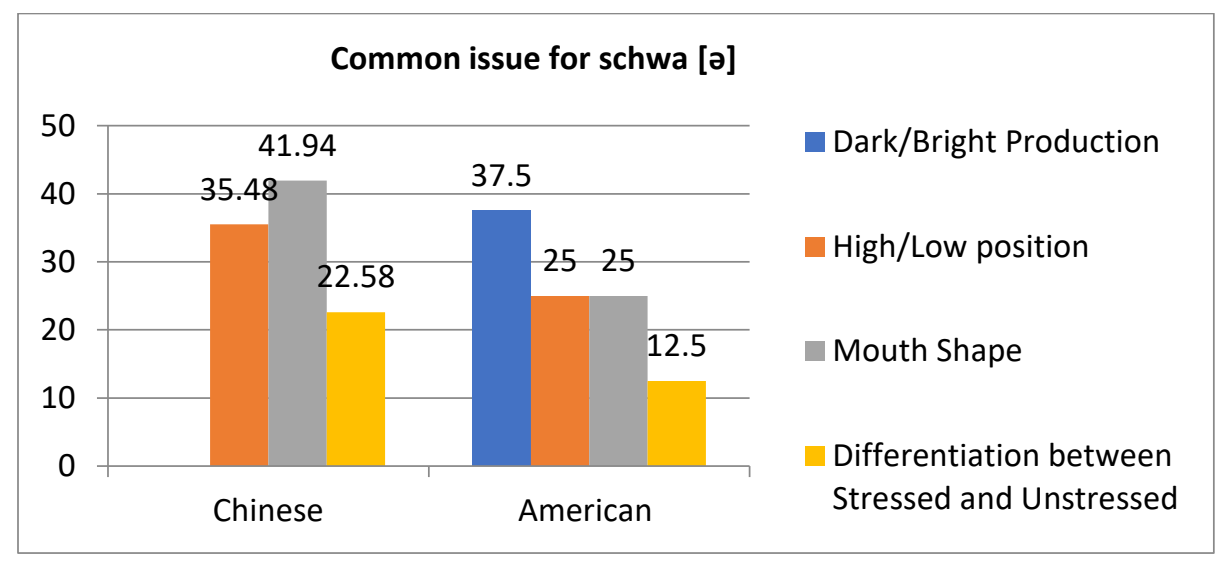

\section{Close [e] vs. open $[\varepsilon]$ :}

As discussed previously, the Mandarin Chinese [e] only exists in vowel combinations but not as a single vowel. In Mandarin Chinese, [e] often appears with vowel [i] or glide [j] before or after it, which somehow causes the [e] to be slightly more open than the close [e] in the four Western languages, but not as open as the open $[\varepsilon]$. When singers encounter $[\mathrm{e}]$ as a single vowel in the four Western languages, they sometimes get confused with the vowel combination [ei] in Mandarin Chinese. But the vowel combination [ei] in Mandarin Chinese is pronounced as one combined sound rather than the diphthong [ei] being pronounced separately in the four Western languages. With this quick combination sound, American voice teachers and vocal coaches might not notice the $[\mathrm{e}]$ being substituted by some Mandarin Chinese singers. The majority of Chinese participants believe that their beginning singers have some difficulty producing a good close [e]; the American participants do not agree completely; $40 \%$ of participants chose "none at all." 
For the open $[\varepsilon]$, there are still more American participants who chose "none at all" than Chinese participants did. Overall, more Chinese participants think the open $[\varepsilon]$ is difficult for Mandarin Chinese singers. Some Mandarin Chinese beginning singers might substitute the open [ع] with the vowel combination [ai]. Since this is pronounced as a quick, combined sound, American voice teachers and vocal coaches might not notice immediately.

Chart 3.11: question of "how much difficulty do you think Mandarin Chinese singers have producing the closed [e] and open $[\varepsilon]$ vowels?"

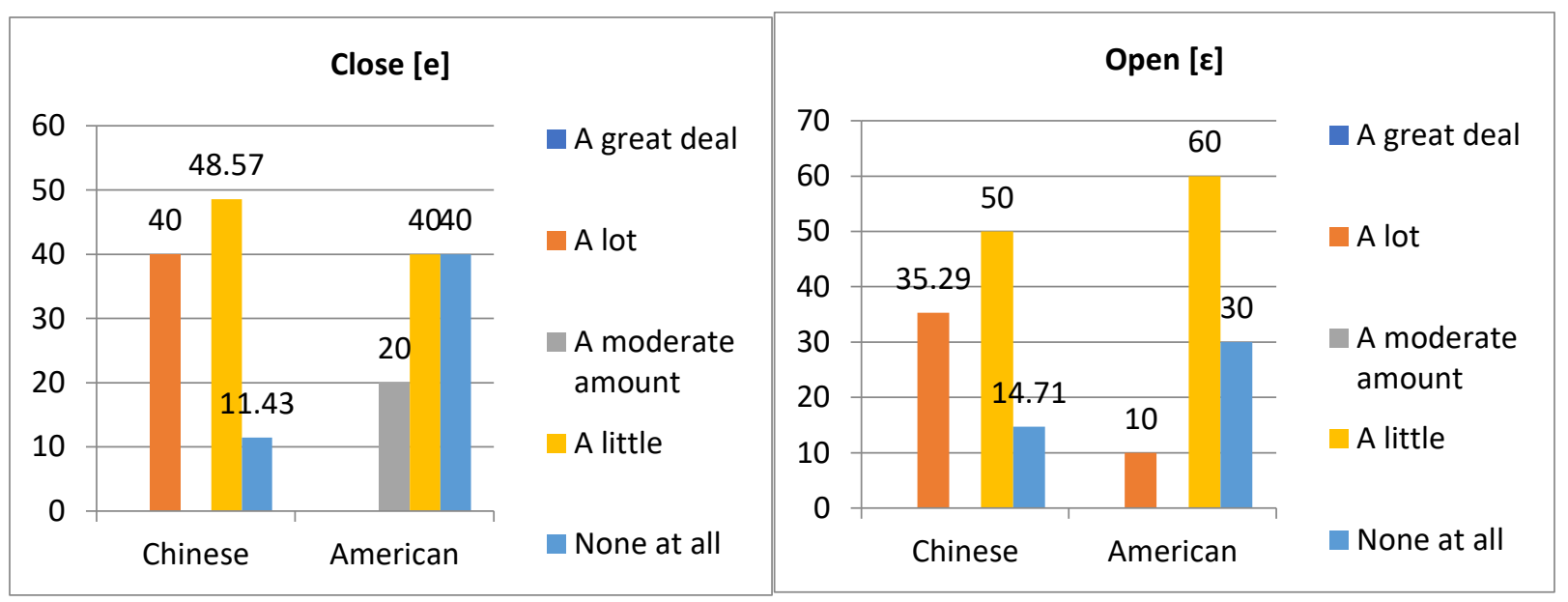

\section{Close [i] and open [I]:}

For this pair of vowels, similar situations with the close [e] and open $[\varepsilon]$ happen again. More Mandarin Chinese participants think that these two vowels bring troubles to their beginning singers than American participants do. The close [i] is the closest and most forward vowel among the other vowels in Mandarin Chinese, which is easier to be sung in a bright timbre. But with the aesthetic standard of voice timbre as mentioned before, Mandarin Chinese classical singers often avoid the brightness in close [i]. Singing a close [i] in a bright timbre also might not be approved by some Chinese voice teachers and vocal coaches based on the aesthetic standard, which might be the reason that more Chinese participants think the close [i] is difficult for their beginning singers. Nevertheless, when the close [i] appears in Western languages, Mandarin 
Chinese singers are able to handle it well, unless they intend to make it darker or modify it with other vowels.

On the other hand, the open [I] does not exist in Mandarin Chinese, so singers usually substitute it with the close version. Chinese voice teachers and vocal coaches certainly think this nonexistent open [I] is very difficult for their beginning singers, but the majority of American participants think there is only "a little" difficulty that the open $[\mathrm{I}]$ brings to Mandarin Chinese singers.

Chart 12: question of "how much difficulty do you think Mandarin Chinese singers have producing the closed [i] and open [I] vowels?"

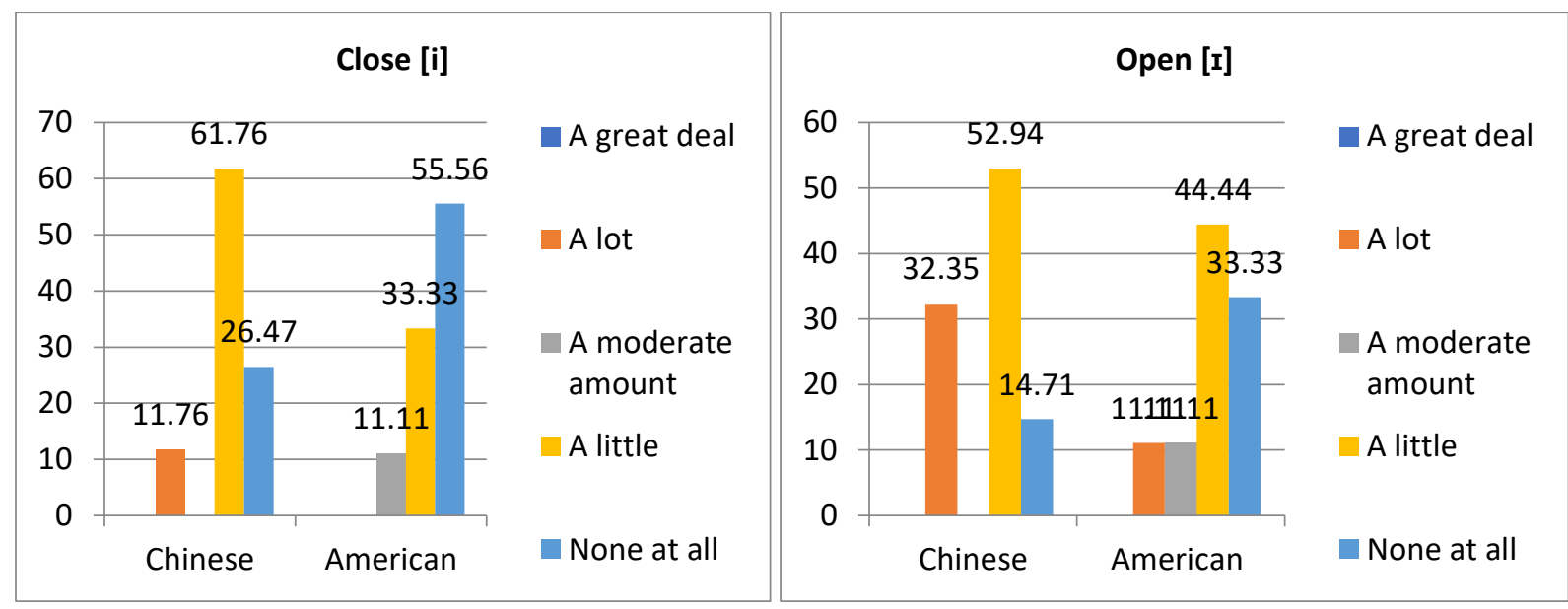

\section{Different Questions:}

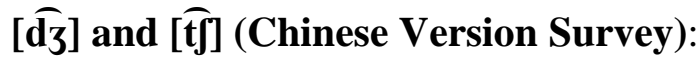

The main purpose of the question "how much difficulty do you think Mandarin Chinese singers have producing the $[\widehat{\mathrm{d}} \mathrm{J}]$ and $[\widehat{\mathrm{t} f}]$ in Western languages?" is to find out if Chinese

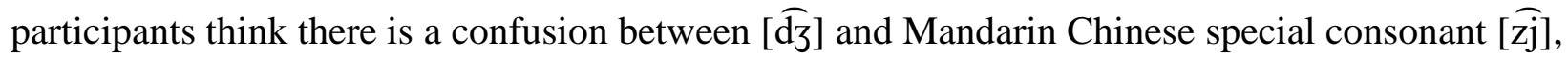
or [ $[\widehat{\mathrm{t}}]$ and Mandarin Chinese special consonant [t $\widehat{\mathrm{sj}}]$. Mandarin Chinese contains $[\widehat{\mathrm{d} z}]$ and $[\widehat{\mathrm{t} f}]$, they are never followed by an [i] vowel or [j] glide as in the four Western languages, but the 
special consonants $[\widehat{\mathrm{zj}}]$ and [tsj] are often followed by an [i] or [j]. Therefore, when $[\widehat{\mathrm{d}} \mathrm{z}]$ and $[\widehat{\mathrm{t} f}]$ are followed by an [i] or [j] in the four Western languages, Mandarin Chinese beginning singers might substitute $[\widehat{\mathrm{d}}]$ and $[\widehat{\mathrm{t} f}]$ with $[\widehat{\mathrm{zj}}]$ and $[\widehat{\mathrm{tsj}}]$ based on the first reaction from their native language reference. Chart 3.13 presents that over $50 \%$ the Chinese participants believe there is only a little difficulty that these two consonants bring to their singers in singing Western language repertoire, and also over $30 \%$ of the participants think there is no difficulty at all. Based on the result, we can conclude that the confusion between $[\widehat{\mathrm{d} z}]$ and $[\widehat{\mathrm{zj}}]$, and $[\widehat{\mathrm{t}}]$ and $[\mathrm{tsj}]$ still exists among some beginning singers. When American voice teachers and vocal coaches hear

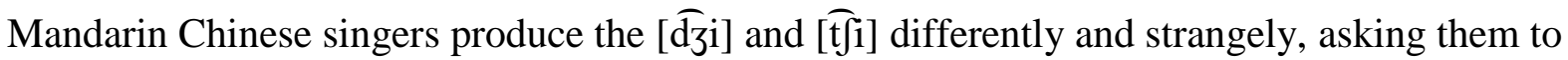
only pronounce the consonants with the following [i] could be an efficient trick.

Chart 3.13: question of "how much difficulty do you think Mandarin Chinese singers have producing the $[\widehat{\mathrm{d}} \mathrm{z}]$ and $[\widehat{\mathrm{t}}]$ in Western languages?"

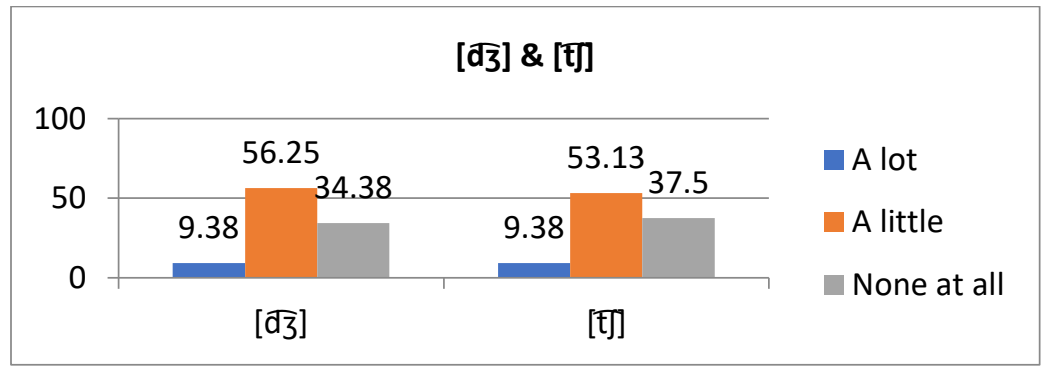

\section{Bright [a] (English Version Survey):}

In Mandarin Chinese, the bright [a] only exists in certain vowel combinations (depends on the vowel before or after it). Based on the Mandarin Chinese language and diction classes that are taught in China, most Mandarin Chinese singers and speakers believe that the letter $a$ is consistently pronounced as the dark [a]. Therefore, the question about the bright [a] was only asked in the English version survey of teaching Mandarin Chinese singers. Chart 3.14 presents 
that the majority of the American participants believe the bright [a] is bringing difficulty to Mandarin Chinese singers. The main reason of the bright [a] being difficult to Mandarin Chinese singers might be that most of them do not realize that the bright [a] exists in their native language. After making this issue clear to most Mandarin Chinese singers, they will have reference from their native language, and this vowel will become easier to produce.

Chart 3.14: question of "how much difficulty do you think Mandarin Chinese singers have producing the bright $[\mathrm{a}]$ ?"

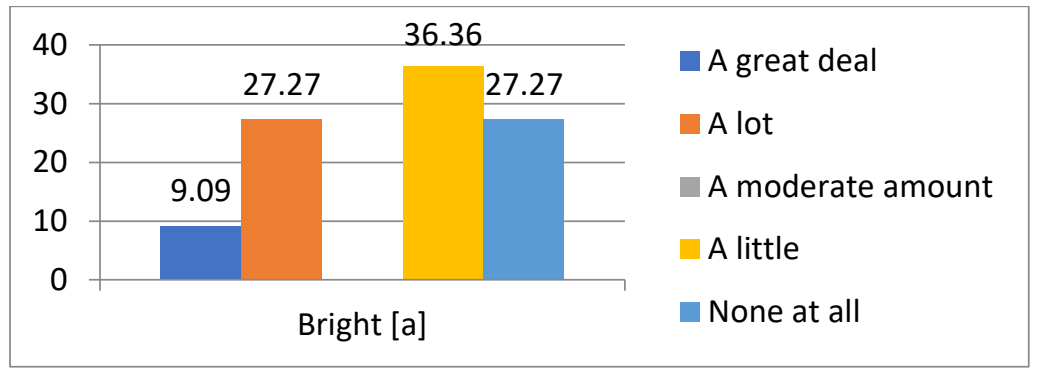

\section{Open Vowels vs. Close Vowels (English Version Survey):}

This question is only asked in the English version survey because the literal translation of the "open and close vowels" to Mandarin Chinese will often get confused with the "forward and back vowels." In chart 3.15, American participants obviously agreed that the open vowels are more difficult than the close vowels for Mandarin Chinese singers. Mandarin Chinese singers often substitute the open version vowels with their close versions since there are almost no open vowels in Mandarin Chinese (except open $[\varepsilon]$ that only exists in word tian). ${ }^{50}$ The close vowels occasionally bring trouble to Mandarin Chinese singers as well. However, it is more likely caused by the aesthetic standard of voice timbre toward classical style singing rather than caused by the pronunciation of Mandarin Chinese. The close vowels can be easily produced in a brighter

\footnotetext{
${ }^{50}$ The open $[\varepsilon]$ only happens in the word tian as an exception.
} 
and more forward timbre, which is often not accepted by many Mandarin Chinese singers or their Chinese voice teachers. When a close vowel, such as [i] or [e], is sung in a dark timbre, it changes its clarity and creates articulatory tension at the same time.

Chart 3.15: question of "how much difficulty do you think Mandarin Chinese singers have producing the open vowels and close vowels?"

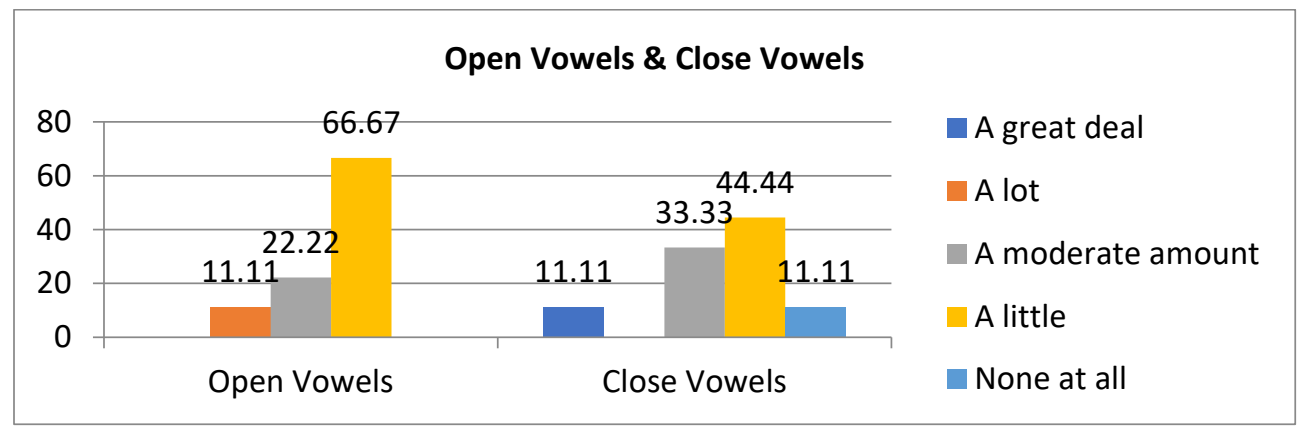

\section{Open-ended Question Feedbacks:}

An open-ended question appeared at the end of each survey. We received more answers from the Chinese version survey because more people participated in the Chinese version survey than in the English version one. In the Chinese version survey, the question is translated in English as "based on your teaching experiences, do you think there are other problems that bel canto students have when they are singing in foreign languages, do you think those problems relate to the pronunciation of Mandarin Chinese?" A few participants mentioned that based on the single syllable rule of Mandarin Chinese, most beginning singers have a hard time connecting the vowels in foreign languages. When teaching beginning singers foreign words, they are usually capable of pronouncing them, but when these individual words happen in singing, especially in a fast tempo, final consonants are often omitted and certain vowels that do not exist in Mandarin Chinese become unclear. One of the participants answered that the pronunciation of Mandarin Chinese is very different than Western languages, and if beginning 
singers always try to find references from Mandarin Chinese to pronounce Western languages that will cause many issues. Another participant said that speaking in Western languages is somehow easier than singing in Western languages for most beginning singers, because when they open their mouth to prepare the space for singing, the vowels are easily modified. Mastering the correct mouth shapes for every vowel, especially for those vowels do not exist in Mandarin Chinese are very important for beginning singers. Lastly, two of the participants mentioned that the diction class for the four Western languages in certain Chinese musical institutions is not strong or even not offered. Many beginning singers lack the basic knowledge of the pronunciation rules of the four Western languages. Many of them only rely on imitating other singers, but not every singer is good at imitating unfamiliar sounds. Also, many similar but completely different sounds exist in the four Western languages; without knowing the correct pronouncing procedures, mistakes can be easy to make.

The open-ended question in the English version survey is "are there other significant problems not addressed in this survey? If so, please list them below." There are only a few responses have been received from the English version survey of teaching Mandarin Chinese singers. In the answers, a few problems that we discussed previously were mentioned, such as the lack of final consonants; substituting the [w] sound for [v]; and the connection between vowels. One of the participants responded that the flipped [ $\mathrm{r}]$ and rolled [r] can be difficult. Mandarin Chinese singers occasionally have a hard time differentiating between the flipped [r] and rolled [r], and many of them would substitute the rolled [r] with the flipped [r]. Another participant mentioned that "most Mandarin Chinese singers she has known are able to make the sounds, but just need to be reminded which sound is appropriate." This participant also stated the imitating issue that "occasionally a Chinese singer will pick up the throaty production from an 
American singer which disturbs the clarity of the vowels, but they usually can easily correct this." 51

\subsection{American English Survey Feedbacks}

The main targets of the survey about teaching American English beginning singers are voice teachers and vocal coaches who speak American English (not necessary as their native languages) and teach American English beginning singers at an university level. The reports will be presented in the order of the questions in the survey.

\section{Vowels Feedbacks:}

\section{Dark [a] vs. Bright [a]:}

In American English, a dark [a] only appears as a single vowel, and the bright [a] only happens in diphthongs. From chart 3.16, we can see American participants agree that both of them are not easy for American English beginning singers. Overall, the bright [a] is considered more difficult than the dark [a] by the American participants. Because the bright [a] never appears as a single vowel in American English, beginning singers sometimes have difficulty producing a bright [a] alone when it appears in the other three Western languages, especially for French and Italian. They would often substitute it with the dark [a].

Chart 3.16: question of "how much difficulty do you think American English beginning singers have producing the dark [a] and bright [a]?"

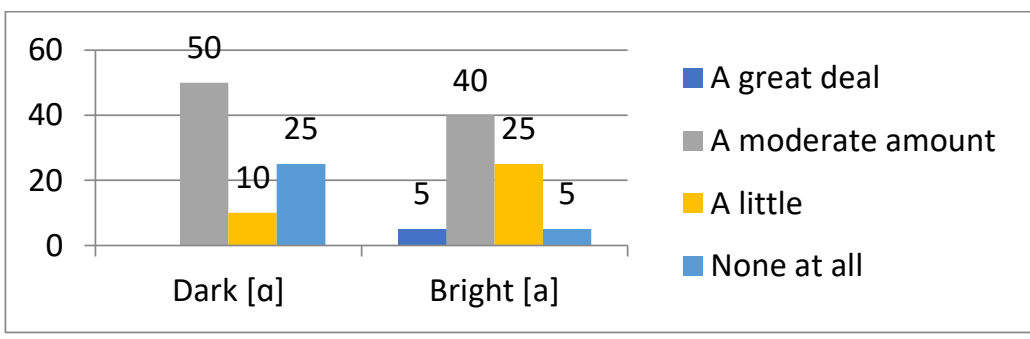

\footnotetext{
${ }^{51}$ Quote from one of the feedbacks of the English version survey of teaching Mandarin Chinese singers.
} 


\section{Close [i] vs. Open [I]:}

For this pair of vowels, American participants gave similar responses to both vowels, but the open [I] has higher percentages in the options of "a moderate amount" and "a great deal," and the percentages of "a little" and "none at all" are both lower than they are in the close [i]. Overall, American participants do agree that the open [I] brings a little more trouble to their beginning singers than the close [i] does. As we discussed previously, the close [i] is often followed by a [j] glide in spoken American English. Many beginning singers might still keep the habit when they are singing the close [i], which often causes a certain amount of tongue tension when the vowel is being sung for a long duration. Even the semi-vowel [j] glide is similar to [i], the [j] is a consonant after all, which should not be sung in as long a duration as every other consonant. The open [I], on the other hand, is easily distorted by beginning singers if they sing it in the spoken way as we discussed earlier.

Chart 3.17: question of "how much difficulty do you think American English beginning singers have producing the close [i] and open [I]?"

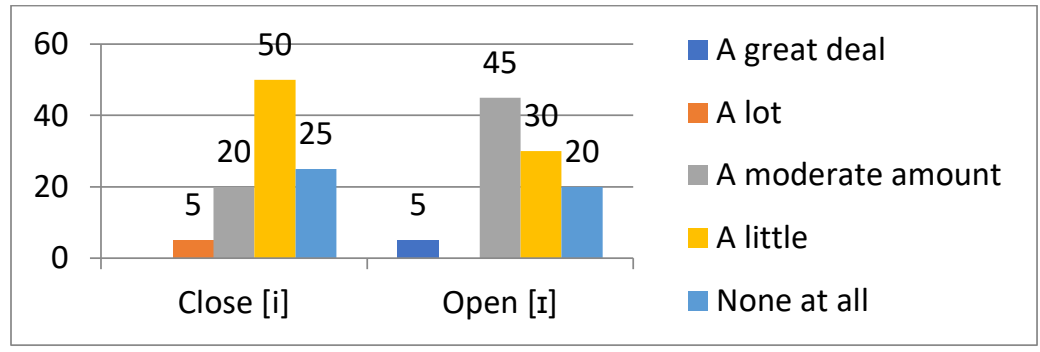

\section{Close [e] vs. Open [e]:}

The close [e] only exists in the diphthongs in American English, but the open $[\varepsilon]$ does exist as a single vowel. Based on these two facts, American English beginning singers have two main problems with this pair of vowels. First, many American English beginning singers often have trouble singing a single [e] in other three Western languages without an [I] to follow. A 
following question was asked to prove if American participants think this situation happens often (chart 19). The second problem is that since the open $[\varepsilon]$ always appears as a single vowel in American English, beginning singers sometimes cannot produce a [e] close enough in the other three Western languages, and often substitute it with the open $[\varepsilon]$. From chart 3.18, we can see more American participants believe the close [e] brings more difficulty to their beginning singers than the open $[\varepsilon]$ does. From chart 3.19, we can see that American participants definitely agree the phenomena of producing a single [e] with a following [r] does happen among beginning singers as we discussed previously.

Chart 3.18: question of "how much difficulty do you think American English beginning singers have producing the close $[\mathrm{e}]$ and open $[\varepsilon]$ ?"

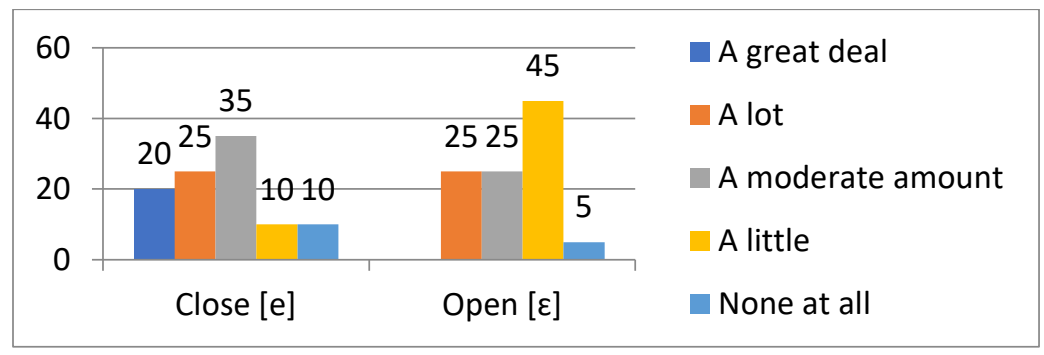

Chart 3.19: question of "how much difficulty do you think American English beginning singers have producing a single [e] without a [r] to follow?"

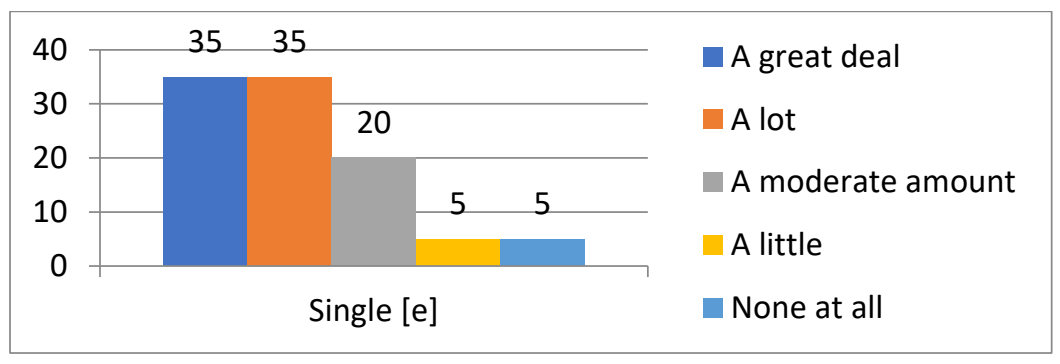

\section{Close [o] vs. Open [o]:}

The responses that American participants gave for the close [o] and open [0] are quite varying, but overall the close [o] has a higher percentage in the options of "a great deal" and "a 
lot," and also lower percentage in the option of "none at all" as shown in chart 3.20. The open [0] occasionally brings troubles to beginning singers when it is sung on longer notes, or when it is sung through the passaggio if the beginning singers do not modify it properly. The main problem with the close [o] is shown in chart 3.21 as it is difficult to be sung without a [ $]$ to follow, since the close [o] only exists in English diphthongs. This diction issue bothers American English beginning singers when they sing in the other three Western languages. The majority of American participants obviously agree with it.

Chart 3. 20: question of "how much difficulty do you think American English beginning singers have producing the close [o] and open [o]?”

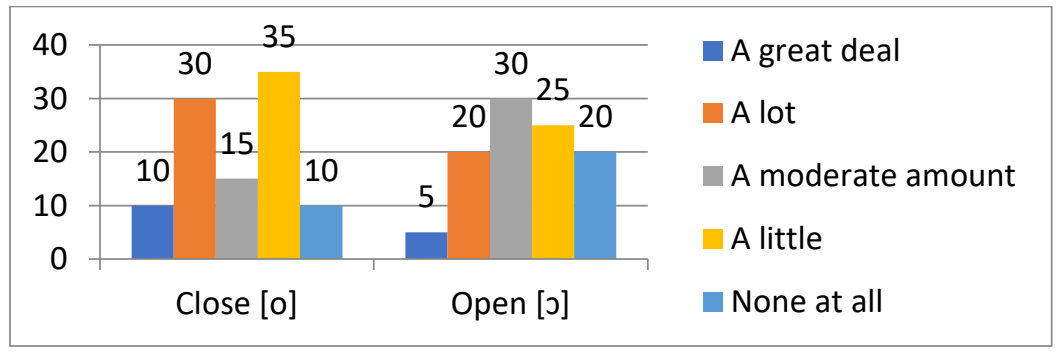

Chart 3.21: question of "how much difficulty do you think American English beginning singers have producing a single $[\mathrm{o}]$ without an $[\mathrm{u}]$ or $[\mho]$ to follow?"

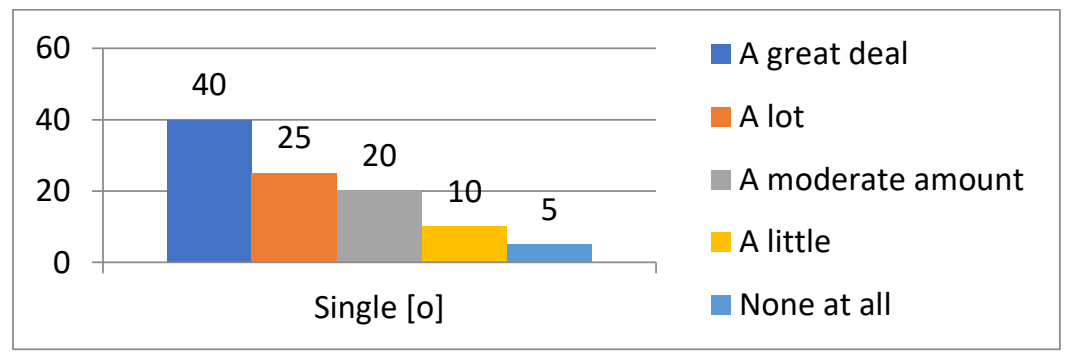

\section{Close [u] vs. Open [ø]:}

Both of these two vowels exist in American English as a single vowel, and both of them are back vowels with a round mouth shape. As we discussed earlier, the close $[u]$ in spoken American English is often followed by a [w] sound. This is the same situation as the close [i] 
being followed by a [j] glide; the [w] is a semi-vowel but still a consonant after all. With the thought of a $[\mathrm{w}]$ being added at the end of an $[\mathrm{u}]$, beginning singers often have trouble relaxing their lips and making a heathy vibrato, especially for a long note. The open [ $\mho]$, on the other hand, is always difficult to sing on a longer note without the sound clarity being distorted. From chart 3.22, we can see that most American participants agreed that the open [ [] at least brings "a moderate amount" of difficulty to beginning singers, and there is zero percent for the option of "none at all."

Chart 3.22: question of "how much difficulty do you think American English beginning singers have producing the Close $[u]$ vs. Open $[\mho]$ ?"

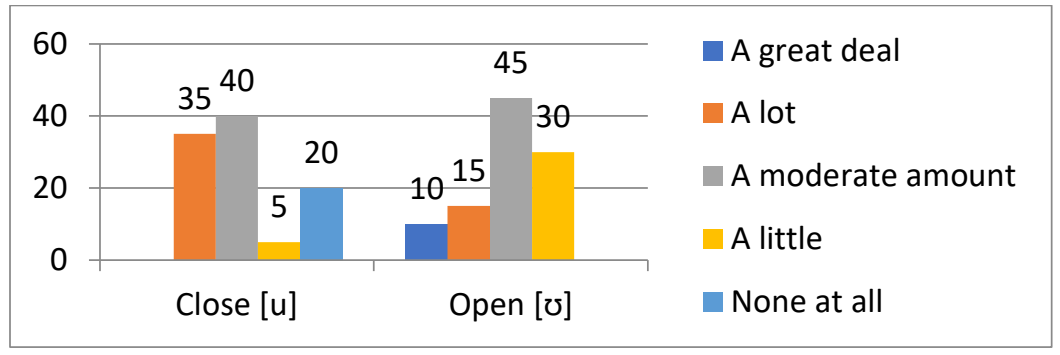

\section{Diphthongs:}

Generally, the main problem that the diphthong brings to American beginning singers is the length or singing duration of each vowel. Otherwise, most American beginning singers can easily produce the diphthongs. However, there is one problem that occasionally happens among American beginning singers, which is the two diphthongs with the bright [a]. The bright [a] only exists in diphthongs [ar] and [av] as we know. Sometimes, beginning singers treat the bright [a] in [aI] and [av] as too spread, which leads to a [æ] sound. This situation might relate to certain dialects in the U.S. rather than the standard North American accent, but it does happen to beginning singers. We can see from chart 3.23, there are few participants who chose the options of "a great deal" and "a lot," but the majority of participants chose the options "a moderate 
amount" and "a lot." The majority of American participants do believe that the diphthongs bring troubles to their beginning singers.

Chart 3.23: question of "how much difficulty do you think American English beginning singers have producing diphthongs?"

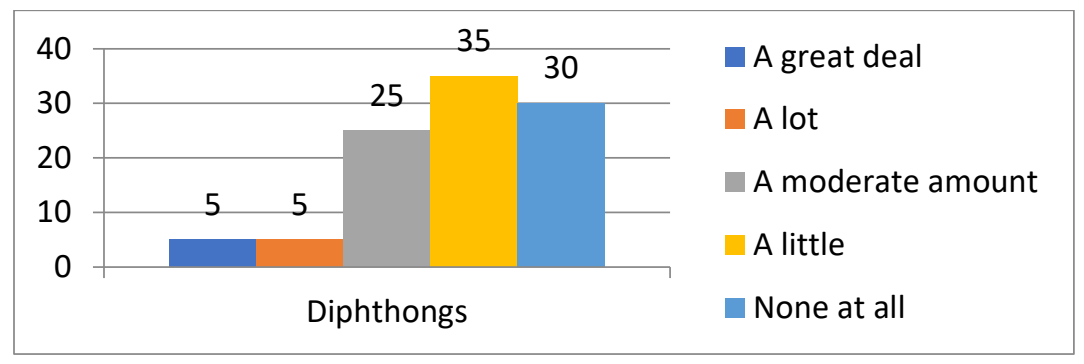

\section{$[\Lambda]$ and [ə]:}

These center vowels are not easy to sing even for mature singers. The $[\Lambda]$ and [ə] are produced in the center of the mouth, but they often cause a low resonant position due to their placement and jaw position, especially for [ə]. From chart 3.24, we can see the majority of American participants agreed that the schwa [ə] is problematic to their beginning singers, but the $[\Lambda]$ does bring "a little" trouble as well.

Chart 3.24: question of "how much difficulty do you think American English beginning singers have producing $[\Lambda]$ and $[ə]$ ?"

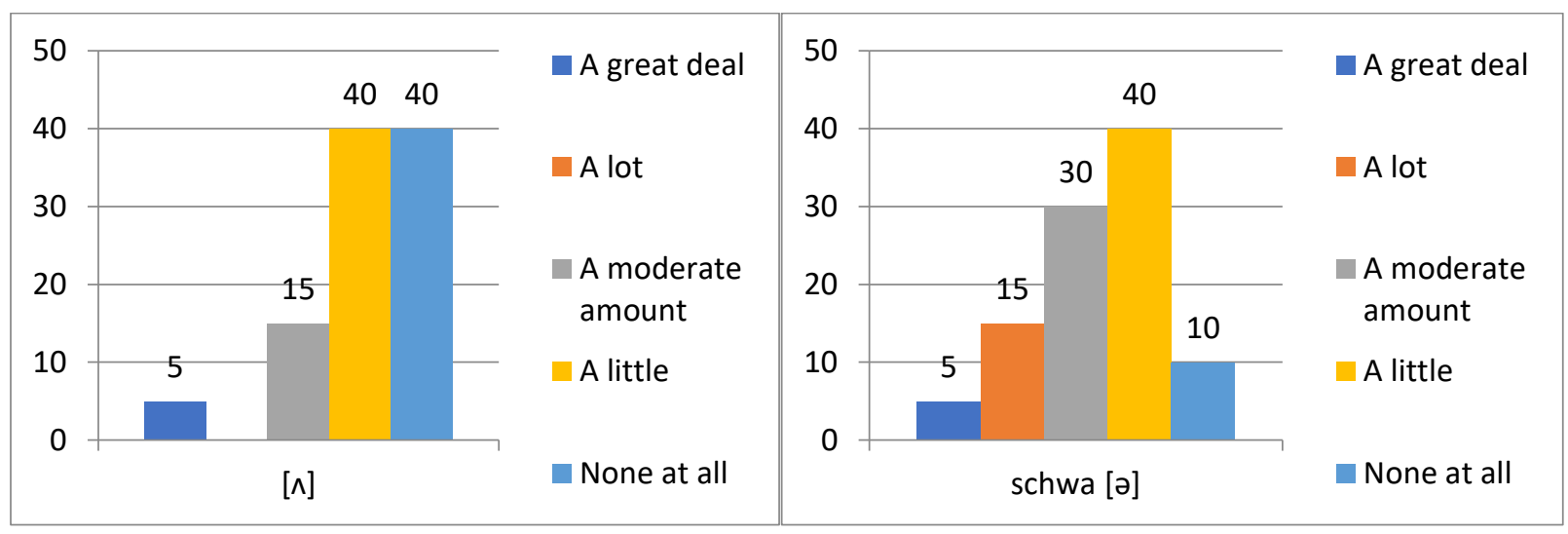




\section{[y] and [y]:}

The [y] and [y] do not exist in English; the open [Y] only exists in German among the other three Western languages, and the close [y] exists in both French and German. Almost every American English beginning singer with no French or German language study background finds these two vowels as very difficult. The difference between these two open and close vowels is not very obvious. On the pronouncing procedure of these two mixed vowels, there are a quite different opinions among diction books: the close [y] is combined with [i] as the tongue position and [o] as the lips position; and the open $[\mathrm{Y}]$ is combined with $[\mathrm{I}]$ as the tongue position and with the lips in [o] position as Grubb states in his book Singing in French $;^{52}$ but William Odom and Benno Schullum state in their book German for Singers that these two vowels are [i] and [I] with the lips rounded. ${ }^{53}$ Some other diction books might use $[\mathrm{u}]$ as the lips position. Nevertheless, the tongue positions of [i] and [I] are apparently the essential parts of these two mixed vowels, but beginning singers usually get easily confused by the lips position $[0]$ or $[\mathrm{u}]$. When they are trying to make the [o] or [u] lips shape, the [i] or [I] tongue positions often gets changed at the same time. Odom and Schullum's method might be better for beginning singers to understand with one less vowel element to worry about. From chart 3.25, we can see that American participants could not be agree more with the difficulty their singers have for these two mixed vowels.

\footnotetext{
${ }^{52}$ Grubb, Singing in French, 39.

${ }^{53}$ Odom, and Schollum, German for Singers, 39-40.
} 
Chart 3.25: question of "how much difficulty do you think American English beginning singers have producing $[\mathrm{y}]$ and $[\mathrm{Y}]$ ?”

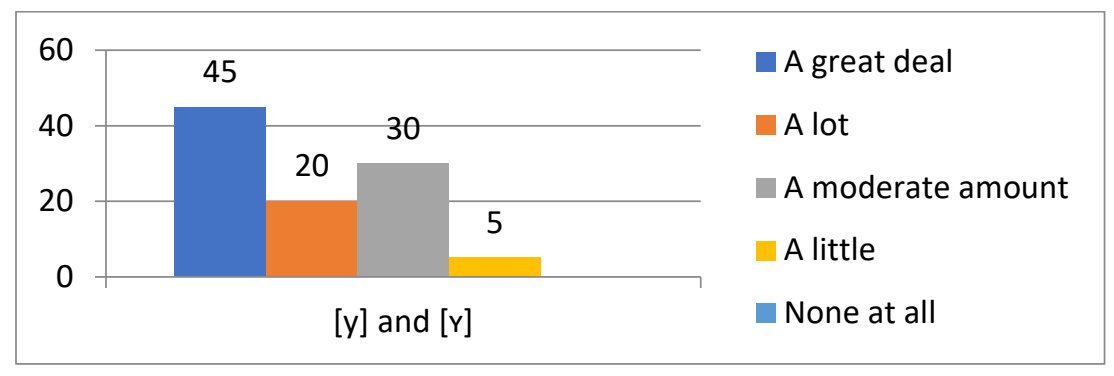

\section{[ø] and [œ]:}

As another pair of nonexistent vowels, $[\varnothing]$ and [œ] might be even more difficult than [y] and $[\mathrm{Y}]$ for American English beginning singers. These two mixed vowels are also in the close and open versions. The close $[\varnothing]$ is mixed with the $[\varepsilon]$ tongue position and $[o]$ lips position; and the open [œ] is mixed with the same [ع] tongue position but the lips are in [o] position. Unlike the $[y]$ and $[\mathrm{y}]$, these two mixed vowels have the same tongue position, and the crucial part to differentiate them will be the lips position or mouth shape. However, the differentiation part usually is not the most difficult part for beginning singers, but the tongue position. The tongue position of $[\varepsilon]$ is much higher than [o] or [o], and beginning singers will often lower their tongue for making the lip position of [o] and [o]. From chart 3.26, we can see all participants chose the first three options. These two mixed vowels $[\varnothing]$ and [œ] made the hardest vowels for American English beginning singers through this survey. 
Chart 3.26: question of "how much difficulty do you think American English beginning singers have producing $[\varnothing]$ and $[œ] ? ”$

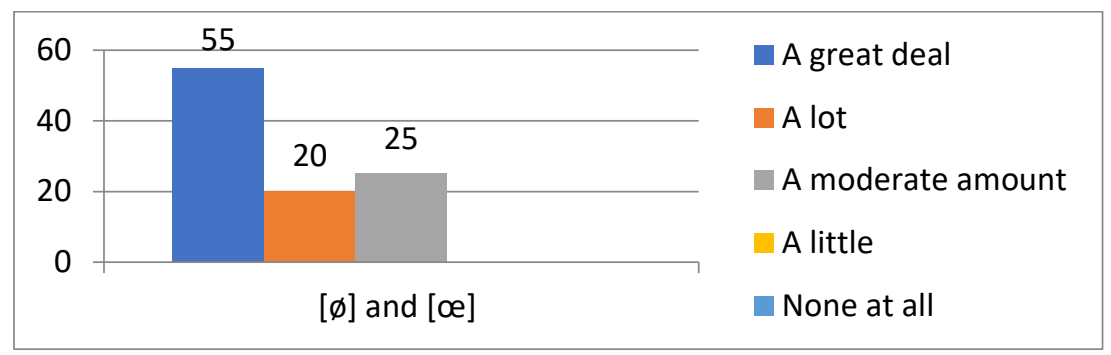

\section{Consonants Feedbacks:}

\section{Final and Medial [1]:}

A consonant should be always produced in a short duration in most Western languages.

However, when a consonant appears in the middle or at the end of a word, American English beginning singers often have trouble to make it as short as it is as an initial consonant. The most significant example will be the [1], there are two types of [1]'s in spoken English that often confuse beginning singers. They are the light and clear [1] that is often used as the initial one, and the dark and back [1] that is often used as the final or medial one ${ }^{54}$ Instead of the tip of the tongue touching the upper gum ridge as the light and clear [1] does, the dark and back [1] requires the middle of the tongue raises and approaches toward the palate, which often causes tongue tension due to the back of tongue being pushed down. This situation happens among beginning singers very often. From chart 3.27, we can see the majority of American participants agree there are some difficulties that their beginning singers have for the final and medial [1].

\footnotetext{
${ }^{54}$ LaBouff, Singing and Communicating, 180.
} 
Chart 3.27: question of "how much difficulty do you think American English beginning singers have producing the final and medial [1]?"

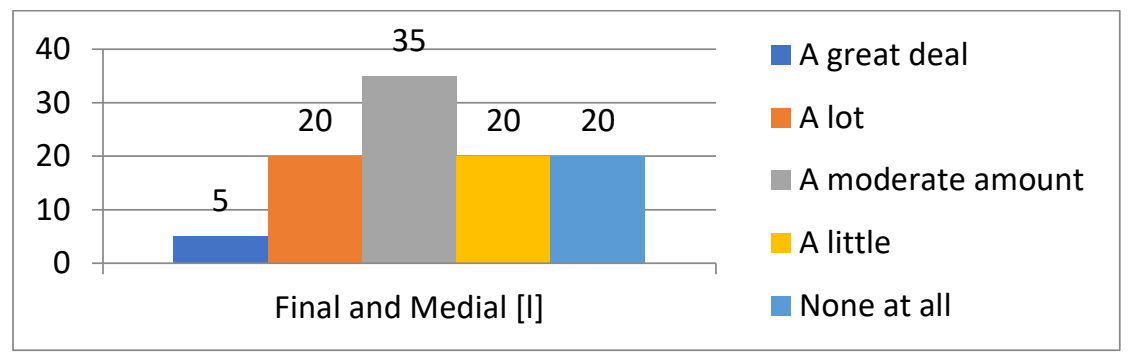

Final and Medial [n]:

The pronouncing procedure of the consonant [n] is always same, no matter if it is being pronounced as the initial one or the final and medial one. However, when it comes as the final or medial consonant, beginning singers might produce it too early or too long, which can affect the tone quality of the vowels before it. For example, when beginning singers start singing the final or medial [n] too earlier and make the vowel before it shorter than it is supposed to be, it could make the lyrics less understandable by the audience. From chart 3.28 , we can see over $65 \%$ of the American participants do agree that there is at least "a moderate amount" or "a little" difficulty for their beginning singers to produce the final and medial [n].

Chart 3.28: question of "how much difficulty do you think American English beginning singers have producing the final and medial $[\mathrm{n}]$ ?"

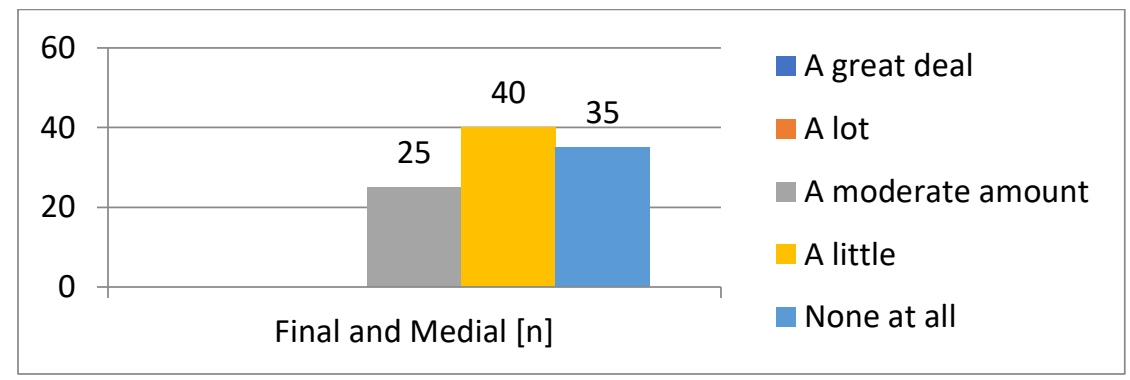




\section{[t.I] and [d.I]:}

These two groups of consonants are often pronounced similarly as $[\widehat{\mathrm{t}}]$ and $[\widehat{\mathrm{d}} \mathrm{z}]$ in spoken American English, and beginning singers occasionally bring this habit into their singing. Both [ [t]] and $[\widehat{\mathrm{d}} 3]$ contain two sounds or elements, but they are single consonants and supposed to be pronounced much more connected than $[\mathrm{t} x]$ and $[\mathrm{d} \mathrm{x}]$. On the other hand, $[\mathrm{t}]$ ] and $[\mathrm{d} \mathrm{I}]$ are two groups of consonants, so every consonant in them need to be pronounced separately and clearly. In quick speed speaking or fast tempo singing, singers might not be able to separate $[\mathrm{t}]$ and $[\mathrm{I}]$, or $[\mathrm{d}]$ and $[\mathrm{x}]$ clear enough, but singers need to understand that the tongue position and articulator movement are different between $[\mathrm{t} x]$ and $[\widehat{\mathrm{t}}]$, or $[\mathrm{d} \mathrm{x}]$ and $[\widehat{\mathrm{d}}] \mathrm{z}]$. The first element or consonants in $[\mathrm{t}]$ and $[\widehat{\mathrm{t}}]$, and $[\mathrm{d} \mathrm{x}]$ and $[\widehat{\mathrm{d}} \mathrm{s}]$ could be considered the same, but the articular movements and placements for $[\mathrm{I}]$ and $\left[\int\right]$, or $[\mathrm{I}]$ and [3] are very different. $\left[\int\right]$ and [3] are postalveolar fricatives, which means the tongue is behind the alveolar ridge and the articulators are not touching but close to each other; [I] is a retroflex approximant, which means the tongue tip is curled backward in the mouth and articulators are further apart than [S] and [3]. The differences between them in fact are very small, but they are different consonants after all. Chart 3.29 shows that $50 \%$ of the American participants agree that there is "a little" trouble for their beginning singers to produce the appropriate $[\mathrm{t} I]$ and $[\mathrm{d} \mathrm{I}]$.

Chart 3.29: question of "how much difficulty do you think American English beginning singers have producing $[\mathrm{t}]$ ] or $[\mathrm{d} I]$ ?"

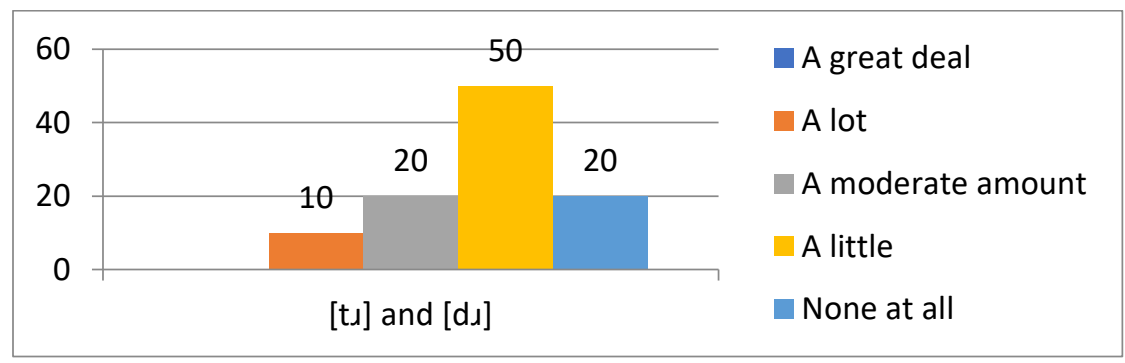




\section{Rolled [r] and Flipped [r]:}

The effect of the American $[\mathrm{I}]$ causes many American beginning singers to have difficulty producing the rolled $[\mathrm{r}]$ or flipped $[r]$ in the other three Western languages. Sometimes, it is difficult for beginning singers to learn how to produce them, but sometimes it is also difficult for beginning singers to remember to do so when they are singing in foreign languages. American English beginning singers often substitute the initial rolled [r] or flipped [r] with the American [x], and use the r-colored vowel [ə] to substitute when the rolled [r] or flipped [r] appears at the end of a word. Chart 3.30 presents that the American participants absolutely found these two consonants to be difficult for their beginning singers, and the rolled [r] is more difficult than the flipped $[r]$.

Chart 3.30: question of "how much difficulty do you think American English beginning singers have producing rolled [r] and flipped [r]?”

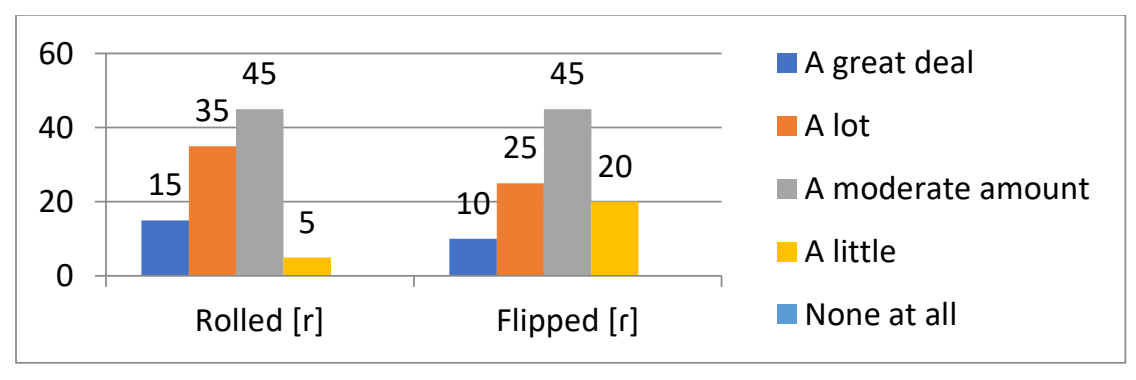

\section{American [.I] Changes the Following Vowel:}

The American $[\mathrm{I}]$ is being categorized as a semi-vowel glide by LaBouff, which is related to the r-colored vowel [ə]. This is to say that the American $[\mathrm{x}]$ contains a vowel sound, and it sometimes changes the following vowel. The question in chart 3.31 asks a specific question about if American participants think when the American [x] is following with vowels as [ıa], [.re], [ıo] and [.ıi], which actually sound like [.ıwa], [.jje], [.ıwo], and [.ıwi]. The responses that American participants gave are quite various, but overall the participants who agreed are slightly 
more than the participants who disagree. This is certainly not a case or problem when beginning singers are singing in American English repertoires, because this is what American English is supposed to sound like. But if they keep the habit when they are singing in the other three Western languages, there will be a [w] or [j] glide added between a rolled [r] and a vowel, or a flipped [r] and a vowel, in this case, the diction will be strange.

Chart 3.31: question of "do you think the American $[\mathrm{x}]$ sometimes changes the following vowel? For example, when [ıa], [.ıe], [.ıo], [.ıi] are pronounced, they actually sound like [.ıwa], [.ıwe], [Iwo], [..wi]."

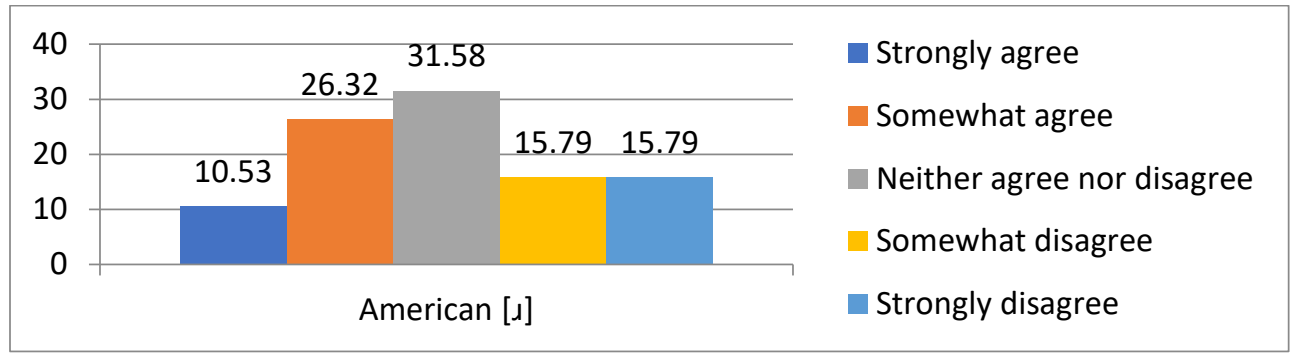

\section{Open-ended Question Feedback:}

The open-ended question is "are there other significant problems not addressed in this survey? If so, please list them below.” There were only four responses received from the American participants. Two of them mentioned the issue of different American accents or dialects as affecting beginning singer, and also the speech-quality vowel sounds. ${ }^{55}$ The accents and dialects issue might not apply to this research, since this research is focusing on the Standard North American accent, but this issue does affect many beginning singers.

One of the responses offers an insightful view, which states that "the more the singer is producing a singing tone with tension in the throat, the more difficult it is for them to produce clear and distinct vowels and voiced consonants. It is also difficult for them to get a forward

\footnotetext{
${ }^{55}$ Quote from one of the feedbacks of the survey of teaching American English beginning singers.
} 
sound which I think helps to get their diction clearly out to the audience. Once the muscles in the throat are neutral and the breathing muscles are able to manage the exhale I think the different sounds can be made clearly." ${ }^{, 56}$ This response could be understood two ways: first of all, American English speakers who use the Standard North American accent often have tension in their throat when speaking, which causes the unclear diction and unhealthy singing habit; the other way to perceive this response could be that an unhealthy singing habit or inappropriate singing techniques also causes the unclear vowels and voiced consonants. The unhealthy singing habit and inappropriate singing techniques that come from beginning singers themselves might vary, but the ones that come from the standard North American English accents often share certain common issues. This participant also mentioned "a sound like the rolled $[\mathrm{r}]$ sometimes requires some extra attention - it doesn't come naturally to everyone," which is very true. The learning process of the rolled [r] often takes a while for most beginning singers.

Another response provided several problems that are not addressed in the survey, which include "[s] as final consonants, consonants that appear at the end of words vs. in the middle, and $[\theta]$ vs. [ð]. ${ }^{, 57}$ When $[\mathrm{s}]$ appears as a final consonant that has two different pronunciations in singing: $[\mathrm{s}]$ or $[\mathrm{z}]$. When a final $[\mathrm{s}]$ is following a vowel or voiced consonant, a voiced $[\mathrm{z}]$ could be easier to be heard than a [s]. When a final [s] is following an unvoiced consonant, a [s] sound will sound appropriate with the unvoiced consonant. This rule only applies for classical style singing, in which most American English beginning singers are able to pronounce the [z], but occasionally need to be reminded. About the "consonants that appear at the end of words vs. in the middle of words," a few consonants have been discussed in the earlier chapter, such as [n], [m], and [1]. Other consonants do not make as big of a difference as the nasal consonants and the

\footnotetext{
${ }^{56}$ Quote from American English survey's feedbacks.

${ }^{57}$ Quote from American English survey's feedbacks.
} 
lyrical [1] do between appearing as final and medial consonants. The "[ $\theta]$ vs. [ð]" issue was not asked in the survey, but it was discussed in the earlier chapter. 


\section{Chapter IV}

\section{The Effect of Native Language Pronunciation}

When people start learning the pronunciation of a new language, they would usually subconsciously look for references from their native language. When their native languages do not have the same sound, people often substitute it with a similar sound that exists in their native language. This is usually the reason why people have accents in foreign languages. A short article "Why do some people have an accent?" is posted on the web site of the Linguistic Society of American. Here is a short quote from the article:

People have trouble with sounds that don't exist in the language (or languages) that they first learned as a young child. We are born capable of both producing and perceiving all of the sounds of all human languages. In infancy, a child begins to learn what sounds are important in his or her language, and to disregard the rest. By the time you're a year old, you've learned to ignore most distinctions among sounds that don't matter in your own language. The older you get, the harder it becomes to learn the sounds that are part of a different language. ${ }^{58}$

For singers, an accent often means the wrong pronunciation. Kathryn LaBouff suggests that even native English speakers still need to study the English diction, because native English speakers tend to be very careless with the language.${ }^{59}$ In many cases, the speaking sounds and ways of American English are not good or healthy for singing; singers need to understand how to sing a sound and how it is different than speaking it. The same situation should apply to other languages' speakers as well. Classical singers should be familiar with the IPA system and its symbols. They also should be capable of labelling their own languages with the accurate IPA symbols, because the more they know the accurate symbols of their own language, the less

\footnotetext{
58 Betty Birner, "Why Do Some People Have an Accent?" Linguistic Society of America, , accessed March 28, 2019, https://www.linguisticsociety.org/content/why-do-some-people-have-accent.

${ }^{59}$ LaBouff, Singing and Communicating, 3.
} 
chance they would substitute foreign sounds with inappropriate sounds from their native language. If the IPA system does not include a symbol to represent certain sounds in their native languages, singers should at least understand and be able to explain the exact mechanism of the pronouncing progress. Also, classical singers should be familiar with the mechanisms of all IPA sounds for avoiding using inappropriate substitutes in singing. If singers only study dictions of foreign languages, sometimes they might not be able to differentiate the similar sounds (but completely different) between a foreign language and their native language.

\subsection{The Overall Mandarin Chinese Effects and Possible Solutions}

As discussed in chapter 2, Mandarin Chinese is not an alphabetic language, which uses its own characters. The Romanization system (Pinyin) of Mandarin Chinese we see is in fact, the pronunciation labels. The single syllable rule and the four-tone system in Mandarin Chinese causes many beginning singers to stress or accent each vowel in singing in the four Western languages, include all unstressed vowels. It also makes Mandarin Chinese singers have difficulty connecting vowels.

Mandarin Chinese has the five fundamental vowels: [a], [e], [i], [o] and [u], plus the sixth one [y]. Theoretically, all six vowels in Mandarin Chinese are close vowels and pronounced as consistent as they are labelled in the Romanization system. However, this is not true. The $[\mathrm{e}],[\mathrm{o}]$ and $[\mathrm{u}]$ do not sound as close as they are in the four Western languages, and certainly do not sound as open as their open versions. This issue often makes some Mandarin Chinese singers' vowels not accurate or clear enough. In addition, certain vowels change sounds in vowel combinations (depending on the vowel or consonant before or after them). This issue sometimes confuses Mandarin Chinese singers when the close and open versions, or the bright and dark versions vowels appear in Western languages. For example, the bright [a] is used in 
vowel combination an in Mandarin Chinese, but the same spelling in German would pronounce with a dark [a]. Mandarin Chinese singers will often pronounce it with the bright [a]. The last significant problem about Mandarin Chinese vowels is that the $[\mathrm{u}]$ always comes with a $[\mathrm{w}]$ in front of it. Mandarin Chinese singers usually do not realize this issue.

In Mandarin Chinese, when two or more vowels appear together in a word, it is not called a diphthong, but a vowel combination. As the name refers, each vowel is a part of the combination, which means all vowel sounds need to be combined rather than pronounced separately. This particular rule somehow affects Mandarin Chinese singers when they are singing the diphthongs in the four Western languages, in which two vowels are required to be pronounced separately. The vowel combination rule also applies to when one or two vowels appear with a glide, and even when consonants $n, n g$ and $r$ appear at the end of words after one or two vowels. The latter one brings a significant problem to Mandarin Chinese singers, because based on the rule of vowel combination, the consonants in vowel combinations are not considered as consonants, but a part of the vowel combination. That being said, the pronouncing procedure is different than when they appear as initial consonants. For $n$ and $n g$, there is no required tongue movement when they are part of vowel combinations, which means the tongue will not touch the hard palate for $n$, and will not touch the soft palate for $n g$. Most Mandarin Chinese singers are unfamiliar with the necessary tongue movement for the final $n$, even if they are capable of pronouncing the initial $n$. On the other hand, $n g$ never appears as an initial consonant; Mandarin Chinese singers have never pronounced this the correct way as it is in the four Western languages, but they are usually capable of producing the correct sound after being taught in detail. The $r$ as a final letter only happens in one spelling but two pronunciations. er 
could be pronounced as [aə] and [əə], which is the same sound as the r-colored vowel [ə] but with stress.

Besides the situation of vowel combinations with consonants, all consonants are initial consonants in Mandarin Chinese. In Mandarin Chinese, the consonants $z$ [z], $c$ [ts], $s$ [s] are called flat-tongue consonants; and $z h[\widehat{\mathrm{d}}], \operatorname{ch}[\widehat{\mathrm{t}}], s h\left[\int\right]$ and $r$ [3] are called curled-tongue consonants, which make any following $i$ a schwa [ə] but with the mouth closed. The letter $r$ pronounced as [3] is surprisingly unconventional. The difference between the American [I] and [3] is only the distance between the upper and low molars. The American [I] requires the molars are being further apart, but [3] needs the molars being close to each other without touching. This tiny difference makes different sounds because the American $[\mathrm{I}]$ is a vowel related glide, but [3] is a voiced consonant, which requires more muscle tension to produce. This issue is rarely audible even for American voice teachers; Mandarin Chinese singers and their teachers are mostly unaware of this. Moreover, Mandarin Chinese has three special consonants that do not exist in the four Western languages, which are $j[\widehat{\mathrm{zj}}], q,[\widehat{\mathrm{tsj}}], x[\widehat{\mathrm{sj}}]$. These three consonants have very similar sounds as $[\widehat{\mathrm{d}}],[\widehat{\mathrm{t}}]$, and $\left[\int\right]$ but with the tongue being flat. The $[\widehat{\mathrm{d}}],[\widehat{\mathrm{t} f}]$, and $\left[\int\right]$ do exist in Mandarin Chinese, but they are never followed by [i] or [j], but the special consonants

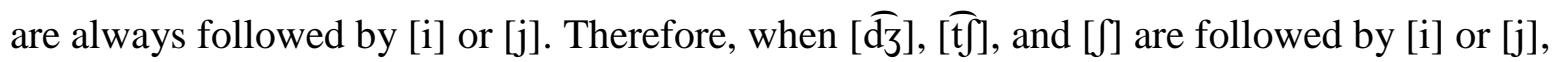
Mandarin Chinese beginning singers might substitute them with the Mandarin Chinese special consonants $j[\widehat{\mathrm{zj}}], q, \widehat{[\mathrm{tsj}}], x[\widehat{\mathrm{sj}}]$ (this situation might only happen to very beginners).

Based on these basic pronunciation rules of Mandarin Chinese, we can see what references Mandarin Chinese singers think of when they are singing in the four Western languages. Inevitably, Mandarin Chinese singers have to face certain sounds that only exist in the four Western languages as we discussed in chapter 2, "Nonexistent Vowels and Consonants." 
For open version vowels, Mandarin Chinese beginning singers often substitute them with the close versions, except $[\varepsilon]$ and [o] because the Mandarin Chinese [e] and [o] are not as close as they are in Western languages. For French nasal vowels, Mandarin Chinese beginning singers might use the references ang and ong at first, but these references are not as nasal as they are in French. Beginning singers might get confused by these references, and might need a while to be

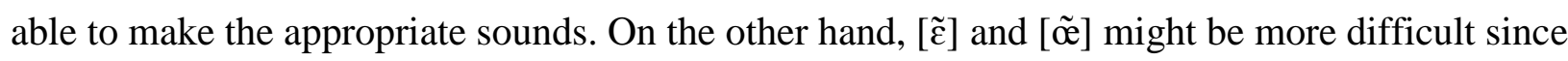
there is no reference from Mandarin Chinese. However, without references, it means that singers have to learn a new sound from scratch, which often brings less confusion. The same situation happens to the mixed vowels $[\varnothing]$ and $[œ]$. Without reference, it might make the beginning step difficult but create less confusion for later. The other nonexistent vowels include the r-colored vowels [३] and [ə]; central or mixed vowels $[\Lambda]$ and [ə]; and the English distinctive vowel [æ]. For these vowels, Mandarin Chinese singers usually try to find references first. The [־] and [ə] are very similar to the Mandarin Chinese word er, which is pronounced as [əə]. The two labels in [əə] $]$ are pronounced as a vowel combination that makes the actual sound become a stressed $[ə]$. The $[\Lambda]$ is often substituted with [a], and [ə] is pronounced as a stressed vowel based on the single syllable rule of Mandarin Chinese. The [æ] is usually substituted by the vowel combination [ai] before Mandarin Chinese singer master the correct sound.

The nonexistent consonants for Mandarin Chinese singers that we have discussed include the final or medial [n], [y], [m] and [1], which Mandarin Chinese singers have never used as final or medial consonants. Even when the [n] and [n] do appear at the end of words, they are only considered as the part of vowel combination without the proper tongue movements. The English distinctive consonants [ $[\theta]$ and [ð] could be difficult for all non-native English speakers. These two are the only dental fricative consonants in voiced and unvoiced versions that bring quite a bit 
of difficulty to Mandarin Chinese singers since the dental articulator movements are very unfamiliar to them. The Enya [n] from Italian and French and Elya $[K]$ from Italian also bother Mandarin Chinese singers, as they are often being substituted with [ni] and [li] as other nonItalian and non-French singers would do. The German Ichlaut and Achlaut: [ç] and [ $\chi$ ], on the other hand, only the [ç] is often substituted with [J] or the Mandarin Chinese special consonant $[\widehat{\mathrm{sj}}]$. The $[\chi]$ is usually easy to pronounce based on the reference of the Mandarin Chinese word he [hə], Mandarin Chinese singers only need to make the tongue closer to the soft palate for the [h]. The majority of Mandarin Chinese singers do have a problem with $[\chi]$. The flipped $[r]$ and rolled [r] in Italian, French, and German can be difficult for any singers, especially for the rolled [r] that does not come easily for everyone. Once Mandarin Chinese singers have mastered the rolled [r], the challenge will become the differentiation between the flipped $[r]$ and rolled $[\mathrm{r}]$. And the last and most important issue of nonexistent consonants is the Mandarin Chinese missing [v] vs. [w]. The letter $v$ is only used for substituting the umlaut $\ddot{u}$. Most Mandarin Chinese singers can quickly learn the correct sound of [v], but they often substitute the [v] with the $[w]$ sound, because the latter one is their instinctive reaction or reference.

\subsection{The Overall American English Effects and Possible Solutions}

English has three kinds of single vowels: forward vowels, central/mixed vowels, and back vowels. The forward vowels include the close $[\mathrm{i}]$ and open $[\mathrm{I}]$, open $[\varepsilon],[\mathfrak{x}]$ and the dark [a]. Besides [æ], other forward vowels also exist in the other three Western languages. However, some of these forward vowels might pronounce differently than the same vowels in Italian, French and German. First of all, the close [i] in spoken American English is usually pronounced with a [j] followed. Some beginning singers certainly bring this habit into their singing, which causes jaw and tongue tensions when holding the [j] glide for a long note. The following [j] 
sometimes restrains beginning singers to modify the close [i] through passaggio. The open $[\mathrm{I}]$, on the other hand, is very difficult to sing on a long note, which easily gets distorted when a beginning singer does not keep forwarding the resonance, but letting the vowel be the exact same way as it is when spoken. The open $[\varepsilon]$ is usually pronounced well by beginning singers, except that it might sometimes be pronounced more spread than it is supposed to be. This same situation happens to the English distinctive vowel [æ]. Both of them should not be pronounced with a spreading mouth shape. In spoken American English, these two vowels are often pronounced in a spreading mouth shape, which is the characteristic of the North American English accent, but it is not a good diction or a healthy way for singing. The last vowel in the category of forward vowels is the dark [a], which is often considered as one of the back vowels. However, based on the placement of articulators, a correctly pronounced dark $[\mathrm{a}]$ should be considered as a forward vowel. The dark [a] is often pronounced too dark and will almost sound like a back vowel by many singers, even for mature singers. This might be the reason that the dark $[a]$ is often considered as a back vowel in some diction books.

The central/mixed vowels in American English are two paired vowels: $[\Lambda]$ and [ə], [3] and [ə]. LaBouff categorizes all of them as mixed vowels, but a more appropriate way to categorize them may be still considering $[\Lambda]$ and [ə] as central vowels since they are placed in the center of the mouth. The [з] and [ə] should be considered as mixed vowels, because each of them contains a vowel and an American $[\mathrm{I}]$ sound. In many diction books, $[\Lambda]$ and $[ə]$ are explained as the same sound in stressed and unstressed versions. However, the sounds between $[\Lambda]$ and [ə] are not exactly the same. The $[\Lambda]$ is slightly more open than [ə], and the [ə] generally has a lower position than $[\Lambda]$. Both of $[\Lambda]$ and [ə] are produced in the center of the mouth, American English beginning singers often bury them under the tongue by pressing down the 
back of the tongue, which is the way people pronounce them in speaking American English. Since the $[\Lambda]$ only exists in English, many voice teachers and vocal coaches suggest young singers to substitute it with an [a] vowel, which can often bring the sound into a higher position. The [ə], on the other hand, also exists in French and German. In French, [ə] is often substituted with [œ] to get the ideal tone quality, which should apply to English as well. The [з] and [ə] as the distinctive r-colored vowels only exist in American English. The $r$ coloring sound often brings trouble to beginning singers. When the $r$ coloring is sung for a long duration, beginning singers usually push down the back of the tongue to seek a resonant space. American voice teachers and vocal coaches usually suggest beginning singers to sing them in a British accent, but not all the beginning singers understand how to achieve that. A better way might be asking beginning singers to keep the tip of the tongue touching the lower teeth as they proceed the American $[x]$ part in $[3]$ and $[x]$.

The back vowels in English are the close [u] and open [v], and open [0]. The close [u] has a similar issue as the close [i]. American English speakers would often secretly add a [w] sound after $[u]$, which keeps the mouth shape rounder but the space inside the mouth is more reduced than the close $[u]$ is supposed to need. Then the lack of space inside the mouth causes the lack of proper resonance. The open $[\mho]$ is the opposite of the close one, which is often being sung too open and distorted. Many American beginning singers have problems with the open [ $\mho$, especially when it is sung on a long note. The mouth shape of $[\mho]$ is difficult to maintain for many beginning singers, since they do not need to maintain it when speaking. Beginning singers need to remind themselves to maintain the mouth shape for the open [ $\mho]$, and sometimes they will need to modify it to the close version to go through the passaggio. Another vowel in the 
category of back vowels is the open [o], which is usually not difficult for beginning singers to produce, except adopting the speaking way might cause a lower position for resonance.

After discussing the single vowels in English, we notice that there are a few vowels missing from this category. English does not have the close [e], close [o] and the bright [a] as single vowels, but they do exist in English diphthongs. English has five diphthongs: [er], [ov], [ат], [ај] and [эг]. The second vowel of these five diphthongs is all labelled as the open versions. This is mostly for singing; the close versions could be used in speaking. The main purpose of the second vowels being the open version is to make the articulators move less between the two vowels. The situation of close [e] and [o] only exists in English diphthongs and does bring a significant issue to American English beginning singer, who often have trouble to pronounce a single [e] or [o] without the following [I] or [v]. The single [e] and [o] often appear in all three other Western languages, but American English beginning singers mostly pronounce them with the following $[\mathrm{I}]$ and $[\mho]$. Another problem that the diphthongs bring to beginning singers is how to divide the length of duration between two vowels. A diphthong requires that the first vowel should be sung for a longer duration than the second one. Beginning singers often pronounce the first one briefly and stay on the second one for a longer duration.

English has three semi-vowel glides: [w], [j] and [x]. In many diction books, the American $[\mathrm{I}]$ is considered as a consonant, but after adopting the theory from LaBouff's book, the $[\mathrm{I}]$ is considered as one of the semi-vowel glides in this research. The reason is that every semi-vowel glide has a related vowel: the related vowel of $[\mathrm{w}]$ is $[\mathrm{u}]$; the related vowel of $[\mathrm{j}]$ is [i]; and the related vowel of $[\mathrm{I}]$ is the r-colored vowel [o]. The glides [w] and [j] are fairly easy for beginning singers, but the $[\mathrm{I}]$ brings some difficulties. The pronouncing procedure of these semi-vowel glides is to initiate the sound with the related vowel, and then start the glide. The 
pronouncing procedure of these three semi-vowel glides approves that the related vowels are the part of the semi-vowel glides. Pronouncing a [x] with [ə] is not a problem in American English. However, American English beginning singers often bring the [ə] sound into the flipped [r] and rolled $[r]$ when they sing the other three Western languages, which changes the following vowel or adds a [w] sound between $[\mathrm{r}]$ and the following vowel. The examples will be that [.ra], [.re], [ıo], [.ıi] are actually sounded like [ıwa], [ıwe], [.ıwo], [ıwi] in American English, but when the flipped $[r]$ and rolled $[\mathrm{r}]$ are added a [w] sound before [a], [e], [o], [i], the accuracy of diction will be changed and a strong American English accent comes along as well.

English contains most consonants that also exist in the other three Western languages, except the exclusive English consonants [ $\theta]$ and [ð]. American English beginning singers usually do not have problems with most consonants, especially for all initial consonants. However, when the nasal consonants $[\mathrm{n}],[\mathrm{m}]$ and the lyrical [1] appear as final or medial consonants, certain problems might occur. When [n] appears as a final or medial consonant, beginning singers often pronounce or prepare it earlier than it is supposed to be. The pronouncing procedure of $[\mathrm{n}]$ is the tongue being in contact with the hard palate. If this tongue movement or even an attempt at it happens too early, the vowel before it gets affected because the space inside the mouth gets reduced. The same situation happens when $[\mathrm{m}]$ is the final or medial consonant as well, in which case beginning singers will close their mouth too early, which causes the vowel before it to get cut off too soon. The more significant problem happens to the lyrical [1], because the pronouncing procedure of [1] itself involves more complicated tongue movements, even when [1] appears as the initial consonant. When pronouncing [1], only the tip of the tongue is in touching the hard palate, the rest of the tongue is being pushed down to create a space between the palates. If this particular tongue movement is being held for a long duration, an unhealthy sound will be 
created. When [1] appears as the initial consonant, most beginning singers are capable to pronounce it quickly and reduce the tongue tension into the minimal level. But when [1] appears in the middle or at the end of a word, beginning singers often tend to sing it for a longer duration than it is supposed to be. In this case, the vowel before it will also get affected as either being shorter or unclear. The problems of these three consonants in English also apply to beginning singers when they sing in the other three Western languages.

American beginning singers only have to deal with a few nonexistent vowels and consonants. The mixed vowels in French and German [ø], [œ], [y] and [y] are usually difficult to pronounce by many beginning singers. The first pair $[\varnothing]$ and [œ] are in close and open versions, and exist in both French and German. The $[\varnothing]$ mixes the $[\varepsilon]$ tongue position and the close $[0]$ lips position; the $[œ]$ mixes the same $[\varepsilon]$ tongue position, but with the open [o] lips position. The main problem of pronouncing these two mixed vowels is that beginning singers usually slightly change the tongue position when the lips position is in shape, which causes the sound to be buried under the tongue. Once beginning singers master the pronouncing procedures, they might have a hard time to differentiate them. The open one often brings more difficulty to beginning singers, and the most common fault is the mouth not being opened enough. Another pair of mixed vowels $[\mathrm{y}]$ and $[\mathrm{y}]$ can also be difficult for most beginning singers. The close [y] exists in both French and German; the open $[\mathrm{Y}]$ only exists in German. Unlike the [ø] and [œ], the difference between $[\mathrm{y}]$ and $[\mathrm{Y}]$ is the tongue position; the close $[\mathrm{y}]$ is pronounced with the close [i] tongue position and a round lips position or a $[\mathrm{u}]$ lips position, while the open [Y] uses the open [I] tongue position with the same lips position as [y]. There is a similar situation for $[\varnothing]$ and [œ], and American beginning singers often cannot mix the two elements well in $[y]$ and $[\mathrm{Y}]$, with the tongue position often being slightly changed with the lips position. 
The nonexistent consonants in American English are the Enya [n] and Elya $[\Lambda]$ in Italian and French; German Ichlaut $[\mathrm{c}]$ and Achlaut $[\chi]$; and the flipped $[r]$ and rolled $[\mathrm{r}]$. The Enya [n] is often substituted with [ni] by beginning singers, in which instead of using the blade of the tongue to touch the hard palate for this single consonant [n], the tip of the tongue quickly touches the hard palate for [n] and then leaves for [i]. On the other hand, the Elya $[\Lambda]$ is easily sung as [li] instead, it only requires one tongue movement, but the common substitute [li] requires two. Between these two common substitutes, [ni] as the incorrect [n] does not sound very obvious since the mouth is more closed, but [li] the incorrect $[K]$ presents an evident sound with a more opened mouth shape. The German Ichlaut $[c ̧]$ and Achlaut $[\chi]$ might not confuse beginning singers as much as Enya $[\mathrm{n}]$ and Elya $[K]$ do, but both of them usually get substituted as well. The Ichlaut $[\mathrm{c}]$ is often substituted with [J]; and the Achlaut $[\chi]$ is occasionally substituted with $[\mathrm{k}]$. Between this pair of consonants, the Ichlaut $[c ̧]$ is more difficult than the Achlaut $[\chi]$ for beginning singers. The Ichlaut [ç] is an unvoiced consonant as well as its common substitute [J], but the tongue position of [ç] is similar to the vowel [i] or semi-vowel glide [j]. Beginning singers often have a hard time maintaining the correct tongue position while producing an unvoiced sound, hence the $\left[\int\right]$ becoming the substitute. The Achlaut $[\chi]$, on the other hand, is often easy to imitate. The substitute $[\mathrm{k}]$ only happens to early beginners occasionally. The flipped [r] and rolled [r], as mentioned earlier, do not come to every singer naturally. The most significant problem is that both of them are often substituted by the American $[\mathrm{I}]$, which causes a distinctive American English accent. Additionally, a [w] sound is added in between the flipped [r] or rolled [r], as well as the following vowel if it is [a], [e], [o] or [i]. The last nonexistent consonant is [ts], which appears in Italian and German. The [ts] mostly can be pronounced 
correctly by beginning singers. It only occasionally get confused with $[\mathrm{z}]$ since the articulator position is very similar.

\subsection{Afterword}

After learning the pronunciation rules of both Mandarin Chinese and American English, we can understand more thoroughly why beginning singers make diction mistakes and the vocal faults that come along with them. Nowadays, more and more Mandarin Chinese speaking singers pursue their musical education in the U.S., which might bring American voice teachers and vocal coaches many questions, such as: why they cannot pronounce the final [n] or [y] properly? why does their $[\mathrm{u}]$ have a $[\mathrm{w}]$ in front of it? why do they keep singing $[\mathrm{w}]$ in the place of $[\mathrm{v}]$ ? One of the purposes of this research is to hopefully explain the common diction faults and concomitant vocal faults of Mandarin Chinese singers to American voice teachers and vocal coaches. After knowing the reasons, they might be able to help their Mandarin Chinese voice students more efficiently.

When people start learning a new language, they always look for references from their native language, and the use of these references are usually acceptable for people who speak the same language. Many Mandarin Chinese mature singers still have very evident diction problems after they have completed an undergraduate degree in China, because those diction problems came from the reference of Mandarin Chinese pronunciation and their voice teachers might find it acceptable as well. This is not to say that those Chinese voice teachers and vocal coaches use incorrect diction themselves, but because of their native language, certain incorrect diction or inappropriate substitutes might become acceptable or forgivable under the circumstances. This same situation happens to American English beginning singers too. Their voice teachers and vocal coaches speak the same language as they do. The allophones among the four Western 
languages create different accents, and incorrect diction. When American English beginning singers use their native language as the reference for the other three Western languages, many sounds might occasionally be accepted or overlooked by their American voice teachers or vocal coaches. Another purpose of this research is to hopefully remind more American voice teachers and vocal coaches that certain diction problems might come from the pronunciation of American English. These diction problems sometimes bring certain vocal faults along.

The last purpose of this research is the hope that all Mandarin Chinese and American English beginning singers get familiar with the IPA system, understanding the pronunciation procedure of every vowel and consonant in their native languages and other languages they sing. The first reaction for a natural imitation always references the native language you speak because that is how our brains work. Studying dictions of all the languages you sing including your native language as well helps you to create the correct and appropriate pronunciation for all the new sounds in foreign languages, and most importantly helps with being able to differentiate all allophones among all the singing languages. Many singers do not think they need to study the diction of their native languages. However, not knowing every accurate IPA label of your native language makes singers consistently use inappropriate references from their native language when learning a new language because they cannot recognize the difference. In addition, the singing language is different than the speaking language, as LaBouff states "as native speakers, we focus usually on the ideas that we are trying to communicate, not on the specific sounds that make up the words we are using to express ourselves. ${ }^{\circ 0}$

Singing is a complicated mechanism and technique, but good singing should be a simple and concrete method that all beginning singers can understand and are capable of learning. I

\footnotetext{
${ }^{60}$ LaBouff, Singing and Communicating, 3.
} 
hope that this research could help more Mandarin Chinese and American English beginning singers, as well as their voice teachers and vocal coaches. 


\section{Appendix 1: Notes for Selected Music Examples}

\section{Chinese Art Songs:}

1. "The Rippling Brook" was written by Chinese composer Yin, Yigong (1924-2005) in 1947, which is based on the folk song style from Yunan province, China. This song is in a key of C-minor and is often sung by sopranos.

2. "A Night-Mooring at the Maple Bridge" was written by Chinese composer Li, Yinghai (1927-2007). The poem was written by the famous Chinese poet Zhang, Ji from the Tang dynasty (618-907). The song is in a key of C\#-minor and is often sung by sopranos.

3. "I Live at the Source of the Yangtze River" was written by Chinese composer Qing, Zhu (1893-1959). The poem was written by Chinese poet Li, Zhiyi (1038-1117) from the Song dynasty (960-1279). This song is in a key of G-major, which is often sung by female singers and lower keys are available.

4. "Spring Nostalgia" was written by Chinese composer Huang, Zi (1904-1938) in 1933, which is from his song cycle Spring Nostalgia. The poem was written by Chinese writer Wei, Hanzhang (1905-1993). This song is in a key of F-major, and other keys are available for all voice types of singers.

5. "Homesickness" is the first song from the song cycle Spring Nostalgia by Huang, Zi. The poem was written by Wei, Hanzhang. This song is in a key of Eb-major, and other keys are available for all voice types of singers.

6. "The Three Wishes of a Rose" is the last song from the song cycle Spring Nostalgia by Huang, Zi. The poem was written by Long, Qi. This song is in a key of E-major, and other keys are available for all voice types of singers.

7. "I Love This Land" was written by Chinese composer Lu, Zaiyi (born. 1943) in 2001. The poem was written by Chinese poet Ai, Qing (1910-1996) in 1938. The song is in a key of Gbmajor, which is written for sopranos.

8. "Thinking of My Mother" is a Yunan folk song that was arranged by Chinese composer Ding, Shande. This song is in a key of Eb-minor, and is usually sung by tenors.

\section{English Art Songs:}

1. "The Chariot" was written by American composer Aaron Copland (1900-1990) in 1950, which is the last song of his song cycle Twelve Poems of Emily Dickinson. The poem was written by American poet Emily Dickinson (1830-1886). The song cycle was written for medium voice and piano. This song is in a key of F\#-minor.

2. "Early in the Morning" was written by American composer Ned Rorem (born. 1923) in 1954. The poem was written by American poet Robert Hillyer (1895-1961). This song is in a key of Bb-major.

3. "Love Has Eyes" was written by English composer Henry Bishop (1786-1855). The poem was written by Charles Dibdin (1745-1814). The song is a key of Bb-major, and this version was edited by Richard D. Row.

4. "Everywhere I Look" was written by English composer Molly Carew (1886-1953) in 1982 (published). The lyric was written by Dena Tempest. This song is in a key of F-major.

5. "The World Feels Dusty" is another song from Aaron Copland's song cycle Twelve Poems of Emily Dickinson. The key of this song is in D-major.

6. "How Beautiful are the Feet" was written by George Frideric Handel, which is an aria for soprano from his Messiah. The key is in G-minor. 
7. "Now Sleep the Crimson Petal" was written by English composer Roger Quilter (1877-1953). The poem was written by British poet Alfred Tennyson (1809-1892) in 1847 (published). The key of this song is in Eb-major.

8. "Under the Greenwood Tree" was written by American composer Douglas Moore (18931969). The poem was written by English poet William Shakespeare (1564-1616). The key of this song is in Db-major.

9. "With Rue My Heart is Laden" was written by American composer Samuel Barber (19101981). The poem was written by English poet A. E. Housman (1859-1936). The song is from Barber's 3 Songs for Voice and Piano, Op. 2, and the key is in F-major.

\section{Italian Songs:}

1. "Caro mio ben" was written by Italian composer Tommaso Giordani (1730-1806). The song is in the key of C-major.

2. "Gia il sole dal Gange" was written by Italian Baroque composer Alessandro Scarlatti (16601725). The lyric was written by Felice Parnasso. The song is in the key of A-major.

3. "Nel cor piu non mi sento" was written by Italian Classical composer Giovanni Paisiello (1740-1816). The lyric was written by Giuseppe Palomba. The song is in a key of G-major. 
Appendix 2: Surveys

1. Survey of Teaching Mandarin Chinese Singers

Q1. How long have you been working with Mandarin Chinese speaking singers?

- 1-2 years

- 3-5 years

- 6-10 years

- Longer than 10 years

Q2. How many Mandarin Chinese speaking singers you have worked with?

- $1-2$

- $3-5$

- 6-10

- More than 10

Q3. Dark [a]: How much difficulty do you think Mandarin Chinese singers have producing the dark $[a]$ vowel?

- A great deal

- A lot

- A moderate amount

- A little

- None at all

Q4. Bright [a]: How much difficulty do you think Mandarin Chinese singers have producing the bright $[a]$ vowel?

- A great deal

- A lot

- A moderate amount

- A little

- None at all

Q5. Closed [e]: How much difficulty do you think Mandarin Chinese singers have producing the closed [e] vowel?

- A great deal

- A lot

- A moderate amount

- A little

- None at all

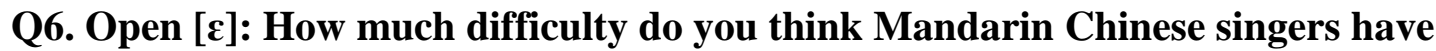
producing the open $[\varepsilon]$ vowel?

- A great deal

- A lot

- A moderate amount

- A little

- None at all

Q7. Closed [i]: How much difficulty do you think Mandarin Chinese singers have producing the closed vowel?

- A great deal

- A lot 
- A moderate amount

- A little

- None at all

Q8. Open [I]: How much difficulty do you think Mandarin Chinese singers have producing the open [I] vowel?

- A great deal

- A lot

- A moderate amount

- A little

- None at all

Q9. Closed [o]: How much difficulty do you think Mandarin Chinese singers have producing the closed [o] vowel?

- A great deal

- A lot

- A moderate amount

- A little

- None at all

Q10. Open [0]: How much difficulty do you think Mandarin Chinese singers have producing the open [o] vowel?

- A great deal

- A lot

- A moderate amount

- A little

- None at all

Q11. Closed [u]: How much difficulty do you think Mandarin Chinese singers have producing the closed [u] vowel?

- A great deal

- A lot

- A moderate amount

- A little

- None at all

Q12. Open [ซ]: How much difficulty do you think Mandarin Chinese singers have producing the open [ $\sigma]$ vowel?

- A great deal

- A lot

- A moderate amount

- A little

- None at all

Q13. Open vowels: How much difficulty do you think Mandarin Chinese singers have producing open vowels?

- A great deal

- A lot

- A moderate amount

- A little

- None at all 
Q14. Closed vowels: How much difficulty do you think Mandarin Chinese singers have producing closed vowels?

- A great deal

- A lot

- A moderate amount

- A little

- None at all

Q15. How much difficulty do you think Mandarin Chinese singers have producing diphthongs?

- A great deal

- A lot

- A moderate amount

- A little

- None at all

Q16. The schwa [ə]: How much difficulty do you think Mandarin Chinese singers have producing [ə]?

- A great deal

- A lot

- A moderate amount

- A little

- None at all

Q17. What is the most common issue of Mandarin Chinese singers producing [ə]?

- Dark/ bright production

- High/ low position

- Mouth shape

- Differentiation between stressed and unstressed

Q18. The [œ] and [ø]: How much difficulty do you think Mandarin Chinese singers have producing [œ] and [ø]?

- A great deal

- A lot

- A moderate amount

- A little

- None at all

Q19. The [æ]: How much difficulty do you think Mandarin Chinese singers have producing [æ]?

- A great deal

- A lot

- A moderate amount

- A little

- None at all

Q20. Final and medial [n]: How much difficulty do you think Mandarin Chinese singers have producing the final and medial [n]?

- A great deal

- A lot

- A moderate amount

- A little 
- None at all

Q21. The "ng" sound [n]: How much difficulty do you think Mandarin Chinese singers have producing $[\eta]$ ?

- A great deal

- A lot

- A moderate amount

- A little

- None at all

Q22. Final and medial [m]: How much difficulty do you think Mandarin Chinese singers have producing or sing the final or medial $[\mathrm{m}]$ ?

- A great deal

- A lot

- A moderate amount

- A little

- None at all

Q23. How much difficulty do you think Mandarin Chinese singers have producing [0]?

- A great deal

- A lot

- A moderate amount

- A little

- None at all

Q24. How much difficulty do you think Mandarin Chinese singers have producing [ð]?

- A great deal

- A lot

- A moderate amount

- A little

- None at all

Q25. Are there other significant problems not addressed in this survey? If so, please list them below. 


\section{Survey of Teaching American English Beginning Singers}

Q1. How long have you been working with American English speaking singers (beginners)?

- 1-2 years

- 3-5 years

- 6-10 years

- Longer than 10 years

Q2. Dark [a]: How much difficulty do you think American English beginning singers have producing the dark $[a]$ ?

- A great deal

- A lot

- A moderate amount

- A little

- None at all

Q3. Bright [a]: How much difficulty do you think American English beginning singers have producing the bright [a]?

- A great deal

- A lot

- A moderate amount

- A little

- None at all

Q4. Closed [i]: How much difficulty do you think American English beginning singers have producing the closed [i]?

- A great deal

- A lot

- A moderate amount

- A little

- None at all

Q5. Open [I]: How much difficulty do you think American English beginning singers have producing the open [I]?

- A great deal

- A lot

- A moderate amount

- A little

- None at all

Q6. Closed [e]: How much difficulty do you think American English beginning singers have producing the closed [e]?

- A great deal

- A lot

- A moderate amount

- A little

- None at all 
Q7. Open [ع]: How much difficulty do you think American English beginning singers have producing the open $[\varepsilon]$ ?

- A great deal

- A lot

- A moderate amount

- A little

- None at all

Q8. Closed [o]: How much difficulty do you think American English beginning singers have producing the closed [o]?

- A great deal

- A lot

- A moderate amount

- A little

- None at all

Q9. Open [0]: How much difficulty do you think American English beginning singers have producing the open [o]?

- A great deal

- A lot

- A moderate amount

- A little

- None at all

Q10. Closed [u]: How much difficulty do you think American English beginning singers have producing the closed $[\mathrm{u}]$ ?

- A great deal

- A lot

- A moderate amount

- A little

- None at all

Q11. Open [0]: How much difficulty do you think American English beginning singers have producing the open $[\sigma]$ ?

- A great deal

- A lot

- A moderate amount

- A little

- None at all

Q12. How much difficulty do you think American English beginning singers have producing a single [e] without a [r] to follow?

- A great deal

- A lot

- A moderate amount

- A little

- None at all 
Q13. How much difficulty do you think American English beginning singers have producing a single [o] without an [u] or [o]to follow?

- A great deal

- A lot

- A moderate amount

- A little

- None at all

Q14. Diphthongs: How much difficulty do you think American English beginning singers have producing diphthongs?

- A great deal

- A lot

- A moderate amount

- A little

- None at all

Q15. The [^]: How much difficulty do you think American English beginning singers have producing $[\Lambda]$ ?

- A great deal

- A lot

- A moderate amount

- A little

- None at all

Q16. The schwa [ə]: How much difficulty do you think American English beginning singers have producing $[ə]$ ?

- A great deal

- A lot

- A moderate amount

- A little

- None at all

Q17. The [y] and [y]: How much difficulty do you think American English beginning singers have producing $[y]$ and $[\mathrm{y}]$ ?

- A great deal

- A lot

- A moderate amount

- A little

- None at all

Q18. The [o] and [ø]: How much difficulty do you think American English beginning singers have producing $[\propto]$ and $[\varnothing]$ ?

- A great deal

- A lot

- A moderate amount 
- A little

- None at all

Q19. Final and medial "L" [1]: How much difficulty do you think American English beginning singers have producing the final and medial [I]?

- A great deal

- A lot

- A moderate amount

- A little

- None at all

Q20. Final and medial [n]: How much difficulty do you think American English beginning singers have producing the final and medial [n]?

- A great deal

- A lot

- A moderate amount

- A little

- None at all

Q21. The [t.x] and [dx]: How much difficulty do you think American English beginning singers have producing $\left[t_{\mathrm{t}}\right]$ or $[\mathrm{d} . \mathrm{I}]$ ?

- A great deal

- A lot

- A moderate amount

- A little

- None at all

Q22. Rolled [r]: How much difficulty do you think American English beginning singers have producing the rolled $[\mathrm{r}]$ ?

- A great deal

- A lot

- A moderate amount

- A little

- None at all

Q23. Flipped [r]: How much difficulty do you think American English beginning singers have producing the flipped [r]?

- A great deal

- A lot

- A moderate amount

- A little

- None at all

Q24. American [I]: Do you think the American [I] sometimes changes the following vowel? For example, when [.ıa], [.re], [.ro], [.ri] are pronounced, they actually sound like [.ıwa], [.rje], [.ıwo], [.ıwi].

- Strongly agree

- Somewhat agree 
- Neither agree nor disagree

- Somewhat disagree

- Strongly disagree

Q25. Are there other significant problems not addressed in this survey? If so, please list them below? 


\section{Survey of Teaching Mandarin Chinese Singers \\ (Chinese Version- English Translation)}

Q1. How long have you been teaching voice lessons (bel canto students)?

- 1-2 years

- 3-5 years

- 6-10 years

- Longer than 10 years

Q2. How many bel canto voice students have you taught?

- 1-5

- 6-10

- 11-20

- More than 20

Q3. How much do you think the habit of pronouncing Mandarin Chinese affects the ability of bel canto voice students to pronounce other foreign languages? Such as, Italian, German, French, English.

- A lot

- A little

- None at all

Q4. How much difficulty do you think bel canto voice students have producing the [a] vowel in foreign languages?

- A lot

- A little

- None at all

Q5. How much difficulty do you think bel canto voice students have producing the close [e] vowel in foreign languages?

- A lot

- A little

- None at all

Q6. How much difficulty do you think bel canto voice students have producing the open [ع] vowel in foreign languages?

- A lot

- A little

- None at all

Q7. How much difficulty do you think bel canto voice students have producing the close [i] vowel in foreign languages?

- A lot

- A little

- None at all

Q8. How much difficulty do you think bel canto voice students have producing the open [I] vowel in foreign languages?

- A lot

- A little

- None at all

Q9. How much difficulty do you think bel canto voice students have producing the close [o] vowel in foreign languages?

- A lot 
- A little

- None at all

Q10. How much difficulty do you think bel canto voice students have producing the open [?] vowel in foreign languages?

- A lot

- A little

- None at all

Q11. How much difficulty do you think bel canto voice students have producing the close [u] vowel in foreign languages?

- A lot

- A little

- None at all

Q12. How much difficulty do you think bel canto voice students have producing the open [б] vowel in foreign languages?

- A lot

- A little

- None at all

Q13. How much difficulty do you think bel canto voice students have producing diphthongs?

- A lot

- A little

- None at all

Q14. How much difficulty do you think bel canto voice students have producing the open [œ] vowel in foreign languages?

- A lot

- A little

- None at all

Q15. How much difficulty do you think bel canto voice students have producing the close [ø] vowel in foreign languages?

- A lot

- A little

- None at all

Q16. How much difficulty do you think bel canto voice students have producing the [æ] vowel in foreign languages?

- A lot

- A little

- None at all

Q17. How much difficulty do you think bel canto voice students have differentiating the [ə] in French and the [e] in Mandarin Chinese?

- A lot

- A little

- None at all

Q18. If you think bel canto voice students have difficulty to differentiate the [ə] in French and the [e] in Mandarin Chinese, what is the main reason?

- Differentiation between stressed and unstressed vowels

- High/low position

- Mouth shape 
Q19. How much difficulty do you think bel canto voice students have producing the final or medial [n] in foreign languages?

- A lot

- A little

- None at all

Q20. How much difficulty do you think bel canto voice students have producing the [n] in foreign languages?

- A lot

- A little

- None at all

Q21. How much difficulty do you think bel canto voice students have producing the final or medial $[\mathrm{m}]$ in foreign languages?

- A lot

- A little

- None at all

Q22. How much difficulty do you think bel canto voice students have producing the [ $\widehat{\mathbf{d}}]$ ] in foreign languages?

- A lot

- A little

- None at all

Q23. How much difficulty do you think bel canto voice students have producing the $[\widehat{\mathbf{t}}]]$ in foreign languages?

- A lot

- A little

- None at all

Q24. How much difficulty do you think bel canto voice students have producing the [ $\theta]$ in foreign languages?

- A lot

- A little

- None at all

Q25. How much difficulty do you think bel canto voice students have producing the [ð] in foreign languages?

- A lot

- A little

- None at all

Q26. Based on your teaching experiences, will you talk about other problems that bel canto voice students have when they pronouncing foreign languages? Do you notice any other problems that are caused by the pronunciation of Mandarin Chinese? 


\section{Bibliography}

1. Birner, Betty. "Why Do Some People Have an Accent?" Linguistic Society of America. Accessed March 28, 2019. https://www.linguisticsociety.org/content/why-do-some-peoplehave-accent.

2. Chao, Yuen Ren, Mandarin Primer: An Intensive Course in Spoken Chinese. Cambridge: Harvard University Press, 1948.

3. Describing Consonants. Accessed March 27, 2019. https://home.cc.umanitoba.ca/ krussll/phonetics/articulation/describing-consonants.html.

4. Grubb, Thomas, Singing in French: A Manual of French Diction and French Vocal Repertoire. Belmont CA: Schirmer, 1979.

5. LaBouff, Kathryn, Singing and Communicating in English: A Singer's Guide to English Diction. New York: Oxford University Press, 2008.

6. Odom, William and Benno Schollum, German for Singers: A Textbook of Diction and Phonetics. Belmont CA: Schirmer, 1997.

7. Prator, Clifford H. Manual of American English Pronunciation. Edited by Betty Wallace Robinett. 3d ed. New York: Holt, Rinehart and Winston, 1972.

8. Wall, Joan, and Robert Caldwell, Diction for singers: A Concise Reference for English, Italian, Latin, German French, and Spanish Pronunciation. $2^{\text {nd }}$ ed. Redmond, WA: Diction for Singers.com, 2009. 